\title{
ipen
}

INSTITUTO DE PESQUISAS ENERGÉTICAS E NUCLEARES

Autarquia associada à Universidade de São Paulo

\section{SÍNTESE E CARACTERIZAÇÃO DE FERRITAS DE Mn-Zn NANOESTRUTURADAS}

WILLIAN CAMARGO AIRES MARANHÃO

Dissertação apresentada como parte dos requisitos para obtenção do Grau de Mestre em Ciências na Área de Tecnologia Nuclear - Materiais.

Orientador: Prof. Dr. Luis Gallego Martinez

SÃO PAULO 


\section{ipen}

INSTITUTO DE PESQUISAS ENERGÉTICAS E NUCLEARES

Autarquia associada à Universidade de São Paulo

\section{SÍNTESE E CARACTERIZAÇÃO DE FERRITAS DE Mn-Zn NANOESTRUTURADAS}

WILLIAN CAMARGO AIRES MARANHÃO

Dissertação apresentada como parte dos requisitos para obtenção do Grau de Mestre em Ciências na Área de Tecnologia Nuclear - Materiais.

Orientador: Prof. Dr. Luis Gallego Martinez

SÃO PAULO 
A meus pais Jairo (in memorian) e Edna, às minhas irmãs, à minha companheira e à minha filha. 


\section{Agradecimentos}

Agradeço a Deus.

Aos meus pais, Jairo (in memorian) e Edna, minhas irmãs, minha companheira Marilúcia e minha filha Gabriela, pelo apoio e paciência, amor e incentivo para seguir em frente. Aos amigos Milton, Humberto, Maxwell, Pedro, José Carlos e aos que me apoiaram e incentivaram a continuar.

Ao Prof. Doutor Luis Gallego Martinez, pela amizade, por me aceitar como orientando e acolher no grupo de pesquisa, com paciência e ensinamentos, tanto profissionais quanto para a vida. Pelo exemplo como pesquisador e como pessoa.

Ao Prof. Doutor Xabier Turrillas pela amizade, conversas e ensinamentos.

Ao Prof. Doutor Hidetoshi Takiishi, pela amizade e orientações.

Ao Prof. Doutor Walter Kenji Yoshito pelas conversas e orientações com a síntese.

À Prof ${ }^{a}$ Doutora Margarida Juri Saeki, pelas conversas e orientações sobre o trabalho.

Ao Prof. Doutor Marcos Tadeu D'Azeredo Orlando pelas medidas magnéticas, orientações e conversas

Ao Doutor Antônio Carlos da Silva pelas Medidas por FTIR.

Ao Msc. Rafael H. L. Garcia pelas medidas de raios X.

Ao Msc. Rodrigo Uchida Ichikawa pela amizade, paciência, cafés e almoços, onde sempre ocorriam longas e frutíferas conversas.

Ao Msc. Francisco Carlos Cione pela amizade, cafés e almoços, que auxiliaram neste caminho.

Aos amigos do grupo de pesquisa Bsc. Fátima, Bsc. André, Bsc. Geraldo e Doutor Luiz Alberto, pelas conversas e apoio.

Aos Prof. Doutores Flavio de Campos e Marco Bettine pelo apoio.

Aos amigos que colaboraram apoiando o trabalho.

Aos demais professores e funcionários e técnicos IFUSP, IQUSP e do IPEN por todo o auxílio e contribuição à minha formação. 
Embora ninguém possa voltar atrás e fazer um novo começo, qualquer um pode começar agora e fazer um novo fim.

Quem fala menos ouve melhor. E quem ouve melhor, aprende mais.

Francisco Cândido Xavier 


\title{
SÍNTESE E CARACTERIZAÇÃO DE FERRITAS DE Mn-Zn NANOESTRUTURADAS
}

\author{
Willian Camargo Aires Maranhão
}

\section{RESUMO}

O objetivo deste trabalho foi investigar a influência da variação da concentração micelar crítica do surfactante cetiltrimetil brometo de amônio (CTAB) na síntese, pelo método de coprecipitação, do composto $\mathrm{Zn}_{0,25} \mathrm{Mn}_{0,75} \mathrm{Fe}_{2} \mathrm{O}_{4}$ (Frankilinita) e ainda a influência do processamento das amostras por reação hidrotermal. Foram utilizadas concentrações de 1, 2, 3, 4, 5 e 10 vezes a concentração micelar crítica de CTAB, resultando em 12 amostras: seis com e seis sem tratamento hidrotermal. As amostras foram caracterizadas por difração de raios $X$, espectrometria de infravermelho (FTIR) e medidas magnéticas. A análise magnética foi realizada por um susceptometria $A C$, sendo possível obter a susceptibilidade magnética e a densidade de energia magnética. Foram realizadas análises dos espectros de absorção por FTIR, identificando duas fases, Frankilinita e Akaganéita. A estrutura e morfologia das nanoferritas foram analisadas por difração de raios $X$, mostrando que na síntese por coprecipitação existiu uma tendência no aumento do tamanho médio de cristalitos da fase Akaganéita e diminuição do tamanho médio de cristalitos da fase Frankilinite. As amostras submetidas a tratamento hidrotermal apresentaram tendência à diminuição do tamanho médio de cristalitos de ambas as fases, bem como o aumento da porcentagem da fase Frankilinite, comparativamente às amostras sintetizadas apenas por coprecipitação, sugerindo que o tratamento hidrotermal foi efetivo na obtenção de materiais nanoestruturados de partículas menores. 


\title{
SYNTHESIS AND CHARACTERIZATION OF NANOSTRUCTURED Mn-Zn FERRITES
}

\author{
Willian Camargo Aires Maranhão
}

\begin{abstract}
The objective of this work was to investigate the influence of the critical micelle concentration of the CTAB surfactant on the synthesis of the compound $\mathrm{Zn}_{0.25} \mathrm{Mn}_{0.75} \mathrm{Fe}_{2} \mathrm{O}_{4}$ (Frankilinite) by the coprecipitation method and then processing fractions of the synthesized material by hydrothermal treatment. The magnetic characterization was performed by $\mathrm{AC}$ susceptometry, being possible to determine the magnetic susceptibility and the dissipated energy. The FTIR analysis identified two phases, Frankilinite and Akaganéite. The structure and morphology of the nanoferrites were analyzed by X-ray diffraction and it was shown that the samples synthesized by coprecipitation only presented the tendency to increasing of crystallite sizes of the akaganéita phase and decreasing of crystallite sizes of the Frankilinite phase as a function of CTAB concentration. The samples submitted to subsequent hydrothermal treatment presented a tendency to decreasing the crystallite sizes of both phases and increasing in Frankilinite phase fraction, compared to the samples synthesized only by coprecipitation, suggesting that the hydrothermal treatment was effective in obtaining nanostructured materials of smaller particles.
\end{abstract}




\section{SUMÁRIO}

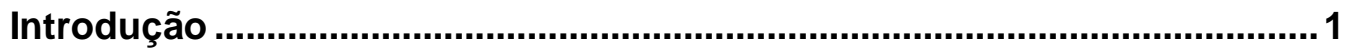

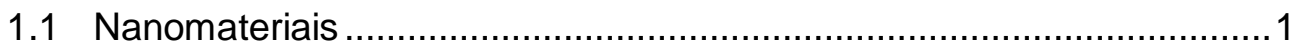

1.2 Ferritas e suas aplicações ...............................................................

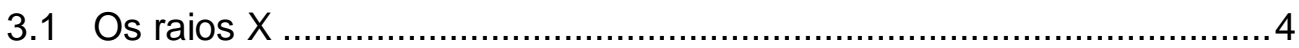

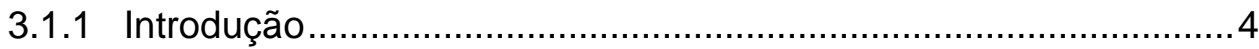

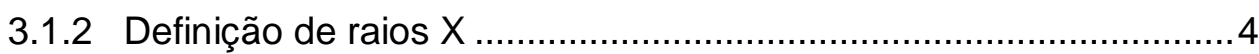

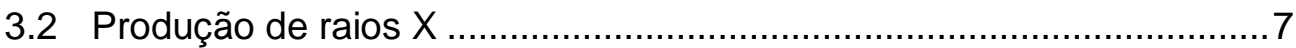

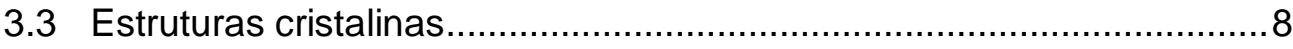

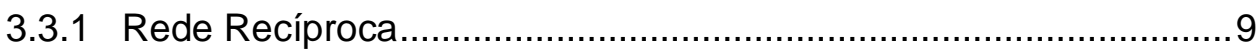

3.3.2 Sistemas Cristalinos ................................................................10

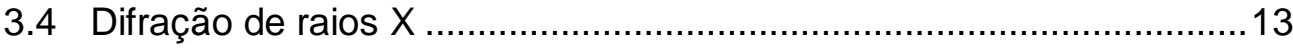

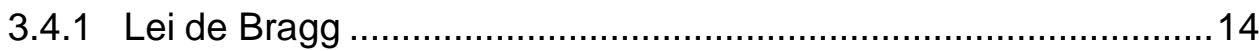

3.4.2 Equações de Laue...................................................................15

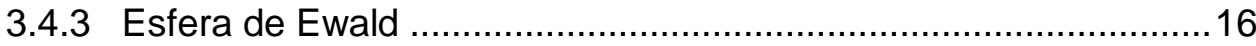

3.4.4 Espalhamento por um elétron ..................................................17

3.4.5 Espalhamento por uma rede cristalina ....................................19

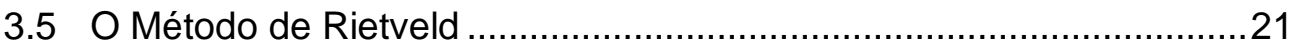

3.5.1 Função do perfil de reflexão .......................................................23

3.5.2 Tamanho de cristalito e microdeformação ....................................25

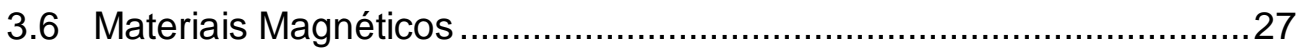

3.6.1 Diamagnetismo e paramagnetismo ..............................................31

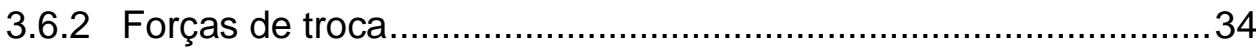

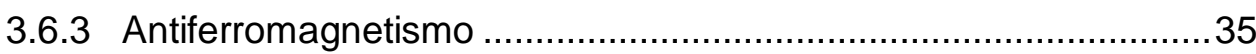

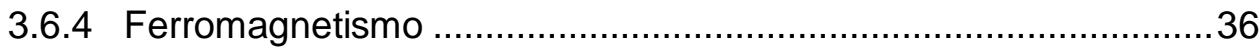

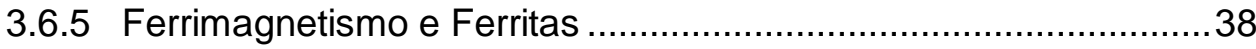




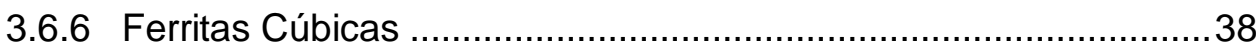

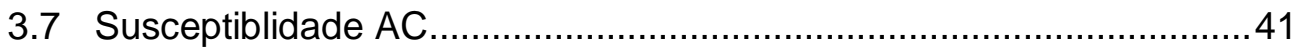

3.8 Método da coprecipitação[18]-[26] …..........................................43

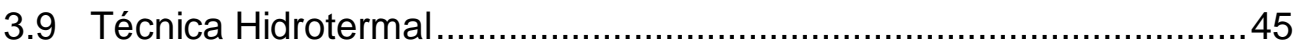

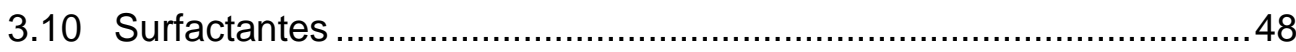

3.10.1 CTAB - Diagrama de Fases …...............................................49

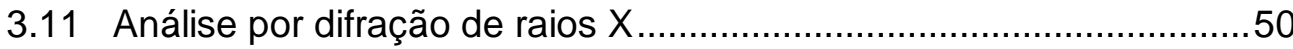

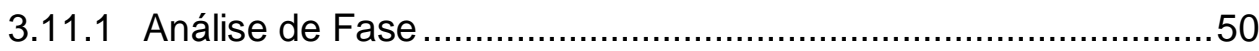

3.11.2 Tamanho médio de cristalitos e microdeformações ...................51

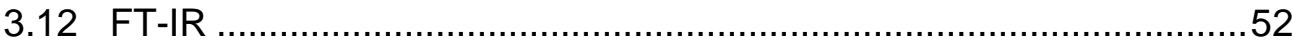

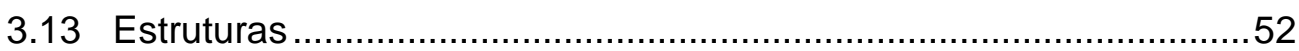

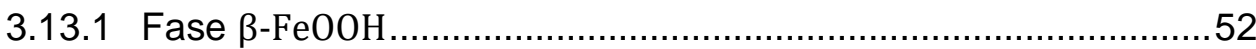

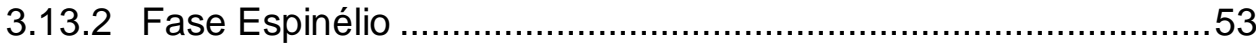

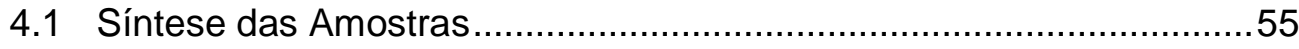

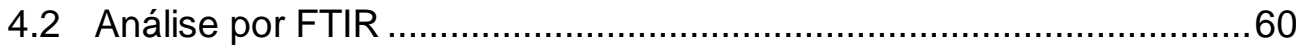

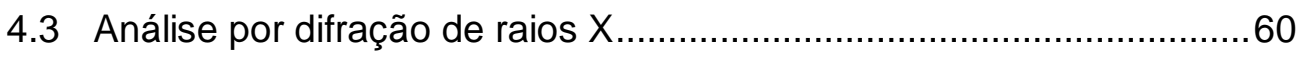

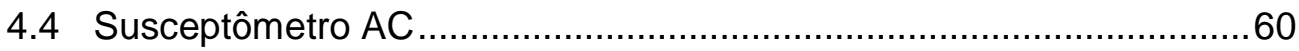

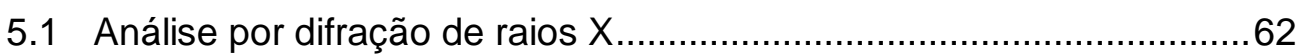

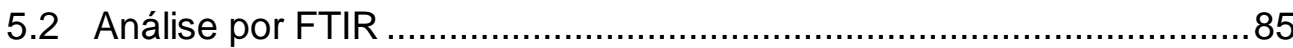

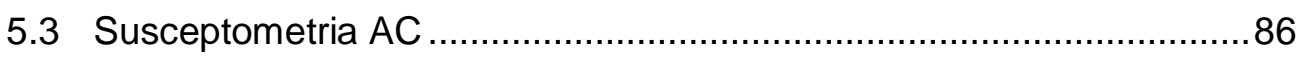

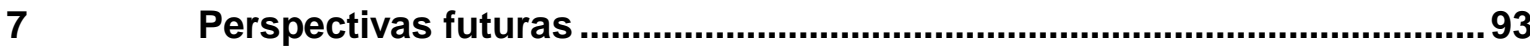

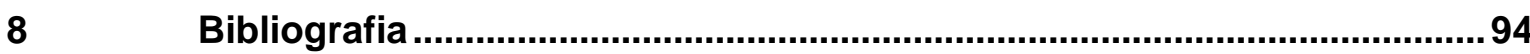




\section{Lista de Figuras}

Figura 3.1 - Espectros de raios $X$ de um alvo de molibdênio em função da tensão aplicada (Adaptado de [7]).

Figura 3.2 - Desenho esquemático de um tubo selado de raios X (Adaptado de [7]).

Figura 3.3 - Definição de um plano utilizando índices de Miller.

Figura 3.4 - Parâmetros da cela unitária de um cristal em três dimensões.[9]

Figura 3.5 - As quatorze redes de Bravais. As referências às celas de face centrada, corpo centrado e base centrada são feitas pelos símbolos $F$, I e C, respectivamente, e $\mathrm{P}$ faz referência à cela primitiva (Adaptado de [7]) 12

Figura 3.6 - llustração esquemática da condição geométrica da Lei de Bragg. O espaçamento entre os planos paralelos e sucessivos (hkl) é dado por dhkl; $2 . \Delta$ é a diferença de trajetória e $\theta$ é o ângulo de Bragg.

Figura 3.7 - Representação Esquemática da Esfera de Ewald (Adaptada de [7]).

Figura 3.8 - Exemplo de um ciclo de histerese de um material ferromagnético[13]

Figura 3.9 - Processo de magnetização em uma substância ferromagnética[13].

Figura 3.10 - Estrutura cristalina de uma ferrita cúbica (Adaptado de [16])....39

Figura 3.11 - Esquema do método de coprecipitação.

Figura 3.12 - Autoclave de uso geral, usada para tratamento e síntese hidrotermal [29].

Figura 3.13 - Reatores mais utilizados no processamento hidrotérmico de materiais: (esq.) Autoclave de Morey (dir.) Autoclave de Tuttle-Roy [29].....

Figura 3.14 - Abaixo da CMC (Esq.) as moléculas estão dispersas; Acima da CMC (Dir.) há a formação de Micelas [31].

Figura 3.15 - Diagrama de Fases de formação de micelas para o surfactante CTAB. CMC1 é classificada como micela esférica e CMC2 como micela em forma de bastão [32]. 50

Figura 3.16 - Representação da molécula de CTAB. 50

Figura 3.17 -Estruturas da Akaganéita, com túnel vazio (a), túnel ocupado por uma molécula de $\mathrm{Cl}^{-}$(b) e túnel ocupado por uma molécula de $\mathrm{H}_{2} \mathrm{O}$ (c) [36]. 
Figura 3.18 - Representação da cela unitária da ferrita $\mathrm{Zn}_{0,25} \mathrm{Mn}_{0,75} \mathrm{Fe}_{2} \mathrm{O}_{4}$ (Adaptado de [41])

Figura 4.1 - Agitador magnético com aquecimento utilizado para a preparação das amostras de ferritas.

Figura 4.2 - Mufla utilizada para a preparação das amostras de ferritas com reator hidrotermal.

Figura 4.3 - Cálculos termodinâmicos das concentrações das espécies $\mathrm{Fe}^{3+} \mathrm{e}$ $\mathrm{Fe}^{2+}$ formadas em diferentes valores de $\mathrm{pH}$ [43].

Figura 4.4 - Desenho esquemático do método de indutâncias mútuas com duas bobinas internas [45]. 60

Figura 5.1 - Difratogramas das amostras sintetizadas. .62

Figura 5.2 - Dados refinados da amostra CMZFC-1 para os picos característicos das fases Frankilinita ( $F$ - ferrita cúbica, estrutura espinélio) e Akaganéita (A - $\beta$-FeOOH, estrutura tetragonal).

Figura 5.3 - Dados refinados da amostra CMZFC-2 para os picos característicos das fases Frankilinita ( $F$ - ferrita cúbica, estrutura espinélio) e Akaganéita (A - $\beta-\mathrm{FeOOH}$, estrutura tetragonal).

Figura 5.4 - Dados refinados da amostra CMZFC-3 para os picos característicos das fases Frankilinita ( $F$ - ferrita cúbica, estrutura espinélio) e Akaganéita (A - $\beta-\mathrm{FeOOH}$, estrutura tetragonal).

Figura 5.5 - Dados refinados da amostra CMZFC-4 para os picos característicos das fases Frankilinita ( $F$ - ferrita cúbica, estrutura espinélio) e Akaganéita (A - $\beta-\mathrm{FeOOH}$, estrutura tetragonal). .64

Figura 5.6 - - Dados refinados da amostra CMZFC-5 para os picos característicos das fases Frankilinita ( $F$ - ferrita cúbica, estrutura espinélio) e Akaganéita (A - $\beta-\mathrm{FeOOH}$, estrutura tetragonal). . .65

Figura 5.7 - Dados refinados da amostra CMZFC-10 para os picos característicos das fases Frankilinita ( $F$ - ferrita cúbica, estrutura espinélio) e Akaganéita (A - $\beta-\mathrm{FeOOH}$, estrutura tetragonal).

Figura 5.8 - Dados refinados da amostra HMZFC-1 para os picos característicos das fases Frankilinita ( $F$ - ferrita cúbica, estrutura espinélio) e Akaganéita (A - $\beta-\mathrm{FeOOH}$, estrutura tetragonal).

Figura 5.9 - Dados refinados da amostra HMZFC-2 para os picos característicos das fases Frankilinita ( $F$ - ferrita cúbica, estrutura espinélio) e Akaganéita (A - $\beta-\mathrm{FeOOH}$, estrutura tetragonal). 
Figura 5.10 - Dados refinados da amostra HMZFC-3 para os picos característicos das fases Frankilinita ( $F$ - ferrita cúbica, estrutura espinélio) e Akaganéita (A - $\beta-\mathrm{FeOOH}$, estrutura tetragonal).

Figura 5.11 - Dados refinados da amostra HMZFC-4 para os picos característicos das fases Frankilinita ( $F$ - ferrita cúbica, estrutura espinélio) e Akaganéita (A - $\beta-\mathrm{FeOOH}$, estrutura tetragonal).

Figura 5.12 - Dados normalizados da amostra HMZFC-5 para os picos característicos das fases Frankilinita ( $F$ - ferrita cúbica, estrutura espinélio) e Akaganéita (A - $\beta-\mathrm{FeOOH}$, estrutura tetragonal). No detalhe, os dados refinados.

Figura 5.13 - Dados normalizados da amostra HMZFC-10 para os picos característicos das fases Frankilinita ( $F$ - ferrita cúbica, estrutura espinélio) e Akaganéita (A - $\beta-\mathrm{FeOOH}$, estrutura tetragonal). No detalhe, os dados refinados. 68

Figura 5.14 - Difratogramas normalizados e sobrepostos das amostras sintetizadas por coprecipitação.

Figura 5.15 - Difratogramas normalizados e sobrepostos das amostras após tratamento hidrotermal.

Figura 5.16 - Dados do parâmetro de rede 'a' da Frankilinita obtidos pelo refinamento dos perfis de difração pelo método de Rietveld para as amostras sintetizadas por coprecipitação $(C)$ e para as amostras que passaram por tratamento hidrotermal $(H)$.

Figura 5.17 - Dados do tamanho médio de cristalito (TMC) da Frankilinita obtidos pelo refinamento dos perfis de difração pelo método de Rietveld para as amostras sintetizadas por coprecipitação (C) e para as amostras que passaram por tratamento hidrotermal $(\mathrm{H})$

Figura 5.18 - Dados da fração da fase Frankilinita obtidos pelo refinamento dos perfis de difração pelo método de Rietveld para as amostras sintetizadas por coprecipitação (C) e para as amostras que passaram por tratamento hidrotermal $(H)$.

Figura 5.19 - Dados dos parâmetro de rede 'a' e 'c' da Akaganéita obtidos pelo refinamento dos perfis de difração pelo método de Rietveld para as amostras sintetizadas por coprecipitação $(C)$ e para as amostras que passaram por tratamento hidrotermal $(H)$.

Figura 5.20 - Dados do tamanho médio de cristalito (TMC) da Akaganéita obtidos pelo refinamento dos perfis de difração pelo método de Rietveld para as amostras sintetizadas por coprecipitação (C) e para as amostras que passaram por tratamento hidrotermal $(\mathrm{H})$. 
Figura 5.21 - Dados da fração da fase Akaganéita obtidos pelo refinamento dos perfis de difração pelo método de Rietveld para as amostras sintetizadas por coprecipitação (C) e para as amostras que passaram por tratamento hidrotermal $(H)$.

Figura 5.22 - Correlação entre o parâmetro de rede 'a' da Frankilinita e a CMC, obtida na síntese pelo método da coprecipitação

Figura 5.23 - Correlação entre o parâmetro de rede 'a' da Frankilinita e a CMC, obtida por tratamento hidrotermal.

Figura 5.24 - Correlação entre o parâmetro de rede 'a' da Akaganéita e a CMC, obtida na síntese pelo método da coprecipitação .77

Figura 5.25 - Correlação entre o parâmetro de rede 'a' da Akaganéita e a CMC, obtida por tratamento hidrotermal. 77

Figura 5.26 - Correlação entre o parâmetro de rede 'c' da Akaganéita e a CMC, obtida na síntese pelo método da coprecipitação 78

Figura 5.27 - Correlação entre o parâmetro de rede 'c' da Akaganéita e a CMC, obtida por tratamento hidrotermal.

Figura 5.28 - Correlação entre o tamanho médio de cristalito (TMC) da Frankilinita e a CMC, obtida na síntese pelo método da coprecipitação. 79

Figura 5.29 - Correlação entre o tamanho médio de cristalito (TMC) da Frankilinita e a CMC, obtida por tratamento hidrotermal. 79

Figura 5.30 - Correlação entre o tamanho médio de cristalito (TMC) da Akaganéita e a CMC, obtida na síntese pelo método da coprecipitação. 80

Figura 5.31 - Correlação entre o tamanho médio de cristalito (TMC) da Akaganéita e a CMC, obtida por tratamento hidrotermal.

Figura 5.32 - Correlação entre a porcentagem de fase da Frankilinita e a CMC, obtida na síntese pelo método da coprecipitação

Figura 5.33 - Correlação entre a porcentagem de fase da Frankilinita e a CMC, obtida na síntese por tratamento hidrotermal.

Figura 5.34 - Correlação entre a porcentagem de fase da Akaganéita e a CMC, obtida na síntese pelo método da coprecipitação 82

Figura 5.35 - Correlação entre a porcentagem de fase da Akaganéita e a CMC, obtida por tratamento hidrotermal.

Figura 5.36 - Interferograma para as amostras sintetizadas pelo método da coprecipitação.

Figura 5.37 - Interferograma para as amostras sintetizadas pelo método da coprecipitação e que passaram por tratamento hidrotermal. 
Figura 5.38 - Susceptibilidade Magnética para as amostras sintetizadas por coprecipitação $(\mathrm{C})$ e para as amostras que passaram por tratamento hidrotermal $(\mathrm{H})$.....88

Figura 5.39 - Densidade de energia por volume e por grama para as amostras sintetizadas por coprecipitação $(C)$ e para as amostras que passaram por tratamento

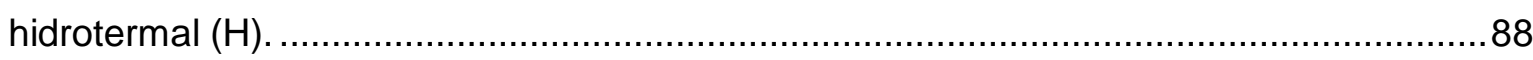




\section{Lista de Tabelas}

Tabela 3.1 - Relação entre comprimentos e ângulos axiais das quatorze redes de Bravais. 13

Tabela 3.2 - Funções analíticas mais utilizadas para o perfil de difração[10]. 24

Tabela 4.1 - Relação mássica entre os elementos da ferrita. 55

Tabela 4.2 - Valores calculados a partir da CMC do CTAB. 56

Tabela 4.3 - Dados dos Reagentes. 56

Tabela 5.1 - Dados obtidos pelo refinamento dos perfis de difração pelo método de Rietveld das amostras sintetizadas por coprecipitação, onde a e c são os parâmetros de rede e TMC os tamanhos médios de cristalitos. .71

Tabela 5.2 - Dados obtidos pelo refinamento dos perfis de difração pelo método de Rietveld das amostras sintetizadas por tratamento hidrotermal. 72

Tabela 5.3 - Correlação entre a variação da concentração micelar crítica (CMC) do CTAB com os parâmetros de refinamento obtidos por análise de perfil de difração de raios $X$ para as amostras sintetizadas por coprecipitação.

Tabela 5.4 - Correlação entre a variação da concentração micelar crítica (CMC) do CTAB com os parâmetros de refinamento obtidos por análise de perfil de difração de raios $\mathrm{X}$ para as amostras após o tratamento hidrotermal. .83

Tabela 5.5 - Dados de massa (corrigida para a fração de Frankilinita) e susceptibilidade magnética obtidos experimentalmente e cálculo da densidade de energia para as amostras sintetizadas por coprecipitação $(C)$ e para as amostras que passaram por tratamento hidrotermal $(\mathrm{H})$.

Tabela 5.6 - Correlação entre a variação da concentração micelar crítica (CMC) do CTAB com a susceptibilidade magnética e a densidade de energia magnética para as amostras sintetizadas 


\section{INTRODUÇÃO}

\subsection{Nanomateriais}

Materiais utilizados em alta tecnologia são, algumas vezes, denominados materiais avançados, sendo 'alta tecnologia' a designação para um dispositivo ou produto que opera ou funciona segundo princípios relativamente sofisticados e intrincados, como os aparelhos eletrônicos, por exemplo.

Os nanomateriais compõem uma nova classe de materiais que possuem características próprias e vasta gama de aplicações tecnológicas. Podem ser formados por metais (elementos metálicos), cerâmicas (compostos entre elementos metálicos e não metálicos), polímeros (compostos de carbono, hidrogênio e elementos não metálicos) e compósitos (compostos de, no mínimo, dois tipos diferentes de materiais). Contudo, ao contrário destes outros materiais, não são distinguidos somente por sua composição química, mas, sim, pelo tamanho (ou dimensões) de suas unidades básicas: o prefixo nano denota que a dimensão destas entidades estruturais é da ordem do nanômetro $\left(10^{-9} \mathrm{~m}\right)$. Como regra, menor que 100 nanômetros (equivalente a, aproximadamente, 500 diâmetros atômicos).

Algumas das características físicas e químicas da matéria podem se modificar drasticamente com a diminuição do tamanho das partículas, na medida em que se aproximam das dimensões atômicas. Por exemplo, materiais opacos no domínio macroscópico podem se tornar transparentes em escala nano; alguns sólidos se tornam líquidos, materiais quimicamente estáveis se tornam combustíveis ou ainda isolantes elétricos se tornam condutores. Além disso, algumas propriedades podem depender dos tamanhos no domínio da nanoescala. Alguns efeitos têm origem na mecânica quântica, outros estão relacionados aos fenômenos de superfície - a proporção de átomos localizado nos sítios das superfícies das partículas aumenta com a diminuição de seu tamanho[1]. 


\subsection{Ferritas e suas aplicações}

Ferritas são óxidos de ferro que apresentam interessantes propriedades magnéticas e estruturais, sendo uma característica notável de sua estrutura o fato de que a composição pode ser modificada enquanto a estrutura de base permanece a mesma. Parâmetros de síntese, composição e microestrutura tem forte influência em suas propriedades. Com a diminuição do tamanho da partícula abaixo de um diâmetro crítico, a coercitividade decresce devido aos efeitos térmicos, que se tornam dominantes o suficiente para desmagnetizar um conjunto de partículas saturado previamente[2], [3].

A possibilidade de preparar ferritas na forma de nanopartículas abriu um novo campo de pesquisa com muitas aplicações, não somente na tecnologia de eletrônicos como em biotecnologia. Dentre estas aplicações, a hipertermia é uma técnica que se utiliza de materiais magnéticos para tratamento de câncer, com a ideia de que um aumento localizado de temperatura pode ser usado para destruir tecidos afetados de forma seletiva.

As ferritas de $\mathrm{Mn}-\mathrm{Zn}$, por exemplo, são potenciais materiais magnéticos de elevada permeabilidade inicial, baixas perdas magnéticas, alta magnetização de saturação e temperatura de Curie relativamente elevada. Elas apresentam amplas aplicações como pós magnéticos moles, em hipertermia, como fluidos magnéticos, em sistemas de transferência de calor, gravação magnética de alta velocidade, imageamento por ressonância magnética e outros[4]. 


\section{OBJETIVOS}

Motivado pelos recentes estudos[5], [6] que utilizam compostos de ferrita para variadas aplicações, em especial a hipertermia, propôs-se neste trabalho a síntese do composto $\mathrm{Zn}_{0,25} \mathrm{Mn}_{0,75} \mathrm{Fe}_{2} \mathrm{O}_{4}$ pelo método de coprecipitação, utilizando diversas concentrações do composto cetiltrimetil brometo de amônio (CTAB) como surfactante, com e sem posterior processamento em reator hidrotérmico e a caracterização dos materiais sintetizados por difração de raios $\mathrm{X}$ (análise de fases, tamanho médio de cristalitos, microdeformações), FTIR (espectrometria de infravermelho com transformada de Fourier) e susceptibilidade AC. 


\section{REVISÃO DA LITERATURA}

\subsection{Os raios $\mathrm{X}$}

\subsubsection{Introdução}

Em 1895, o físico alemão Wilhelm C. Röntgen descobriu os raios X, que foram assim denominados por sua natureza desconhecida na época. Apesar de não visíveis, apresentavam comportamento igual ao da luz visível, viajando em linha reta e podendo afetar um filme fotográfico do mesmo modo, porém com alto poder penetrante, de modo a atravessar objetos densos e serem detectados do outro lado[7].

Em 1912, Max von Laue desenvolveu a teoria da difração de raios X para um arranjo periódico e seus colaboradores relataram a primeira observação experimental de difração de Raios $\mathrm{X}$ por cristais. A importância dos raios $\mathrm{X}$ para esta tarefa é que eles são ondas e têm comprimento de onda comparável ao comprimento de uma unidade da estrutura cristalina. Esta análise também pode ser feita com difração de nêutrons e com difração de elétrons, mas os raios $X$ são mais usualmente utilizados

O trabalho sobre difração provou decisivamente que os cristais são construídos de um arranjo periódico de átomos ou grupos de átomos. A evidência experimental original para a periodicidade da estrutura está na descoberta pelos mineralogistas de que os índices que definem as orientações de um cristal são inteiros[8].

\subsubsection{Definição de raios $X$}

Raios X são uma radiação eletromagnética da mesma natureza da luz visível, porém de menor comprimento de onda. A unidade de medida na região dos 
raios $X$ é o angstrom $(\AA)$, que equivale a $10^{-10} \mathrm{~m}$, e os raios $X$ normalmente utilizados em difração têm comprimentos de onda situados na faixa de $0,5-2,5 \AA$, enquanto que o comprimento de onda da luz visível é da ordem de $6000 \AA$. Os raios $X$, portanto, ocupam a região entre os raios gama e a radiação ultravioleta no espectro eletromagnético completo.

Usualmente os raios $X$ são produzidos pela rápida desaceleração de uma partícula carregada eletricamente, elétrons, por exemplo, que ocorre com a colisão em um alvo metálico, localizado em um tubo de raios $X$, produzindo radiação no ponto de impacto e irradiando em todas as direções. $A$ onda emergente vinda do alvo é uma banda contínua de comprimentos de onda, sendo a variação da intensidade com o comprimento de onda dependente da tensão elétrica aplicada na aceleração dos elétrons.

A intensidade dos raios $X$ incidentes é zero até um certo comprimento de onda, chamado de limite de comprimento de onda curto $\left(\lambda_{S W L}\right)$, aumentando rapidamente para um máximo e então diminuindo, sem limite exato para comprimento de onda longo. Quando a tensão do tubo aumenta, a intensidade de todos os comprimentos de onda aumenta, deslocando $\lambda_{S W L}$ e a posição do máximo para comprimentos de onda menores

As curvas apresentadas na FIG. 3.1 correspondem a tensões aplicadas de 5 a $25 \mathrm{kV}$ para um alvo de molibdênio. Esta radiação contínua é policromática ou branca, uma vez que é composta, como a luz branca, de variados comprimentos de onda. A radiação branca também é chamada Bremsstrahlung, palavra alemã para "radiação de frenagem", porque é causada pela desaceleração do elétron. 


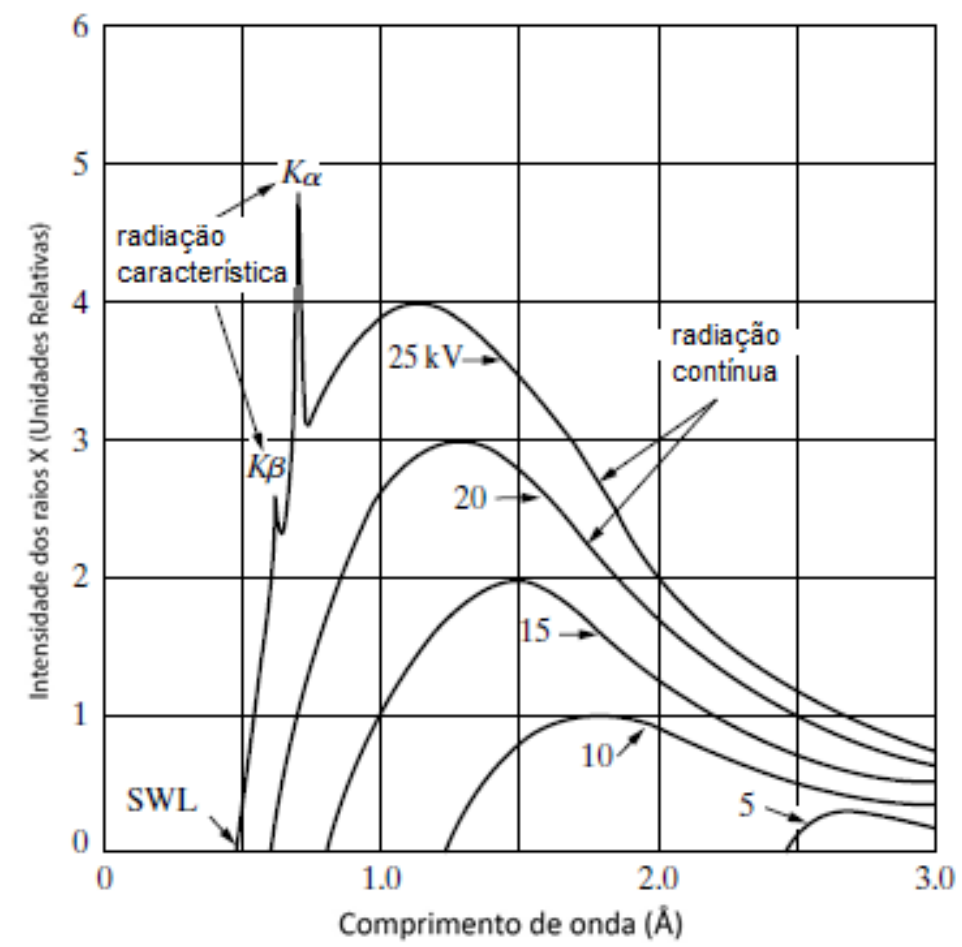

Figura 3.1 - Espectros de raios $X$ de um alvo de molibdênio em função da tensão aplicada (Adaptado de [7]).

Os elétrons que transferem todo seu momento em um único impacto produzem fótons de energia máxima, isto é, raios $X$ de comprimento de onda mínimo, transferindo toda sua energia para os fótons, de modo que:

$$
\begin{gathered}
E=e \cdot V=h \cdot v_{\max } \\
\lambda_{S W L}=\lambda_{\min }=\frac{c}{v_{\max }}=\frac{h \cdot c}{e \cdot V}
\end{gathered}
$$

Sendo $h$ a constante de Planck, $c$ a velocidade da luz, $e$ a carga do elétron e $V$ a tensão aplicada entre os eletrodos.

Se o elétron não for totalmente desacelerado num único evento, uma fração da energia é emitida, produzindo um fóton de energia menor que $h$. $v_{\max }$.

Os metais alvo de que são formados os tubos de raios $X$, quando atingidos por elétrons de determinada energia, emitem máximos de intensidade superpostos ao espectro contínuo, com valores bem definidos e característicos do metal, sendo denominados linhas características. O conjunto de linhas compõe o espectro característico de emissão do metal. 
A intensidade de qualquer linha característica, medida acima do espectro contínuo, depende tanto da corrente de tubo I como da quantidade pela qual a tensão aplicada $V$ excede a tensão crítica para essa linha.

Estas linhas características foram descobertas por W. H. Bragg e sistematizadas pelo trabalho de H. G. Moseley, que determinou uma relação (lei de Moseley) entre a raiz quadrada da linha com frequência $v$ e o número atômico $Z$ :

$$
\sqrt{v}=C(Z-\sigma)
$$

sendo $C$ e $\sigma$ constantes.

\subsection{Produção de raios $X$}

A produção de raios $X$ usualmente é feita em tubos que contém dois eletrodos, sendo um anodo (o alvo metálico) em potencial terra e um cátodo, mantido em potencial negativo de alta voltagem. Um invólucro de vidro evacuado contém o ânodo numa das extremidades e o cátodo no outro, sendo o cátodo um filamento de tungstênio e o ânodo um bloco de cobre resfriado com água, contendo uma pastilha do metal alvo desejado.

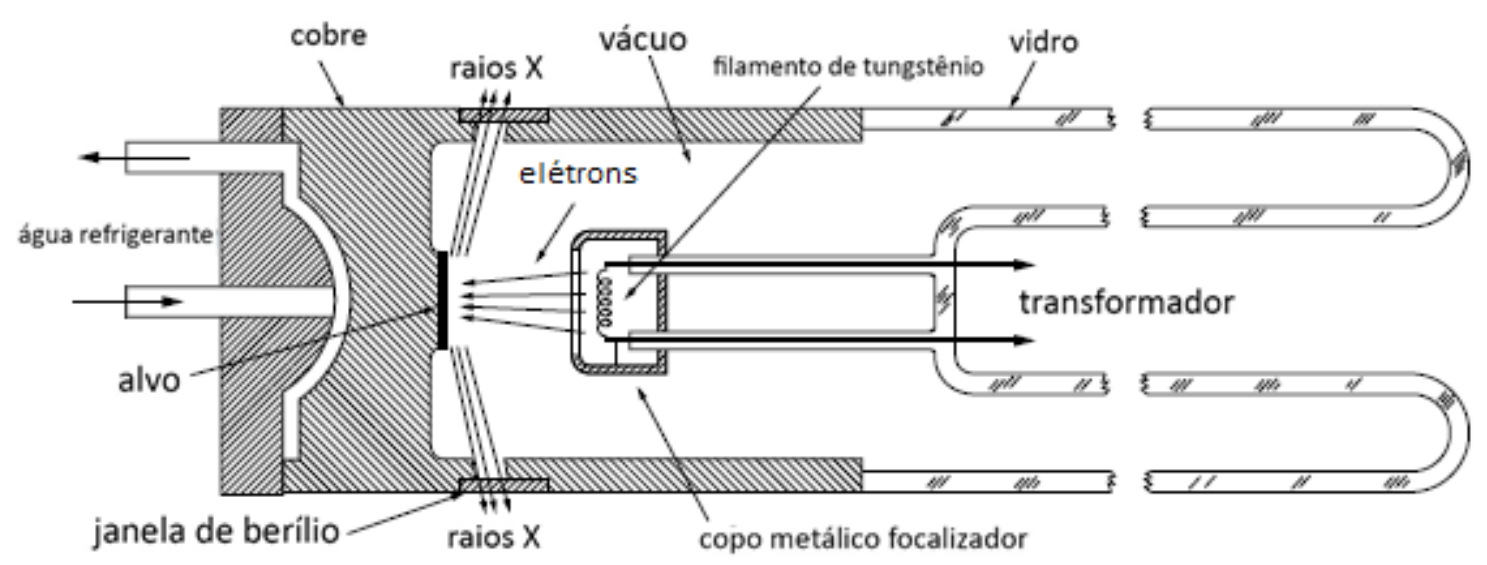

Figura 3.2 - Desenho esquemático de um tubo selado de raios X (Adaptado de [7]).

O filamento é aquecido pela passagem de corrente elétrica e emite elétrons, que são rapidamente atraídos para o alvo devido à diferença de potencial produzida pela alta tensão. Um pequeno recipiente de metal em torno do filamento 
é mantido na mesma alta tensão (negativa) que o filamento, repelindo, portanto, os elétrons e tendendo a focalizá-los em uma região estreita do alvo, chamado de ponto focal. Os raios $X$ são emitidos a partir do ponto focal em todas as direções e saem do tubo através de duas ou mais janelas altamente transparentes para raios $\mathrm{X}$, geralmente feitas de berílio.

\subsection{Estruturas cristalinas}

Um cristal pode ser definido como um sólido composto por átomos, íons ou moléculas dispostos num padrão periódico em três dimensões, diferindo fundamentalmente dos gases e dos líquidos pois os arranjos atômicos, iônicos ou moleculares nestes últimos, não possuem periodicidade, um requisito essencial do estado cristalino. Muitos sólidos são cristalinos e, se não são monocristais, consistem em cristais não contíguos, isto é, são policristalinos. No entanto, nem todos os sólidos são cristalinos. Alguns são amorfos, como o vidro, e não têm nenhum arranjo interior regular, não possuindo diferença essencial para um líquido, a não ser pelo estado físico.

Relações de simetria são observadas nos cristais, considerando o arranjo ordenado de átomos, íons ou moléculas como matrizes periódicas, que pode ser representado de forma geométrica como uma rede cristalina, ou seja, um conjunto tridimensional de pontos (pontos de rede), cercado por elementos idênticos.

Para definir a orientação de um plano cristalino na rede, são utilizados os índices de Miller, definidos como os recíprocos das intercepções fracionárias que o plano faz com os eixos cristalográficos. Escritos entre parêntesis, os índices ( $h k l$ representam a intercepção fracionada de $1 / h, 1 / k, 1 / l$, com o plano e, sendo os comprimentos dos eixos $a, b, c$, os planos interceptam os eixos nos pontos $a / h$, $b / k, c / l$, sendo $\boldsymbol{a}, \boldsymbol{b}, \boldsymbol{c}$ os vetores da base com respeito à origem. 


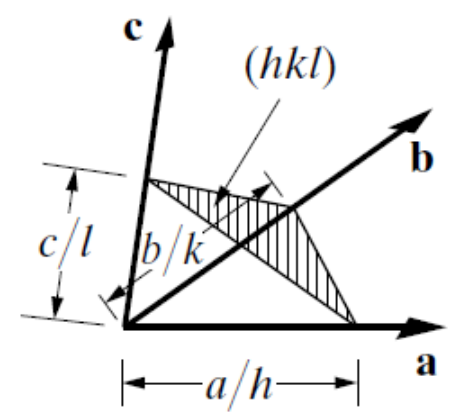

Figura 3.3 - Definição de um plano utilizando índices de Miller.

O recíproco do intercepto é utilizado para evitar a introdução do infinito na descrição da orientação do plano, sendo zero quando o plano e o eixo são paralelos.

\subsubsection{Rede Recíproca}

A representação por meio de rede recíproca permite relacionar os planos do espaço direto, definido pelos índices de Miller, com o espaço recíproco, preservando a simetria.

Vetores do tipo $\boldsymbol{a}_{i}$ (como por exemplo $\boldsymbol{a}, \boldsymbol{b}, \boldsymbol{c}$ ) podem definir os vetores da base de uma rede tridimensional. Esta rede do espaço direto pode, também, ser transformada por meio de uma rede recíproca $\boldsymbol{b}_{i}$ (no espaço recíproco) por meio das seguintes relações:

$$
\begin{aligned}
& \boldsymbol{b}_{1}=\frac{\boldsymbol{a}_{2} \times \boldsymbol{a}_{3}}{\boldsymbol{a}_{1 \cdot\left(\boldsymbol{a}_{2} \times \boldsymbol{a}_{3}\right)}} \\
& \boldsymbol{b}_{2}=\frac{\boldsymbol{a}_{3} \times \boldsymbol{a}_{1}}{\boldsymbol{a}_{1 \cdot\left(\boldsymbol{a}_{2} \times \boldsymbol{a}_{3}\right)}} \\
& \boldsymbol{b}_{3}=\frac{\boldsymbol{a}_{1} \times \boldsymbol{a}_{2}}{\boldsymbol{a}_{1} \cdot\left(\boldsymbol{a}_{2} \times \boldsymbol{a}_{3}\right)}
\end{aligned}
$$

O produto vetorial no numerador indica que a rede é ortonormal, de modo que: 


$$
\boldsymbol{a}_{i} \boldsymbol{b}_{j}=\delta_{i j}
$$

Sendo $\delta_{i j}$ o delta de Kroenecker e igual a 0 , se $i \neq j$ e 1 se $i=j$.

Um vetor $\boldsymbol{H}_{h k l}$, construído da origem a qualquer ponto do espaço recíproco que possua coordenadas $h, k, l$, é perpendicular ao plano no espaço direto, no qual o índice de Miller é $h, k, l$. O comprimento $H_{h k l}$ do vetor do espaço recíproco

$$
\boldsymbol{H}_{h k l}=h . \boldsymbol{b}_{1}+k \cdot \boldsymbol{b}_{2}+l \cdot \boldsymbol{b}_{3}
$$

é igual ao recíproco da periodicidade de (hkl), ou seja, $H_{h k l}=1 / d_{h k l}$.

Portanto, um ponto no espaço recíproco, definido por $\boldsymbol{H}_{h k l}$, é suficiente para representar uma série de infinitos planos do espaço direto.

\subsubsection{Sistemas Cristalinos}

A cela unitária de um cristal pode ser definida por um conjunto de três vetores $(\boldsymbol{a}, \boldsymbol{b}, \boldsymbol{c})$ não coplanares. Dependendo do comprimento e orientação destes vetores e dando valores especiais aos comprimentos e ângulos axiais, são produzidas celas unitárias de várias formas e, portanto, vários tipos de pontos da rede, uma vez que os pontos da rede estão localizados nos vértices das celas unitárias primitivas.

Estes vetores coincidem com os três vértices independentes da cela elementar, que podem ser descritos por um vetor $\boldsymbol{r}$ :

$$
\boldsymbol{r}=u \boldsymbol{a}+v \boldsymbol{b}+w \boldsymbol{c}
$$

onde $u, v$ e $w$ são números inteiros.

Os três vetores da base $(\boldsymbol{a}, \boldsymbol{b}, \boldsymbol{c})$ e todos dos vetores derivados $(\boldsymbol{q})$ representam translações da cela unitária na rede, incluindo todos os átomos ou moléculas localizadas nos limites da cela, nas três dimensões, preenchendo todo o espaço do cristal. 
Qualquer ponto da rede pode ser tomado como origem das coordenadas, sendo possível descrever completamente a cela unitária por meio de seis quantidades escalares, que representam os parâmetros da rede:

$$
a, b, c, \alpha, \beta, \gamma
$$

Os parâmetros $a, b, c$ representam os comprimentos dos limites da cela e $\alpha, \beta, \gamma$ representam os ângulos entre eles, conforme é mostrado na FIG. 3.4:

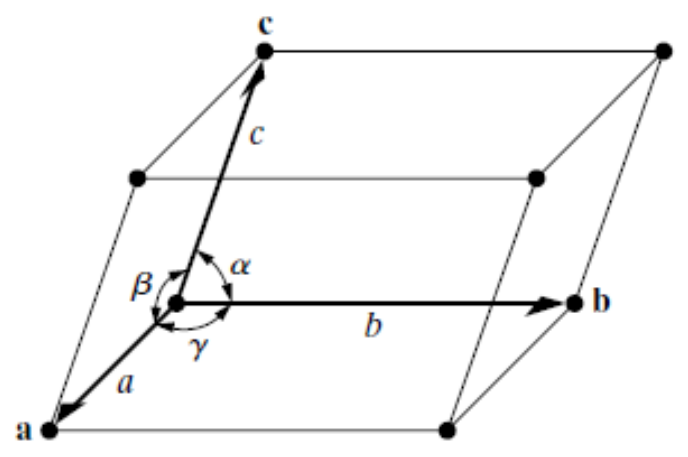

Figura 3.4 - Parâmetros da cela unitária de um cristal em três dimensões.[9]

O conjunto de pontos da rede pode ser expresso por sete tipos diferentes de celas, correspondentes aos sete sistemas cristalinos, nos quais os cristais podem ser classificados. Cada tipo diferente de cela unitária pode ser descrita como simples ou primitiva ( $\mathrm{P}$ ou $\mathrm{R}$ ) e como não primitiva, sendo que as células primitivas têm apenas um ponto de rede por cela, enquanto que as não primitivas têm mais de um. Um ponto de rede no interior de uma cela está contido nela, enquanto que um ponto em uma face de célula é compartilhado por duas celas e um ponto em um dos vértices é compartilhado por oito celas. O número de pontos da cela pode ser calculado como:

$$
N=N_{i}+\frac{N_{f}}{2}+\frac{N_{v}}{8}
$$

Sendo $N_{i}$ o número de pontos interiores, $N_{f}$ o número de pontos nas faces e $N_{v}$ o números pontos nos vértices. O conjunto de todos os arranjos de celas correspondem às quatorze redes de Bravais, mostradas na FIG. 3.5 e na TAB. 3.1. 
As referências às celas de face centrada, corpo centrado e base centrada são feitas pelos símbolos $F$, I e $C$, respectivamente, e $P$ faz referência à cela primitiva.

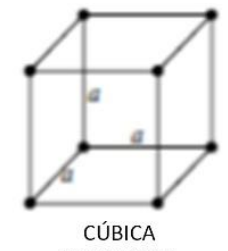
SIMPLES (P)

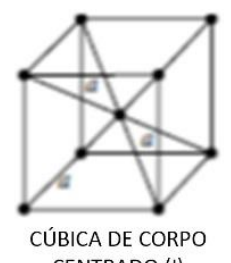

CENTRADO (I)

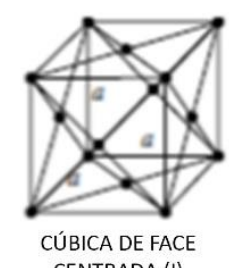

CENTRADA (I)

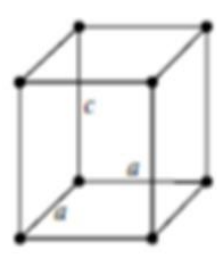

TETRAGONAL SIMPLES (P)

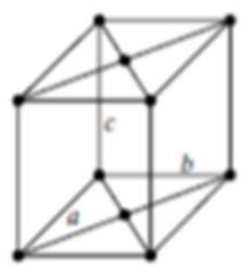

ORTORRÔMBICA DE BASE CENTRADA (C)

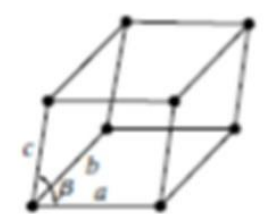

MONOCLÍNICA SIMPLES (P)
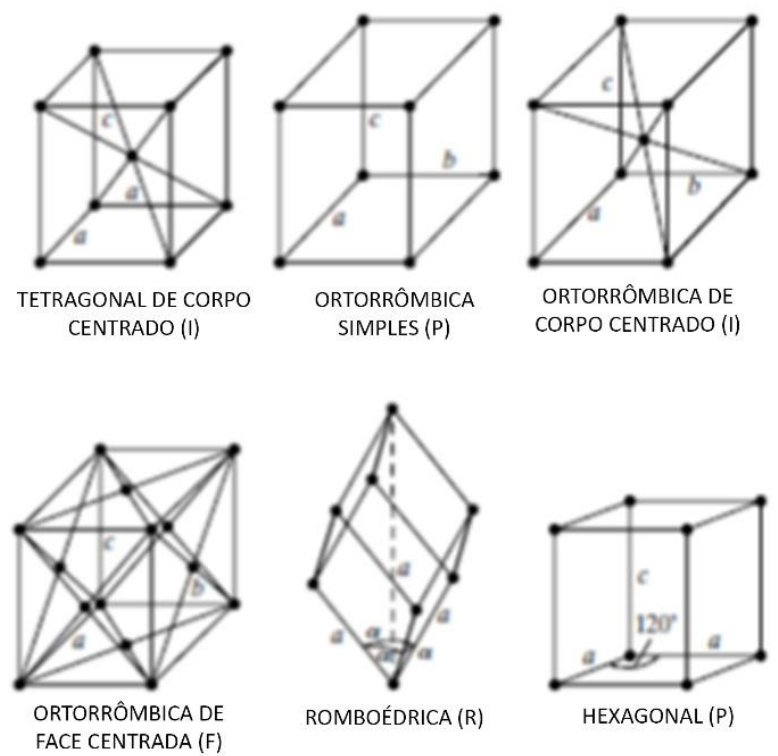

CORPO CENTRADO (I)
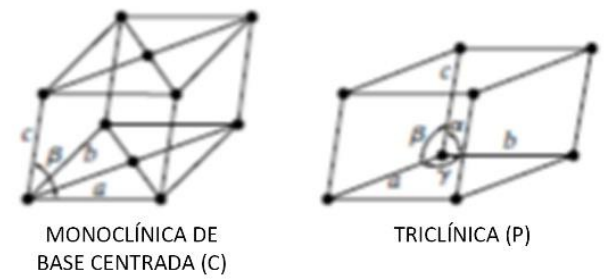

TRICLÍNICA (P)

Figura 3.5 - As quatorze redes de Bravais. As referências às celas de face centrada, corpo centrado e base centrada são feitas pelos símbolos $F$, I e $C$, respectivamente, e $P$ faz referência à cela primitiva (Adaptado de [7]) 
Tabela 3.1 - Relação entre comprimentos e ângulos axiais das quatorze redes de Bravais.

\begin{tabular}{|c|c|c|c|}
\hline Sistema & $\begin{array}{l}\text { Comprimentos e ângulos } \\
\text { axiais }\end{array}$ & Rede de Bravais & Símbolo da rede \\
\hline \multirow{3}{*}{ Cúbico } & \multirow{3}{*}{$\begin{array}{c}a=b=c \\
\alpha=\beta=\gamma=90^{\circ}\end{array}$} & Simples & $P$ \\
\hline & & Corpo centrado & I \\
\hline & & Face centrada & $F$ \\
\hline \multirow{3}{*}{ Tetragonal } & $a=b \neq c$ & Simples & $P$ \\
\hline & $\alpha=\beta=\gamma=90^{\circ}$ & Corpo centrado & I \\
\hline & & Simples & $P$ \\
\hline \multirow{3}{*}{ Ortorrômbico } & $a \neq b \neq c$ & Corpo centrado & 1 \\
\hline & $\alpha=\beta=\gamma=90^{\circ}$ & Base centrada & $\mathrm{C}$ \\
\hline & & Face centrada & $\mathrm{F}$ \\
\hline $\begin{array}{l}\text { Romboédrico } \\
\text { (ou trigonal) }\end{array}$ & $\begin{array}{c}a=b=c \\
\alpha=\beta=\gamma \neq 90^{\circ}\end{array}$ & Simples & $\mathrm{R}$ \\
\hline \multirow{3}{*}{ Hexagonal } & $a=b \neq c$ & & \\
\hline & $\alpha=\beta=90^{\circ}$ & Simples & $P$ \\
\hline & $\gamma=120^{\circ}$ & & \\
\hline \multirow{2}{*}{ Monoclínico } & $a \neq b \neq c$ & Simples & $P$ \\
\hline & $\alpha=\gamma=90^{\circ} \neq \beta$ & Base centrada & C \\
\hline Triclínico & $\begin{array}{c}a \neq b \neq c \\
\alpha \neq \beta \neq \gamma \neq 90^{\circ}\end{array}$ & Simples & $P$ \\
\hline
\end{tabular}

\subsection{Difração de raios $X$}

A difratometria de raios $X$ envolve a medição da intensidade de raios $X$ espalhados por elétrons ligados a átomos, sem alteração no comprimento de onda, mantendo a mesma fase e energia do fóton incidente em função do ângulo de espalhamento. Este espalhamento somente ocorre se o comprimento de onda é comparável à distância entre os elementos espalhadores, satisfazendo determinadas condições geométricas, expressas nas equações de Bragg ou de Laue.

Os raios $\mathrm{X}$ possuem alta energia, penetrando profundamente dentro do material, onde reflexões adicionais ocorrem em um grande número de planos 
paralelos consecutivos. Como o feixe de raios $X$ é refletido na mesma direção, ocorre a superposição dos raios espalhados.

As ondas espalhadas por átomos em posições diferentes chegam ao detector com um deslocamento de fase relativo, de modo que as intensidades medidas fornecem informações sobre as posições atômicas relativas, resultando em um padrão de difração, característico de cada substância. A análise do padrão de difração permite a elucidação e identificação de sua estrutura.

\subsubsection{Lei de Bragg}

Um conjunto de planos paralelos, separados por uma distância d, pode ser caracterizado por índices de Miller, de modo que $d=d_{h k l}$. A reflexão dos raios $X$ nos planos da estrutura resultam em uma diferença de trajetória 2. (vide FIG. 3.6), de forma que a interferência construtiva ocorre quando $2 . \Delta=n \lambda$, possibilitando a observação da intensidade refletida nestas condições. A lei de Bragg descreve esta reflexão relacionando-a com o ângulo $\theta$ de incidência, também denominado ângulo de Bragg:

$$
n \lambda=2 \cdot d_{h k l} \cdot \operatorname{sen}(\theta)
$$

Por meio desta equação, considera-se a difração em termos de um conjunto de planos cristalográficos $(h k l)$, ou seja, um conjunto de planos equidistantes e paralelos, possuindo orientação e espaçamento definidos.

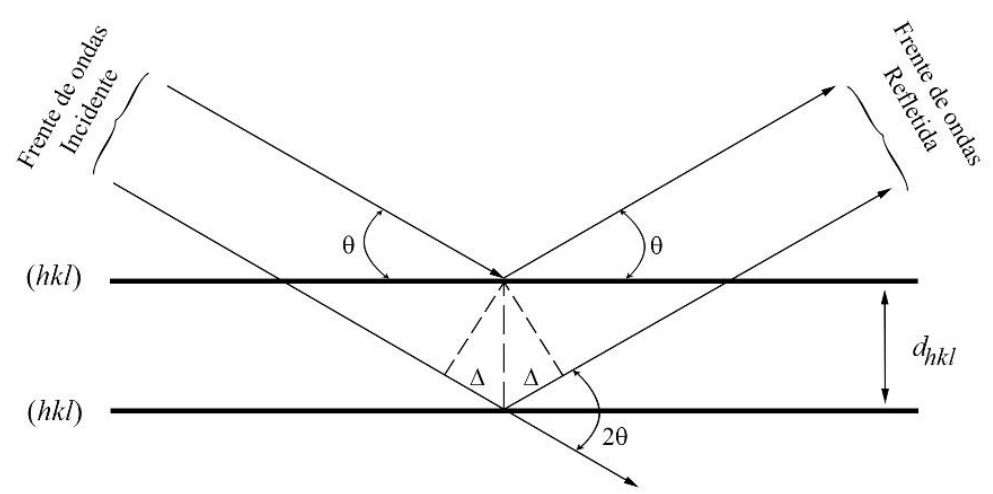

Figura 3.6 - Ilustração esquemática da condição geométrica da Lei de Bragg. O espaçamento entre os planos paralelos e sucessivos $(h k l)$ é dado por $d_{h k l} ; 2 . \Delta$ é a diferença de trajetória e $\theta$ é o ângulo de Bragg. 
A lei de Bragg pode, também, ser expressa no espaço recíproco utilizando o vetor de espalhamento $\boldsymbol{H}$. Considerando os vetores unitários $\boldsymbol{S}_{\mathbf{0}}$ e $\boldsymbol{S}$ relativos aos feixes incidente e espalhado, respectivamente, é possível construir os vetores $S_{0} / \lambda$ e $S / \lambda$, coplanares, com ângulo $\theta$ em relação aos planos difratantes, relacionando-os do seguinte modo:

$$
\frac{\left(\boldsymbol{S}-\boldsymbol{S}_{0}\right)}{\lambda}=\boldsymbol{H}=\boldsymbol{H}_{h k l}
$$

Comparando com a lei de Bragg:

$$
\begin{gathered}
\frac{1}{d_{h k l}}=\frac{2 \cdot \operatorname{sen} \theta}{\lambda} \\
\left|\frac{\left(\boldsymbol{S}-\boldsymbol{S}_{0}\right)}{\lambda}\right|=H_{h k l}=\frac{1}{d_{h k l}}=\frac{2 \cdot \operatorname{sen} \theta}{\lambda}
\end{gathered}
$$

Portanto, a representação da lei de Bragg no espaço recíproco produz uma representação gráfica de forma que para um conjunto dado de planos $h k l$ temos um vetor $\boldsymbol{H}_{h k l}$ para o ponto $h k l$ do espaço recíproco.

\subsubsection{Equações de Laue}

Considerando um arranjo periódico de átomos com espaçamento $a$, um feixe incidente de raios $\mathrm{X}$ dado pelo vetor unitário $S_{0}$ e um feixe espalhado na direção do vetor unitário $S$, a diferença de caminho dos dois feixes deve ser igual a um número inteiro de comprimento de onda:

$$
\boldsymbol{a}=\left(\boldsymbol{S}-\boldsymbol{S}_{0}\right)=h \cdot \lambda
$$

sendo $h$ um número inteiro.

Os feixes incidente e emergente não são necessariamente coplanares, de modo que para que ocorra espalhamento em fase numa rede periódica 
tridimensional, com três translações $\boldsymbol{a}, \boldsymbol{b}$ e $\boldsymbol{c}$, as condições abaixo devem ser satisfeitas simultaneamente:

$$
\begin{aligned}
& \text { a. }\left(\boldsymbol{S}-\boldsymbol{S}_{0}\right)=h . \lambda \\
& \text { b. }\left(\boldsymbol{S}-\boldsymbol{S}_{0}\right)=k . \lambda \\
& \text { c. }\left(\boldsymbol{S}-\boldsymbol{S}_{0}\right)=l . \lambda
\end{aligned}
$$

Estas relações são denominadas equações de Laue. As três equações podem ser relacionadas com a rede recíproca, utilizando as propriedades da rede.

Definindo o vetor de espalhamento:

$$
\boldsymbol{H}_{h k l}=\frac{\left(\boldsymbol{S}-\boldsymbol{S}_{0}\right)}{\lambda}=h \cdot \boldsymbol{a}^{*}+k \cdot \boldsymbol{b}^{*}+l \cdot \boldsymbol{c}^{*}
$$

Uma onda que satisfaça as condições expressas nas equações de Laue, é refletida no conjunto de plano com índices de Miller $h, k, l$. Portanto, a difração ocorre se o produto escalar de um vetor qualquer $\boldsymbol{r}=u \boldsymbol{a}+v \boldsymbol{b}+w \boldsymbol{c}$ do espaço real com o vetor de espalhamento $\boldsymbol{H}_{h k l}$ é um inteiro.

\subsubsection{Esfera de Ewald}

A construção de Ewald é um dos modos mais úteis para a compreensão da ocorrência dos picos de difração. Ao construir uma esfera de raio $1 / \lambda$, colocase no centro o elemento cristalino. A origem da rede recíproca está no feixe transmitido, no limite da esfera de Ewald. Os picos de difração ocorrem quando as 3 equações de Laue, ou equivalentemente, a equação de Bragg na forma vetorial, é satisfeita. Esta condição ocorre sempre que um ponto da rede recíproca coincide com a esfera de Ewald.

Na representação esquemática da FIG. 3.7 a direção do feixe incidente $S_{0} / \lambda$, com magnitude $1 / \lambda$, passa pela origem da esfera de reflexão e termina na origem da rede recíproca. A direção do feixe difratado $S / \lambda$, com magnitude $1 / \lambda$, passa pela origem da esfera e termina num ponto $h k l$ da rede recíproca, satisfazendo a lei de Bragg, representada pelo vetor de espalhamento $\boldsymbol{H}_{\boldsymbol{h k l}}$, para um conjunto de planos $h k l$. 


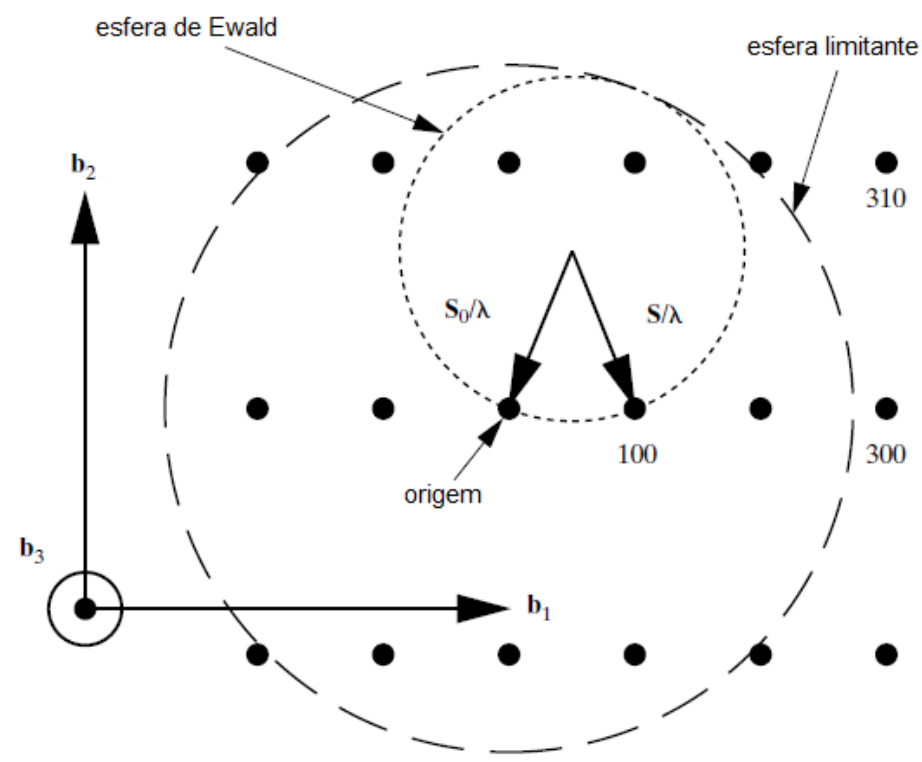

Figura 3.7 - Representação Esquemática da Esfera de Ewald (Adaptada de [7]).

Para determinar os demais pontos de reflexão, rotaciona-se o cristal posicionado na origem da esfera de modo que os pontos da rede recíproca passem pela esfera, sendo as reflexões correspondentes sucessivamente excitadas. Somente podem ser observadas as reflexões para as quais o módulo do vetor de espalhamento seja $H_{h k l} \leq 2 / \lambda$ (diâmetro da esfera de Ewald) e para as quais os pontos da rede recíproca estão dentro de uma esfera de centro $O$ e raio $2 / \lambda$, sendo esta a esfera limite. Caso o comprimento de onda da radiação incidente seja maior que o maior espaçamento $d_{\max }$ dos planos do cristal, não existe ponto na rede recíproca dentro da esfera limite, não sendo encontradas reflexões de Bragg, portanto, para $\lambda<d_{\max }$.

\subsubsection{Espalhamento por um elétron}

Um feixe de raios $X$ possui um campo elétrico oscilante que, ao incidir em um elétron, perturba sua posição de repouso aumentando sua energia. Se a 
energia adicional, no entanto, não é suficiente para ionizar o átomo ejetando o elétron, este ao retornar à sua posição de repouso libera a energia adicional recebida na forma de onda eletromagnética.

Neste processo o elétron causa o espalhamento coerente dos raios $X$, quando a onda espalhada possui a mesma frequência e comprimento de onda que o feixe incidente, pois o elétron não recebe momento do impacto, também podendo ser denominado espalhamento Thomson.

No caso da radiação incidente interagir com um elétron mais fracamente ligado ao átomo (elétron secundário), a onda incidente transfere momento ao elétron ejetando-o da órbita com certa energia cinética, sendo a onda espalhada em outra direção e com menor energia. Este processo é denominado espalhamento Compton ou incoerente.

A relação para o espalhamento coerente provê o espalhamento completo da componente perpendicular e uma dependência angular $(\theta)$ para 0 componente paralelo, significando que a onda se torna parcialmente polarizada. A intensidade da onda espalhada num ponto $R$ é dada por:

$$
\frac{I}{I_{0}}=\left(\frac{\mu_{0}}{4 \pi}\right)^{2} \frac{e^{4}}{m_{e}^{2}}\left(\frac{1+\cos ^{2} 2 \theta}{2}\right) \frac{1}{R^{2}}=\sigma_{e}\left(\frac{1+\cos ^{2} 2 \theta}{2}\right) \frac{1}{R^{2}}
$$

Sendo $\mu_{0}, e, m_{e}$ constantes e $\sigma_{e}=7,94 \times 10^{26} \mathrm{~cm}^{2}$, que é a seção de choque clássica para um espalhamento de elétron.

Os espalhamentos coerente e incoerente ocorrem simultaneamente e em todas as direções. O espalhamento coerente por átomos arranjados regularmente, como em um cristal, é reforçado em certas direções e cancelado em outras, produzindo os feixes difratados.

O fator de espalhamento atômico, ou fator de forma, descreve o espalhamento pelos elétrons que estão em torno de um átomo, sendo descrita pela transformada de Fourier de $\rho(r)$, que representa a integração de toda interferência no espaço real.

$$
f(\boldsymbol{H})=\int_{-\infty}^{+\infty} \rho(r) \cdot e^{2 \pi i(\boldsymbol{r} \cdot \boldsymbol{H})} d r
$$


Onde 2. $\pi .(\boldsymbol{r} \cdot \boldsymbol{H})=\varphi$ é a diferença de fase entre dois átomos, que possuem densidade eletrônica $\rho(r)$ cada um e estão separados por uma distância $r$, de modo que:

$$
\varphi=\frac{2 . \pi}{\lambda} \cdot \boldsymbol{r} \cdot\left(\boldsymbol{S}-\boldsymbol{S}_{\mathbf{0}}\right)=2 \cdot \pi\left(r \cdot \frac{\left(\boldsymbol{S}-\boldsymbol{S}_{\mathbf{0}}\right)}{\lambda}\right)=2 . \pi \cdot(\boldsymbol{r} \cdot \boldsymbol{H})
$$

Sendo os vetores de $\boldsymbol{r}$ e $\boldsymbol{H}$ definidos nos espaços real e recíproco, respectivamente. A interferência ocorre entre as ondas espalhadas, paralelas ao vetor $\boldsymbol{S}$.

Quando a energia de raios $\mathrm{X}$ aproxima-se da energia de ligação de um dos elétrons em um átomo, o espalhamento é afetado pela possível absorção do fóton e posterior ejeção do elétron. Assim, ocorre um aumento acentuado na absorção de raios $\mathrm{X}$ em cada uma das energias de ligação de elétrons.

$\mathrm{Na}$ borda de absorção, ocorre uma mudança na fase entre a onda incidente e a onda espalhada, por meio de um efeito de ressonância. Este desvio de fase cria um componente imaginário para o fator de espalhamento atômico e uma modificação da parte real:

$$
f(\boldsymbol{H})=f_{0}(\boldsymbol{H})+f^{\prime}+i f^{\prime \prime}
$$

Sendo $f_{0}(\boldsymbol{H}) \circ$ fator de espalhamento atômico, descrito na equação acima.

Os fatores de dispersão anômala ou de ressonância são independentes de $\boldsymbol{H}$, mas são dependentes de $\lambda$, pois o efeito é devido à absorção de energia pelas camadas mais internas.

\subsubsection{Espalhamento por uma rede cristalina}

A disposição atômica em cristais forma uma rede tridimensional com a repetição de celas unitárias que possuem propriedades intrínsecas. A cela unitária pode conter mais de um átomo e, portanto, a função de espalhamento $f$ deve ser 
substituída pelo espalhamento por toda a cela unitária, que forma o arranjo periódico do cristal.

A função de espalhamento de uma cela unitária, $F$, é chamada de fator de estrutura e contém os fatores de espalhamento de todos os átomos na cela unitária, juntamente com outros parâmetros atômicos relevantes. Como resultado, um padrão de difração produzido por uma rede cristalina pode ser definido como:

$$
F(\boldsymbol{H})=\int_{V} \rho(r) \cdot e^{2 \pi i(\boldsymbol{r} \cdot \boldsymbol{H})} d r
$$

A densidade de espalhamento $\rho(r)$ pode ser postulada como sendo função de cada átomo presente na rede, podendo ser atribuído a cada um deles um fator de espalhamento $f(\boldsymbol{H})$, de modo que a integral no volume da cela tornase uma somatória sobre as $N$ posições atômicas. Considerando o vetor $\boldsymbol{r}$ no espaço real e o vetor de espalhamento $\boldsymbol{H}$ como sendo, respectivamente:

$$
\boldsymbol{r}=u \boldsymbol{a}+v \boldsymbol{b}+w \boldsymbol{c} \quad \boldsymbol{H}=h \cdot \boldsymbol{a}^{*}+k \cdot \boldsymbol{b}^{*}+l \cdot \boldsymbol{c}^{*}
$$

A integral pode ser reescrita como:

$$
F(\boldsymbol{H})=\sum_{n=1}^{N} f_{n} \cdot e^{2 \pi i(\boldsymbol{r} \cdot \boldsymbol{H})}=\sum_{n=1}^{N} f_{n} \cdot e^{2 \pi i\left(h u_{n}+k v_{n}+l w_{n}\right)}
$$

O fator de estrutura $F$ descreve como os arranjos atômicos, dados pelas posições $\boldsymbol{r}$ para cada átomo, afetam os feixes espalhados, mostrando a amplitude e a fase da onda resultante. $\mathrm{O}$ valor absoluto $|\boldsymbol{F}|$ refere-se à amplitude da onda resultante em termos da amplitude da onda espalhada por um elétron.

A intensidade do feixe difratado por todos os átomos de uma cela unitária na direção predita pela lei de Bragg é proporcional ao quadrado do fator de estrutura, obtido pela multiplicação da equação acima por seu complexo conjugado, permitindo o cálculo da intensidade da reflexão de qualquer plano, definido pelos índices de Miller $h k l$, de posições atômicas conhecidas. 


\subsection{O Método de Rietveld}

O método de Rietveld é uma análise baseada em procedimentos computacionais que utiliza toda a informação contida no padrão de difração. Neste método são realizadas sucessivas iterações pelo método dos mínimos quadrados até que o melhor ajuste seja obtido entre o padrão de difração medido (ou experimental) e o padrão calculado, baseado em modelos refinados simultaneamente, de estruturas cristalinas, efeitos óticos da difração, fatores instrumentais e outras características da amostra (parâmetros de rede, por exemplo). Durante o refinamento ocorre uma troca contínua de respostas, resultante do aumento do conhecimento da estrutura e a melhora da alocação das intensidades observadas às sobreposições das reflexões de Bragg individuais.

O padrão de difração obtido para um comprimento de onda constante, consiste em $i$ passos de ângulos de espalhamento $\theta_{i}$ e da intensidade $y_{i}$ em cada passo. O refinamento é dado pelo melhor ajuste das intensidades $y_{i}$ simultaneamente. No ajuste por mínimos quadrados, a quantidade minimizada é o residuo $S_{y}$ :

$$
S_{y}=\sum_{i} w_{i}\left(y_{i}-y_{c i}\right)^{2}
$$

Onde:

$w_{i}=1 / y_{i}$

$y_{i}=$ intensidade observada no $i$-ésimo passo

$y_{c i}=$ intensidade calculada no $i$-ésimo passo

Um perfil de difração de um material cristalino consiste em uma reunião de perfis de reflexões individuais, cada qual possuindo uma altura e posição de pico, um alargamento, extremidades que decaem gradualmente com a distância em relação à posição do pico, e uma área integrada, proporcional à intensidade de Bragg, $I_{K}$, sendo $K$ os índices de Miller $h k l$. A intensidade $I_{K}$ é proporcional ao quadrado do valor absoluto do fator de estrutura, $\left|F_{K}\right|^{2}$.

As intensidades calculadas $y_{c i}$ são obtidas pelos valores $\left|F_{K}\right|^{2}$ calculados do modelo estrutural pela soma das contribuições calculadas das 
reflexões de Bragg dos elementos da vizinhança (dentro de um alcance específico) mais a radiação de fundo (background):

$$
y_{c i}=s \sum_{k} L_{K}\left|F_{K}\right|^{2} \phi\left(2 \theta_{i}-2 \theta_{k}\right) P_{K} A+y_{b i}
$$

Sendo:

$s=$ fator de escala,

$K=$ índices de Miller, $h k l$, para uma reflexão de Bragg

$L_{K}=$ representa a polarização de Lorentz e os fatores de multiplicidade

$\phi=$ função de perfil

$P_{K}=$ função de orientação preferencial

$A=$ fator de absorção

$F_{K}=$ Fator de estrutura para a $k$-ésima reflexão de Bragg

$y_{b i}=$ intensidade de background no $i$-ésimo passo

O procedimento da minimização por mínimos quadrados conduz a um conjunto de equações envolvendo derivativas de todas as intensidades calculadas, $y_{c i}$, com respeito a cada parâmetro ajustável, sendo solucionável pela inversão da matriz dos dados, com elementos $M_{j k}$ :

$$
M_{j k}=-\sum_{i} 2 w_{i}\left[\left(y_{i}-y_{c i}\right) \frac{\partial y_{c i}}{\partial x_{j} \partial x_{k}}-\left(\frac{\partial y_{c i}}{\partial x_{j}}\right)\left(\frac{\partial y_{c i}}{\partial x_{k}}\right)\right]
$$

Sendo os parâmetros $x_{j}, x_{k}$ do mesmo conjunto de parâmetros ajustáveis. Lida-se, portanto, com a criação e inversão de uma matriz $n \times n$, sendo $n$ o número de parâmetros refinados.

O resíduo da função é não linear, assim a solução é determinada por um procedimento iterativo, sendo os passos, $\Delta x_{k}$ :

$$
\Delta x_{k}=\sum M_{j k}{ }^{-1} \frac{\partial S_{y}}{\partial x_{k}}
$$

Os passos $\Delta x_{k}$ calculados são aplicados aos parâmetros iniciais, resultando, em princípio, em um modelo melhorado e, então, todo o procedimento 
é repetido. Como as relações entre os parâmetros ajustáveis e as intensidades são não lineares, o modelo inicial deve ser próximo ao modelo correto, de modo que o procedimento leve a um mínimo global.

\subsubsection{Função do perfil de reflexão}

Ambos os tipos de efeitos, instrumentais (assimetrias, por exemplo) e característicos da amostra, como aberrações devidas à absorção, deslocamento e alargamento (devido ao tamanho de cristalito e efeito de microdeformação), são aproximados pela função $\phi$ do perfil de reflexão. A tabela abaixo mostra as funções analíticas mais utilizadas.

Para dados que utilizam dispersão angular, a dependência do alargamento $H$ dos perfis de reflexão medidos como largura a meia altura (full width at half maximum - FWHM) pode ser modelada como [10]:

$$
H^{2}=U t g^{2} \theta+V t g \theta+W
$$

sendo $U, V$ e $W$ parâmetros refináveis.

As contribuições separadas para o alargamento não são simplesmente adicionadas, mas se combinam por uma convolução de suas funções:

$$
h(x)=\int g\left(x^{\prime}\right) f\left(x-x^{\prime}\right) d x^{\prime}
$$

onde $x=\left(2 \theta_{i}-2 \theta_{k}\right), x^{\prime}$ é a variável de integração, no mesmo domínio de $x, g(x)$ é a função de perfil instrumental, $f(x)$ é a função de perfil da difração intrínseca e $h(x)$ é função de perfil resultante observada. 
Tabela 3.2 - Funções analíticas mais utilizadas para o perfil de difração[10].

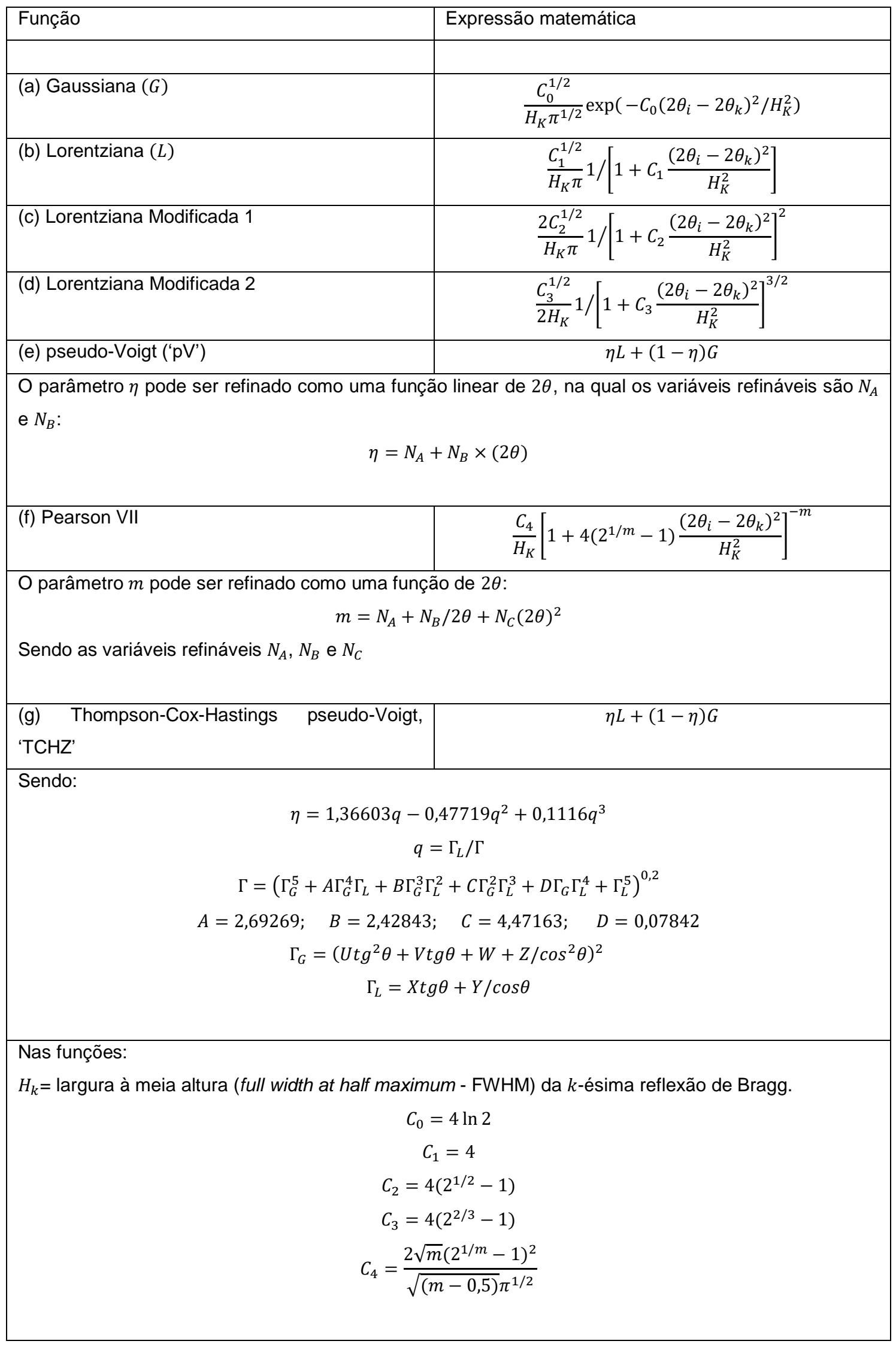


Caso $g(x)$ seja mais larga que $f(x)$, a função de perfil observada, $h(x)$, refletirá pouco ou não muito da característica de $f(x)$. Se a função de difração intrínseca, $f(x)$, não for estreita comparada com $g(x)$, pode ser modelada aproximadamente, tal que seja possível ajustar o perfil para concordar com as estimativas das intensidades de Bragg, mesmo no refinamento de Rietveld.

\subsubsection{Tamanho de cristalito e microdeformação}

Para um cristal perfeito, infinito, a rede recíproca é um conjunto de pontos, cada um representando um conjunto de planos no espaço real. A condição de difração no espaço recíproco é definida por uma relação geométrica, representada pela esfera de Ewald. O tamanho dos pontos, para este cristal, é determinado somente por fatores instrumentais e absorção, de modo que a largura a meia altura (FWHM) é pequena.

Quando a intensidade difratada não está representada por um ponto mas se alonga por uma região que possui tamanho e forma, relaciona-se com os domínios cristalinos, que são regiões de espalhamento coerente do feixe incidente, também denominados cristalitos[11].

A relação obtida por Scherrer[11] representa o tamanho médio de cristalito, utilizando a largura da linha do perfil de raios $X$, sendo dada por:

$$
\beta(2 \theta)=\frac{\lambda \cdot K_{\beta}}{D \cdot \cos (\theta)}
$$

onde:

$K_{\beta}$ é a constante de Scherrer, adimensional, de valor 0,9 para formatos esféricos;

$\lambda$ é o comprimento de onda dos raios $X$;

$\beta$ é a largura da linha do perfil (FWHM), depois de subtraído o alargamento gerado pela linha de perfil instrumental;

$D$ é o tamanho médio dos domínios cristalinos ordenados;

$\theta$ é o ângulo de Bragg. 
Ao deformar elasticamente um material policristalino, de tal modo que a deformação seja uniforme em distâncias relativamente grandes, os espaçamentos dos planos da rede nos grãos constituintes modificam-se de forma constante de um grão para outro, para cada conjunto de planos orientados de modo similar com respeito à tensão aplicada. Esta macrotensão uniforme desloca as linhas do perfil de difração para novas posições $2 \theta$.

Por outro lado, no caso em que os espaçamentos de um conjunto particular de planos $(h k l)$ varia de um grão a outro, uma microdeformação não uniforme é gerada, causando um alargamento da linha do perfil de difração correspondente.

Estes efeitos são geralmente superpostos, de modo que as linhas do perfil de difração podem ser tanto alargadas quanto deslocadas. Deste modo, a difração de raios $X$ pode, portanto, ser utilizada para determinação, de modo indireto, da tensão aplicada.[7]

Considerando o efeito de uma deformação macroscopicamente homogênea (macrodeformação), expressa como $\varepsilon=\Delta d / d$ e tomando a derivada da lei de Bragg para um comprimento de onda constante[11]:

$$
0=2 \cdot \Delta d \cdot \operatorname{sen}(\theta)+2 \cdot d \cdot \Delta \theta \cdot \cos (\theta)
$$

Reescrevendo em função de $\varepsilon$ :

$$
\begin{gathered}
2 . \Delta \theta=-2 \cdot \frac{\Delta d}{d} \cdot \operatorname{tg}(\theta)=-2 \cdot \varepsilon \cdot \operatorname{tg}(\theta) \\
\beta_{e}=-2 \cdot \varepsilon \cdot \operatorname{tg}(\theta)
\end{gathered}
$$

Para um campo de deformações não homogêneo as diversas partes do material difratariam em ângulos ligeiramente diferentes, produzindo um perfil alargado. O alargamento e forma do perfil dependerão da distribuição das deformações na amostra. Sendo:

$$
\beta_{e} \propto-\varepsilon \cdot \operatorname{tg}(\theta)
$$

Reescrevendo de modo geral: 


$$
\beta_{e}=C \cdot \varepsilon \cdot \operatorname{tg}(\theta)
$$

Sendo o valor da constante $C$ dependente das suposições iniciais feitas sobre a natureza da deformação inomogênea.

Os componentes de tamanho e deformação podem ser separados pela representação gráfica de $\beta \cos (\theta)$ como função de $\operatorname{sen}(\theta)$, denominado gráfico de Williamson-Hall.

Rearranjando os termos da equação de Scherrer, têm-se:

$$
\beta_{L} \cos (\theta)=\lambda \cdot K_{\beta} / D
$$

Aproximando a convolução das contribuições do tamanho, $\beta_{L}$, e da deformação, $\beta_{e}$, para o alargamento do perfil de difração para uma soma, $\beta_{h k l}$, destas resulta em:

$$
\begin{gathered}
\beta_{h k l}=\beta_{e}+\beta_{L}=C \cdot \varepsilon \cdot \operatorname{tg}(\theta)+\frac{\lambda \cdot K_{\beta}}{D \cdot \cos (\theta)}=C \cdot \varepsilon \cdot \frac{\operatorname{sen}(\theta)}{\cos (\theta)}+\frac{\lambda \cdot K_{\beta}}{D \cdot \cos (\theta)} \\
\beta_{h k l} \cdot \cos (\theta)=C \cdot \varepsilon \cdot \operatorname{sen}(\theta)+\frac{\lambda \cdot K_{\beta}}{D}
\end{gathered}
$$

Esta equação pode ser comparada com a equação da reta:

$$
y=a \cdot x+b
$$

Deste modo o intercepto resulta no inverso do tamanho de cristalito, $D$, e o coeficiente angular dá a microdeformação, $\varepsilon$.

\subsection{Materiais Magnéticos}

Os diferentes tipos de materiais magnéticos podem ser classificados segundo sua permeabilidade $(\mu)$ ou susceptibilidade $(\chi)$, que representam a resposta de um material a um campo magnético. 
O primeiro grupo são materiais para os quais $\chi$ é pequeno e negativo. Estes materiais são chamados diamagnéticos e sua resposta magnética se opõe ao campo magnético aplicado.

Um segundo grupo de materiais para os quais $\chi$ é pequeno e positivo são os paramagnéticos. A magnetização dos paramagnetos é fraca, mas alinhada paralelamente à direção do campo magnético. Exemplos de paramagnetos são alumínio, platina e manganês. Os materiais magnéticos mais amplamente reconhecidos são os sólidos ferromagnéticos para os quais a susceptibilidade é positiva e muito maior do que 1. Exemplos destes materiais são ferro, cobalto, níquel e vários metais de terras raras e suas ligas.

A permeabilidade do meio é uma relação entre o campo $\mathrm{H}$, gerado neste meio pela passagem de corrente elétrica, e o campo magnético $B$, que aparece como resposta à passagem desta. No vácuo, os campos $\mathrm{B}$ e $\mathrm{H}$ estão relacionados pela seguinte relação:

$$
\boldsymbol{B}=\mu_{0} \times \boldsymbol{H}
$$

sendo $\mu_{0}$ a permeabilidade magnética do vácuo $\left(\mu_{0}=4 \pi \times 10^{-7} \mathrm{H} / \mathrm{m}\right)$.

$\mathrm{O}$ campo $\mathrm{H}$ é gerado por correntes elétricas fora do material, por exemplo por um solenoide, um eletromagneto ou um ímã permanente, induzindo nele um campo magnético $B$.

A magnetização do material é outro fator que contribui para a geração do campo magnético B. Esta é gerada pela resultante vetorial do momento angular orbital e do spin dos elétrons dentro do sólido.

Como as propriedades magnéticas do material e os campos gerados pela passagem de corrente elétrica contribuem para a geração do campo magnético, estas podem ser somadas:

$$
\boldsymbol{B}=\mu_{0}(\boldsymbol{H}+\boldsymbol{M})
$$

A susceptibilidade magnética indica o grau de magnetização devido a um campo $\mathrm{H}$ aplicado. É definido como: 


$$
\chi=\frac{M}{H}
$$

Substituindo a Eq. 3.6.2 na Eq. 3.6.3, temos:

$$
\boldsymbol{B}=\mu_{0}(\boldsymbol{H}+\boldsymbol{M}) \Rightarrow \boldsymbol{B}=\mu_{0}(\boldsymbol{H}+\chi \boldsymbol{H})=\mu_{0}(1+\chi) \boldsymbol{H}=\mu \boldsymbol{H}
$$

Pode-se definir as permeabilidade e susceptibilidade diferenciais:

$$
\begin{aligned}
\mu^{\prime} & =\frac{d \boldsymbol{B}}{d \boldsymbol{H}} \\
\chi^{\prime} & =\frac{d \boldsymbol{M}}{d \boldsymbol{H}}
\end{aligned}
$$

pois, dependendo do tipo de material, B e $\mathbf{M}$ podem não ser funções lineares de um meio ou material, resultando que tanto a permeabilidade quanto a susceptibilidade podem não ser constantes.

A permeabilidade relativa, $\mu_{r}$, de um meio indica a relação entre a permeabilidade do meio e a permeabilidade do vácuo:

$$
\mu_{r}=\frac{\mu}{\mu_{0}}
$$

e está relacionada à susceptibilidade magnética pela expressão:

$$
\mu_{r}=1+\chi
$$

A densidade de energia por volume $\left(u_{B}\right)$, devido a presença de um campo magnético pode, então, ser determinada para um meio, utilizando-se a expressão[12]:

$$
u_{B}=\frac{\boldsymbol{B}^{2}}{2 \times \mu}=\frac{\boldsymbol{B}^{2}}{2 \times \mu_{0}(1+\chi)}
$$


As propriedades magnéticas de um material são caracterizadas não somente pela magnitude e pelo sinal de $\mathbf{M}$, mas também pelo modo como $\mathbf{M}$ varia com o campo $\mathrm{H}$. Curvas típicas de $M \times H$ são denominadas curvas de magnetização. Por meio desta curva pode-se estabelecer relações para o comportamento magnético das diferentes substâncias, de modo a agrupá-las de acordo com a susceptibilidade.

Substâncias denominadas diamagnéticas, paramagnéticas e ferromagnéticas possuem curvas $M \times H$ lineares, pois não retém magnetismo quando o campo magnético é removido. A curva de um material ferromagnético ou ferrimagnético é não linear, de modo que a susceptibilidade varia com o campo $\mathrm{H}$ e passa por um valor máximo. A saturação ocorre para valores suficientemente altos do campo $\mathrm{H}$, em que a magnetização $\mathrm{M}$ se torna constante em um valor de saturação $\mathrm{Ms}_{\mathrm{s}}$.

Após a saturação, um decréscimo no campo $H$ à zero não reduz $M$ à zero, de modo que materiais ferromagnéticos e ferrimagnéticos podem também se tornar ímãs permanentes, gerando um comportamento irreversível, denominado histerese. A forma com a qual materiais ferromagnéticos e ferrimagnéticos se magnetizam podem ser classificadas em dois tipos:

Materiais magnéticos moles: pequenos campos aplicados produzem saturação da magnetização;

Materiais magnéticos duros: a saturação da magnetização é obtida pela aplicação de altos campos magnéticos;

Na FIG. 3.8 está mostrado um exemplo para curva de magnetização em termos de B (linha cheia) e M (linha pontilhada). A curva de magnetização normal $\mathrm{B} \times \mathrm{H}$, mostra os campos indo do estado desmagnetizado à saturação. Observa-se que, apesar de atingido $\mathrm{M}_{\mathrm{s}}, \mathbf{B}$ continua a crescer com $\mathbf{H}$ porque $\mathrm{H}$ está relacionado com B, até atingir o campo de saturação Bs. Neste ponto, a inclinação da curva $d B / d H$ tende à unidade.

Com a redução do campo $\mathrm{H}$ à zero, após atingir a saturação na direção positiva a indução decresce de $\mathrm{B}_{s}$ para $\mathrm{B}_{\mathrm{r}}$, valor que representa a retentividade ou indução residual. Para retornar o material para o estado de indução zero é necessário a aplicação de um campo $\mathrm{H}$ no sentido contrário, igual à coercividade $H_{c}$. O campo necessário para reduzir $\mathbf{M}$ à zero é denominado coercividade 
intrínseca $H_{c i}$. Ao continuar a aplicação de um campo $\mathrm{H}$ contrário serão atingidos os valores $-\mathrm{B}_{\mathrm{s}},-\mathrm{B}_{\mathrm{r}} \mathrm{e}+\mathrm{B}_{\mathrm{s}}$, formando o ciclo de histerese.

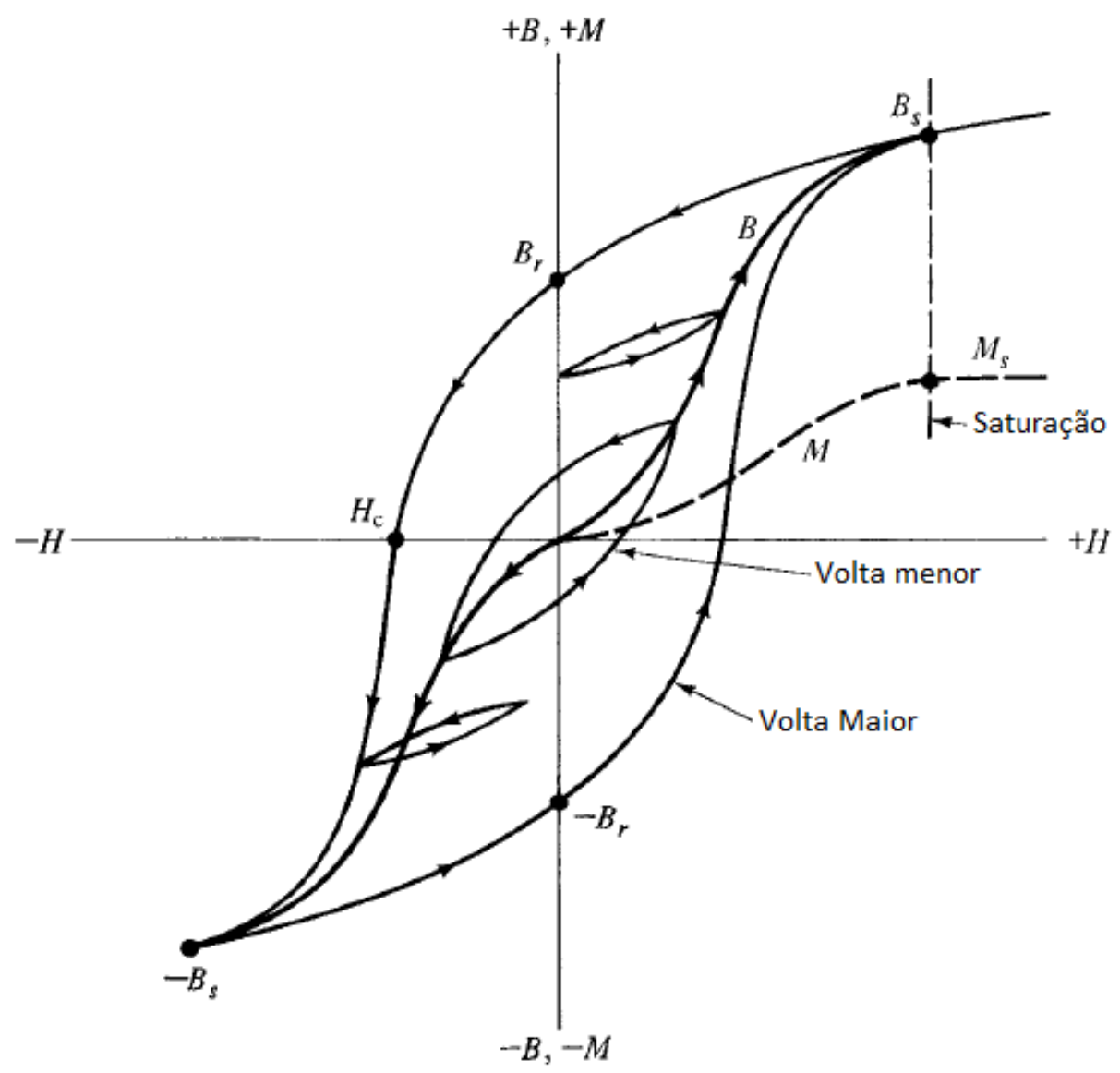

Figura 3.8 - Exemplo de um ciclo de histerese de um material ferromagnético[13]

\subsubsection{Diamagnetismo e paramagnetismo}

Materiais diamagnéticos são sólidos que não possuem momento magnético permanente por átomo. A susceptibilidade diamagnética surge do realinhamento dos orbitais eletrônicos devido à ação de um campo magnético, portanto, todos os materiais possuem uma susceptibilidade magnética, apesar de nem todos serem classificados deste modo. Alguns materiais possuem um momento magnético por átomo, devido a um spin eletrônico não pareado em cada átomo, resultando em paramagnetismo, ou ainda, a estados de ordenamento magnético, como o ferromagnetismo. Nos casos das susceptibilidades paramagnética ou ferromagnética, estas são muito maiores que a diamagnética, sendo o efeito dominante. 
Do ponto de vista da mecânica quântica, o momento magnético de um átomo livre possui três fontes principais: o spin com o qual os elétrons são dotados, seu momento angular orbital sobre o núcleo e a mudança no momento orbital induzida por um campo magnético aplicado. Os dois primeiros efeitos dão contribuições paramagnéticas para a magnetização, e o terceiro dá uma contribuição diamagnética. Os átomos com todas as camadas eletrônicas preenchidas têm spin zero e momento orbital zero. Portanto, os momentos finitos são associados com camadas não preenchidas.

O diamagnetismo está associado com a tendência de cargas elétricas blindarem parcialmente o interior de um corpo de um campo magnético aplicado[8]. O campo magnético da corrente induzida é oposto ao campo aplicado. O tratamento usual do diamagnetismo de átomos e íons emprega o teorema de Larmor: Considerando o movimento em órbita circular dos elétrons ao redor de um núcleo central, a adição de um campo magnético fraco produz um movimento de precessão sobreposto ao movimento inicial da partícula carregada. Este movimento de precessão dos elétrons ocorre com frequência angular $\omega$, denominada frequência de Larmor:

$$
\omega=\frac{e B}{2 m}
$$

Aplicando-se lentamente o campo, o movimento no sistema de referência giratório será o mesmo que o movimento original no sistema de repouso antes da aplicação do campo.

Se a corrente média de elétrons ao redor do núcleo for inicialmente zero, a aplicação do campo magnético causará uma corrente finita ao redor do núcleo. $\mathrm{A}$ corrente é equivalente a um momento magnético oposto ao campo aplicado, assumindo-se que a frequência de Larmor é muito menor do que a frequência do movimento original no campo central.

Pode ser demonstrado, tanto classicamente quanto quanticamente[8] a susceptibilidade diamagnética:

$$
\chi=-\frac{\mu_{0} N Z e^{2}}{6 . m}\left\langle r^{2}\right\rangle
$$


Sendo $Z$ o número de elétrons, $N$ o número de átomos por unidade de volume, $\left\langle r^{2}\right\rangle$ a distância quadrática média dos elétrons em relação ao núcleo, e a carga e $m$ a massa do elétron.

Os materiais que exibem paramagnetismo são geralmente átomos e moléculas com um número ímpar de elétrons, de modo que há um spin de elétron não emparelhado, dando origem a um momento magnético. Estes incluem átomos e íons com camadas internas parcialmente preenchidas, tais como elementos de transição. Alguns elementos com números pares de elétrons são paramagnéticos.

A susceptibilidade nos materiais paramagnéticos varia inversamente com a temperatura absoluta, de acordo com a lei de Curie:

$$
\chi=\frac{C}{T}
$$

Onde $T$ é a temperatura em kelvin e $C$ é a constante de Curie.

Posteriormente, Weiss mostrou que a lei de Curie é um caso especial de uma lei mais geral, a lei de Curie-Weiss [8]:

$$
\chi=\frac{C}{T-\theta}
$$

Com dimensão de temperatura, $\theta$ é uma constante de cada substância, sendo igual a zero para as substâncias que obedecem à lei de Curie.

Nas substâncias paramagnéticas submetidas a campos magnéticos mais intensos, a magnetização $M$ é proporcional ao campo $H$. Na maioria dos casos os spins não são acoplados ou são apenas fracamente acoplados para que possam ser considerados independentes, em razoável aproximação. A energia térmica é alta o suficiente para que os momentos permaneçam aleatórios quando não há campo aplicado. $\mathrm{Na}$ aplicação do campo, os momentos começam a se alinhar, mas em pequena proporção. 


\subsubsection{Forças de troca}

As forças de troca são consequência do princípio de exclusão de Pauli, que determina que dois elétrons somente podem possuir a mesma energia se tiverem spin opostos. Portanto, se dois elétrons com spin antiparalelo estão próximos a soma de todas as forças é atrativa e uma molécula estável é formada, sendo a energia total dos átomos menor para uma certa distância do que para os átomos separados. Se estão paralelos, os átomos se repelem.

Os dois átomos adjacentes, ligados, estão com elétrons orbitando o núcleo, porém os elétrons são indistinguíveis, onde deve-se considerar a possibilidade da troca de posição destes, que passariam a orbitar o outro núcleo. A troca de posição dos elétrons, que ocorre em altas frequências, possui uma energia de troca, que toma parte importante na energia total das moléculas.

O fenômeno do ferromagnetismo é devido ao alinhamento dos spins de átomos adjacentes. Considerando dois átomos $i$ e $j$ que possuem momento angular $S_{i} h / 2 \pi$ e $S_{j} h / 2 \pi$, a energia de troca entre estes é dada por:

$$
E_{e x}=-2 J_{e x} \boldsymbol{S}_{i} \boldsymbol{S}_{j}=-2 J_{e x} S_{i} S_{j} \cos \phi
$$

A integral de troca, $J_{e x}$, está relacionada ao efeito de troca, sendo $\phi 0$ ângulo entre os spins. Para $J_{e x}>0$ : com spins paralelos $(\cos \phi=1), E_{\text {ex }}$ assume valor mínimo e com spins antiparalelos $(\cos \phi=-1), E_{e x}$ assume valor máximo. Portanto, para que ocorra ferromagnetismo nas substâncias, $J_{\text {ex }}$ positivo é uma condição necessária. $O$ fenômeno do antiferromagnetismo ocorre com $J_{e x}$ negativo.

Considerando uma estrutura cristalina, um átomo com número de coordenação $z$, cujas forças de troca ocorrem somente entre os vizinhos próximos, sendo que todos possuem o mesmo spin $S$ e todos estão paralelos, a energia de troca entre este átomo e os demais pode ser escrita como:

$$
E_{e x}=z\left(-2 J_{e x} S^{2}\right)
$$

Comparando com a energia potencial do átomo, submetido ao campo molecular $\mathrm{H}_{\mathrm{M}}$ e com momento magnético $\mu_{H}$ alinhado a este: 


$$
H_{M}=(\gamma \rho) \sigma_{0}=\frac{z 2 J_{e x} S^{2}}{\mu_{H}}
$$

Sendo $\sigma_{0}$ a magnetização de saturação a $T=0 K, \gamma$ a constante do campo molecular e $\rho$ a densidade.

Quando $J=S$ (somente spin) e com os parâmetros $\gamma \rho$ e $\theta$ relacionados por[13]:

$$
\theta=\frac{\mu_{H}(\gamma \rho) \sigma_{0}(J+1)}{3 k J}
$$

Pode-se relacionar a integral de troca com a temperatura de Curie:

$$
J_{e x}=\frac{3 k \theta}{2 z S(S+1)}
$$

Por exemplo, no ferro com estrutura CCC, para o qual $z=8$, e para $S=$ $1 / 2$, a integral de troca possui valor $J_{e x}=0,25 k \theta$.

\subsubsection{Antiferromagnetismo}

As substâncias antiferromagnéticas têm uma pequena susceptibilidade positiva a todas as temperaturas, porém estas variam de forma característica com a temperatura. À medida que a temperatura diminui $\chi$ aumenta, atingindo um máximo na temperatura de Néel, $\mathrm{T}_{\mathrm{N}}$. A substância possui comportamento paramagnético acima e antiferromagnético abaixo de $T_{N}$.

A temperatura de Néel geralmente é muito menor que a temperatura ambiente, de modo que é necessária uma série de medições de susceptibilidade para que seja possível determinar se uma substância, paramagnética à temperatura ambiente, não é antiferromagnética à baixa temperatura.

A temperatura $T_{N}$ divide a escala de temperatura em uma região magneticamente ordenada, abaixo, e outra desordenada (paramagnética), 
semelhante à temperatura $T_{c}$, obedecendo à lei de Curie-Weiss, porém com um valor negativo para $\theta$ :

$$
\chi=\frac{C}{T-(-\theta)}
$$

Com a proporcionalidade de $\gamma$ e $\theta$, para $\theta<0, \gamma<0$, de modo que enquanto $H$ atua no sentido de alinhar os momentos magnéticos, $H_{M}$ age desalinhando-os.

\subsubsection{Ferromagnetismo}

O comportamento de substâncias ferromagnéticas diferencia-se das paramagnéticas por conta da não proporcionalidade entre o campo magnético $B$ e o campo $\mathrm{H}$. O material ferromagnético pode reter o campo magnético residual mesmo na ausência de um campo externo, de modo que suas propriedades magnéticas dependem tanto do campo externo aplicado quanto dos estados anteriores a que foi submetido. As susceptibilidades magnéticas podem atingir altos valores $\left(\sim 10^{3}\right)$.

Os momentos magnéticos interagem entre si, podendo esta interação ser expressa em termos de um campo molecular $\mathrm{H}_{\mathrm{M}}$, que atua em conjunto com o campo $\mathrm{H}$ aplicado, sendo diretamente proporcional à magnetização:

$$
H_{m}=\gamma M
$$

sendo $\gamma$ a constante do campo molecular. Portanto, o campo total que atua no material pode ser escrito como:

$$
H_{t}=H+H_{m}
$$

Substituindo $\mathrm{H}$ por $\mathrm{H}_{\mathrm{t}}$ na lei de Curie e resolvendo para $\mathrm{M}$ : 


$$
\chi_{M}=\frac{M}{\rho H}=\frac{C}{T} \Rightarrow M=\frac{\rho C H}{T-\rho C \gamma}
$$

Concluindo que $\theta=\rho C \gamma$ é uma medida da força da interação, por sua proporcionalidade com a constante $\gamma$, sendo $\theta=\gamma=0$ para substâncias que obedecem à lei de Curie.

Para temperaturas acima da temperatura de Curie $T_{C}$, que é o ponto crítico no qual os momentos magnéticos intrínsecos de um material mudam de direção, uma substância ferromagnética torna-se paramagnética e sua susceptibilidade segue a lei de Curie-Weiss, com valor de $\theta$ aproximadamente igual a $T_{C}$.

O processo de magnetização de uma substância ferromagnética ocorre por meio da orientação dos momentos magnéticos dos domínios magnéticos presentes, separados por paredes de domínios, em que dois domínios estão magnetizados espontaneamente em direções diferentes, de modo que o campo aplicado organiza o estado de multi-domínios em um domínio magnetizado na mesma direção deste, conforme é ilustrado na FIG. 3.9. Durante o processo não existe mudança na magnitude da magnetização, apenas em sua direção, rotacionando a magnetização para direções paralelas e atingindo o estado de saturação Ms.

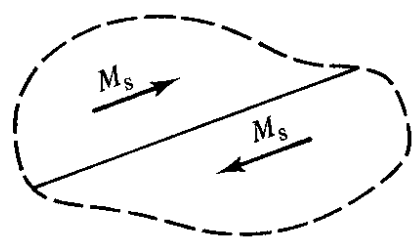

(a) $\quad M=0$

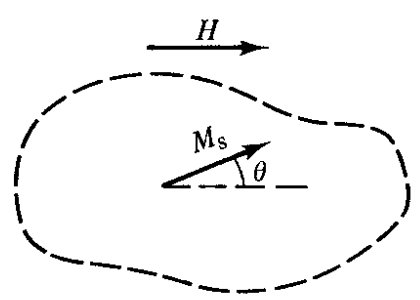

(c) $M=M_{\mathrm{s}} \cos \theta$

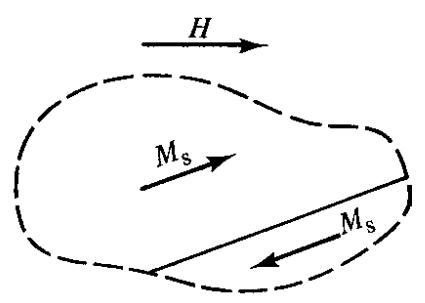

(b) $M>0$

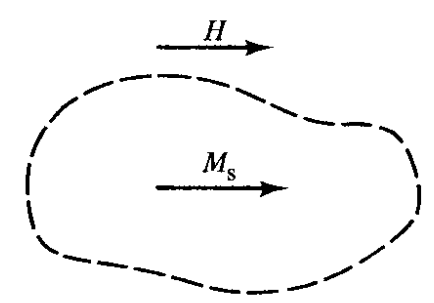

(d) $M=M_{\mathrm{s}}$

Figura 3.9 - Processo de magnetização em uma substância ferromagnética[13]. 


\subsubsection{Ferrimagnetismo e Ferritas}

Tanto as substâncias ferrimagnéticas como as ferromagnéticas possuem domínios magneticamente saturados, produzindo saturação magnética e histerese. Mostram magnetização espontânea em temperatura ambiente, que desaparece acima da temperatura de Curie, $T_{c}$, característica da substância, tornando-se paramagnética. As ferritas são as substâncias ferrimagnéticas mais importantes, formadas óxidos duplos de ferro e outro metal, apesar de nem todas serem ferrimagnéticas

A primeira explicação para o entendimento das ferritas foi realizada por L. Néel [14] tendo, inclusive, cunhado o termo ferrimagnetismo.

As ferritas são divididas em dois grupos principais, com estruturas cristalinas diferentes:

- Cúbicas, que possuem a fórmula geral $\mathrm{MO} \mathrm{Fe}_{2} \mathrm{O}_{3}$, sendo $\mathrm{M}$ um íon metálico divalente, como: $\mathrm{Mn}^{2+}, \mathrm{Zn}^{2+}, \mathrm{Fe}^{2+}$ ou $\mathrm{Mg}^{2+}$. A ferrita de Cobalto $\mathrm{CoO}_{\text {. }} \mathrm{Fe}_{2} \mathrm{O}_{3}$ é magneticamente dura, mas todas as demais cúbicas são moles;

- Hexagonais, que são magneticamente duras, sendo as mais importantes as de Bário e Estrôncio.

\subsubsection{Ferritas Cúbicas}

Um cristal de ferrita possui íns metálicos que ocupam dois diferentes sítios cristalográficos, denominados $\mathrm{A}$ e $\mathrm{B}$. Assumindo que a força de troca atuante entre um íon no sitio $A$ e outro no sitio B é negativa, como em um material ferromagnético, os íons em $A$ estão magnetizados em uma direção e os íons em $B$ na direção oposta. Contudo, estas intensidades em A e B não são equivalentes, de modo que os momentos magnéticos opostos não se cancelam, produzindo uma magnetização espontânea. Assim, estes materiais também podem ser vistos como antiferromagnéticos incompletos.

As ferritas cúbicas possuem uma estrutura denominada espinélio (ou spine), que possuem a estrutura cristalina do espinélio natural $\mathrm{MgAl}_{2} \mathrm{O}_{4}$, determinado pela primeira vez por Bragg. Esta estrutura cristalina, de grupo 
espacial Fd3m, é particularmente estável, uma vez que existe uma variedade extremamente grande de óxidos que a adotam, cumprindo as condições de proporção de cátion para ânion global de $3 / 4$ com uma valência catiônica total de 8.

A simetria geral dos oxigênios é FCC (cúbica de face centrada), que define dois tipos de locais intersticiais: 64 sítios tetraédricos e 32 sítios octaédricos, para uma célula unitária contendo 8 vezes a fórmula básica $\mathrm{AB}_{2} \mathrm{O}_{4}$. Apenas um oitavo dos sítios tetraédricos e metade dos sítios octaédricos são ocupados por cátions [15].

A cela unitária da estrutura cristalina está esquematizada na FIG. 3.10.

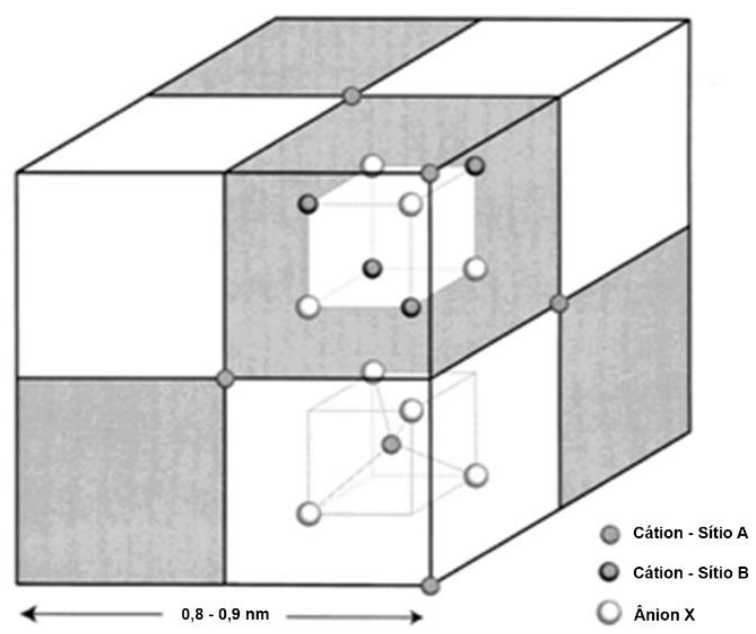

Figura 3.10 - Estrutura cristalina de uma ferrita cúbica (Adaptado de [16]).

A cela unitária da estrutura possui parâmetro (ou comprimento) a e foi dividida em oito octantes, cada um com comprimento $a / 2$, evidenciando os sítios tetraédrico e octaédrico.

Os íons metálicos não ocupam todos os sítios, sendo que $1 / 8$ dos sítios A e $1 / 2$ dos sítios $B$ estão ocupados. No espinélio mineral os íons $\mathrm{Mg}^{2+}$ estão nos sítios $\mathrm{A}$ e os $\mathrm{Al}^{3+}$ estão nos sítios $\mathrm{B}$ e, visto que algumas ferritas $\mathrm{MO}$. $\mathrm{Fe}_{2} \mathrm{O}_{3}$ seguem este mesmo padrão, com os íons $\mathrm{M}^{2+}$ nos sítios $\mathrm{A}$ e os $\mathrm{Fe}^{3+}$ nos sítios $\mathrm{B}$, são denominadas estruturas espinélio normal (normal spinel). As ferritas também podem se organizar com estrutura espinélio invertido (inverse spinel), na qual os íons divalentes estão nos sítios $\mathrm{B}$ e os trivalentes estão distribuídos igualmente entre os sítios A e B. Estruturas intermediárias também são possíveis, com frações 
diferentes dos íons nos sites $\mathrm{A}$ e B, podendo variar conforme o tratamento térmico a que são submetidos.

Em substâncias ferrimagnéticas, os sítios $A$ e $B$ são cristalograficamente diferentes, significando que a interação entre os sítios $A A$ será diferente da interação entre os sítios BB, mesmo que os íons envolvidos sejam idênticos, uma vez que um íon no sítio $A$ possui número e arranjos diferentes de vizinhos em relação ao mesmo íon no sítio B. Para desenvolver a teoria do campo molecular para este caso, segundo Néel, os íons magnéticos (considerados como idênticos) foram divididos em frações diferentes entre os sítios $A$ e $B$.

Tomando $n$ como o número de íons magnéticos idênticos por unidade de volume, com uma fração $\lambda$, localizada nos sítios $A$, e uma fração $v=(1-\lambda)$, nos sítios $\mathrm{B}$ e sendo $\mu_{A}$ o momento médio de um íon no sítio $\mathrm{A}$ na direção do campo à temperatura $\mathrm{T}$ (diferente de $\mu_{B}$ ), a magnetização do sítio $\mathrm{A}$ pode ser escrita como:

$$
M_{A}=n \lambda \mu_{A}
$$

Fazendo:

$$
n \mu_{A}=M_{a} \quad \Rightarrow \quad M_{A}=\lambda M_{a} \text { e } M_{B}=\lambda M_{b}
$$

Resultando na magnetização total:

$$
M=M_{A}+M_{B}=\lambda M_{a}+v M_{b}
$$

O campo molecular atuando no sítio A:

$$
H_{m A}=-\gamma_{A B} M_{B}+\gamma_{A A} M_{A}
$$

Sendo os coeficientes do campo molecular, $\gamma$, positivos, os sinais atribuídos correspondem à interação negativa (antiparalela) entre os íons dos sítios $A$ e $B$ e à interação positiva (paralela) entre os íons do sítio $A$. Resolvendo para 0 sítio $B$ : 


$$
H_{m B}=-\gamma_{A B} M_{A}+\gamma_{B B} M_{B}
$$

Expressando os coeficientes $\gamma_{A A}$ e $\gamma_{B B}$ em função de $\gamma_{A B}$, pode-se definir:

$$
\alpha=\frac{\gamma_{A A}}{\gamma_{A B}} \quad e \quad \beta=\frac{\gamma_{B B}}{\gamma_{A B}}
$$

Substituindo nas Eq. 3.6.5 e Eq. 3.6.6, temos:

$$
\begin{aligned}
& H_{m A}=\gamma_{A B}\left(\alpha \lambda M_{a}-v M_{b}\right) \\
& H_{m B}=\gamma_{A B}\left(\beta \lambda M_{b}-\lambda M_{a}\right)
\end{aligned}
$$

Que representam os campos moleculares e são válidos acima e abaixo da temperatura de Curie.

\subsection{Susceptiblidade AC}

Considerando um campo magnético $\mathrm{H}$ alternado do tipo: $H(t)=$ $H_{0} \cdot \cos (\omega t)$ aplicado sobre uma amostra, os momentos magnéticos presentes tentarão se alinhar com este, resultando em:

$$
M(t)=M_{0} \cdot \cos (\omega t+\varepsilon)
$$

Onde $M_{0}$ é a magnetização da amostra e $\varepsilon 0$ atraso na fase em relação ao campo $\mathrm{H}$ aplicado. Utilizando a notação complexa para $H(t)$ e $M(t)$ :

$$
\begin{gathered}
H(t)=H_{0} \cdot \mathrm{e}^{-\mathrm{i} \omega t} \Rightarrow \frac{H(t)}{H_{0}}=e^{-i \omega t} \\
M(t)=M_{0} \cdot \mathrm{e}^{-\mathrm{i}(\omega \mathrm{t}-\varepsilon)}=M_{0} \cdot e^{-i \omega t} \cdot e^{i \varepsilon} \Rightarrow M(t)=M_{0} \cdot \frac{H(t)}{H_{0}} \cdot e^{i \varepsilon}
\end{gathered}
$$

Pode-se escrever a susceptibilidade diferencial: 


$$
\chi_{0}=\frac{\partial M(t)}{\partial H(t)}=\frac{M_{0}}{H_{0}} \cdot e^{i \varepsilon}=\chi^{\prime}+i \chi^{\prime \prime}
$$

Portanto, a susceptibilidade diferencial possui partes real e imaginária, em que ambas dependem da frequência e do campo $\mathrm{H}_{0}$ aplicado. A componente $\chi^{\prime}$ representa a componente em fase da susceptibilidade magnética e $\chi^{\prime \prime}$ a componente resistiva ou componente fora de fase da susceptibilidade. A componente resistiva é proporcional à energia dissipada na amostra, a qual é devida aos efeitos de relaxação [17].

A susceptibilidade diferencial pode ser obtida por meio de um susceptômetro $A C$, que faz a comparação entre as tensões induzidas em duas bobinas em série com defasagem de fase da tensão de $180^{\circ}$. A soma das tensões, por conta da defasagem, deve ser nula e quando a amostra é introduzida em uma delas é possível fazer a leitura de $\Delta V$, que é numericamente igual à susceptibilidade. Esta relação pode ser deduzida como segue.

Considerando o fluxo magnético através de uma bobina, podemos escrever:

$$
\phi=\int_{S} \boldsymbol{B} \cdot d \boldsymbol{S}
$$

sendo S a área secção transversal da bobina e B o campo magnético aplicado.

De acordo com a lei de Lenz:

$$
\varepsilon=-\frac{d \phi}{d t}
$$

Sendo $\varepsilon$ a força eletromotriz (f.e.m.) induzida pela variação do fluxo magnético na bobina. Supondo um campo H do tipo:

$$
H(t)=H_{0} \cdot \cos (\omega t)
$$

atuando na mesma direção de S, pode-se obter o valor de $\varepsilon$ induzido: 


$$
\varepsilon=-\frac{d \phi}{d t}=-\frac{d}{d t}\left(\mu \cdot H_{0} \cdot \cos (\omega t)\right)=\omega \cdot \mu \cdot H_{0} \cdot \operatorname{sen}(\omega t)
$$

Os dois solenoides em série estão submetidos ao mesmo fluxo, portanto ao mesmo campo $\mathrm{H}$. Sendo $\mu$ a permeabilidade magnética dentro do solenoide com a amostra e $\mu_{0}$ a permeabilidade magnética do vácuo (dentro do solenoide sem a amostra) e denominando $\varepsilon_{A}$ a f.e.m induzida no solenoide com a amostra e $\varepsilon_{B}$ a f.e.m induzida no outro, pode-se escrever:

$$
\begin{gathered}
\varepsilon_{A}=\omega \cdot \mu \cdot H_{0} \cdot \operatorname{sen}(\omega t) \quad e \quad \varepsilon_{B}=\omega \cdot \mu_{0} \cdot H_{0} \cdot \operatorname{sen}(\omega t) \\
\frac{\Delta V}{V_{B}}=\frac{\varepsilon_{A}-\varepsilon_{B}}{\varepsilon_{B}}=\frac{\omega \cdot \mu \cdot H_{0} \cdot \operatorname{sen}(\omega t)-\omega \cdot \mu_{0} \cdot H_{0} \cdot \operatorname{sen}(\omega t)}{\omega \cdot \mu_{0} \cdot H_{0} \cdot \operatorname{sen}(\omega t)}=\frac{\mu-\mu_{0}}{\mu_{0}}=\frac{\mu_{0}(1+\chi)-\mu_{0}}{\mu_{0}}=\chi_{0}
\end{gathered}
$$

De modo que a susceptibilidade diferencial é uma grandeza adimensional.

\subsection{Método da coprecipitação[18]-[26]}

Precipitação é o processo pelo qual um sólido separado por fases é formado a partir de uma solução homogênea após a supersaturação em relação ao sólido precipitante ter sido atingida. A cristalização a partir da solução é um processo no qual o sólido é obtido diretamente sob a forma cristalina. A cristalização ocorre tipicamente a uma supersaturação relativamente baixa, sendo induzida principalmente pela redução da temperatura ou evaporação do solvente.

O termo precipitação é frequentemente utilizado para a descrição de processos nos quais a formação de sólidos é induzida pela adição de um agente que inicia uma reação química ou que reduz a solubilidade. Normalmente envolve uma supersaturação elevada e, assim, são obtidos frequentemente intermediários amorfos como os primeiros sólidos formados.

Precipitação (ou cristalização simples) envolve dois passos principais nucleação e crescimento. Na fase de nucleação formam-se cristais muito pequenos da fase sólida. Estes possuem elevada área superficial específica e elevada energia superficial, sendo, por isso, instáveis. Abaixo de um tamanho crítico do núcleo a energia livre de formação da fase sólida é menor que a sua energia superficial e a nova fase é termodinamicamente instável. Acima deste tamanho 
crítico as partículas sólidas podem crescer. De acordo com as condições, este passo de crescimento é principalmente controlado por fenômenos de interface ou difusão.

As técnicas de precipitação também são utilizadas, por exemplo, na produção de óxidos de ferro, óxidos de titânio ou zircônias. As principais vantagens da precipitação na preparação de tais materiais são a possibilidade de criar materiais muito puros e a flexibilidade do processo em relação à qualidade do produto final.

Outros materiais com base em mais de um componente podem ser preparados por coprecipitação. A coprecipitação é a precipitação simultânea de um componente normalmente solúvel com um macrocomponente da mesma solução pela formação de cristais mistos[27]. Os três modos em que ocorrem a precipitação simultânea são[28]:

- Coprecipitação por Adsorção - Cristais imperfeitos ou muito pequenos possuem grandes áreas superficiais em relação à própria massa. Grandes áreas deixam muitos íons expostos à solução, a qual atrai íons de carga oposta, causando coprecipitação por adsorção. Íons comuns ao precipitado são absorvidos mais fortemente.

- Coprecipitação por oclusão - É o aprisionamento das impurezas iônicas dentro dos cristais. Isto ocorre quando o cristal cresce tão rapidamente que os íons do precipitado não têm tempo de substituir todas as impurezas adsorvidas antes que o cristal cresça em torno delas. Produz distorções no cristal e modifica a sua composição.

- Coprecipitação por Inclusão - Íons que possuam tamanhos e cargas semelhantes a um íon da rede cristalina podem entrar nesta como substituinte por adsorção química, desde que o interferente precipite com a mesma estrutura cristalina. Existe maior probabilidade da formação de uma inclusão quando o íon de interferência está presente em concentrações mais elevadas que o íon da rede. A presença de uma inclusão não diminui a quantidade de material precipitado, desde que o precipitante seja adicionado em excesso, tornando a massa do precipitado maior que o esperado.

O método de síntese por meio da coprecipitação consiste na adição da solução de cátions metálicos a uma solução aniônica contendo hidróxido, 
controlando $\circ \mathrm{pH}$ da suspensão final formada. A temperatura, a velocidade de agitação e a de adição são variáveis importantes a serem consideradas. Uma agitação vigorosa da solução enquanto se adiciona o composto químico, provocando a precipitação, atua de duas formas: cada volume elementar da solução atinge rapidamente o maior grau de supersaturação; depois, este elemento da solução entra em contato várias vezes com o agitador e as paredes do recipiente, promovendo a nucleação heterogênea. Uma adição rápida do agente precipitante garante um alcance rápido do grau mais elevado de supersaturação em todo o volume da solução, resultando em uma taxa de nucleação máxima. O método de coprecipitação está resumido no esquema apresentado na FIG. 3.11.

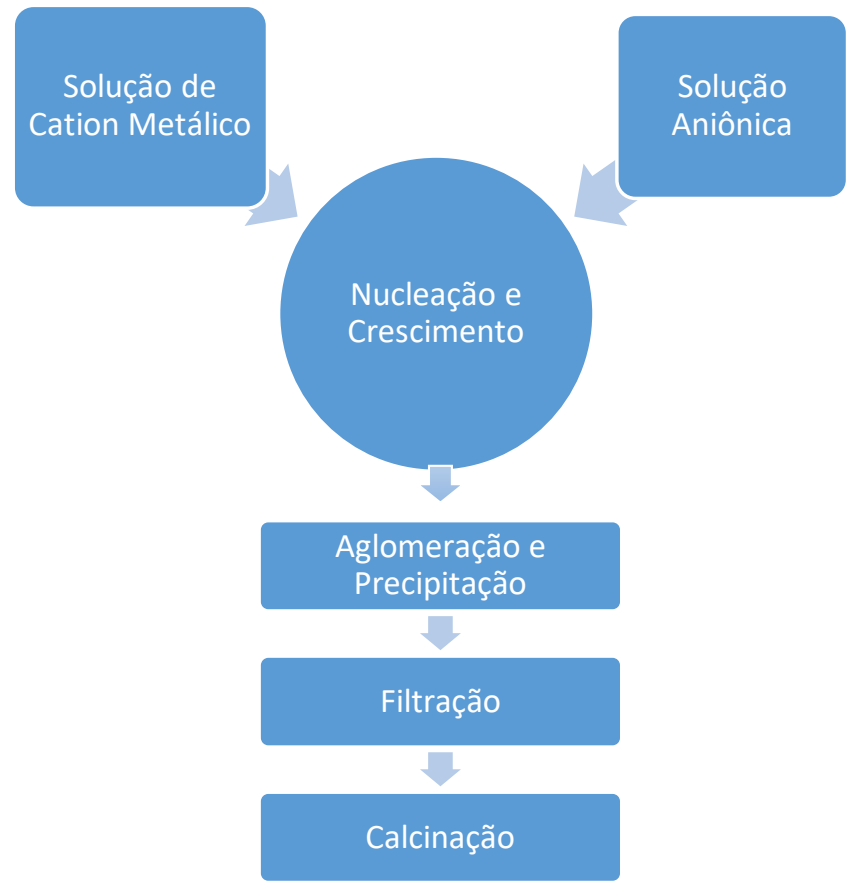

Figura 3.11 - Esquema do método de coprecipitação.

\subsection{Técnica Hidrotermal}

A técnica hidrotermal[29] configura-se como uma das ferramentas mais importantes para o processamento de materiais avançados, especialmente devido às suas vantagens no processamento de materiais nanoestruturados para uma ampla variedade de aplicações tecnológicas. Além de atuar no processamento de nanopartículas monodispersas e altamente homogêneas, também se mostra como 
uma das técnicas mais atraentes para o processamento de materiais nanohíbridos e nanocompósitos. O termo hidrotérmico descreve todas as reações químicas heterogêneas que ocorrem num sistema fechado na presença de um solvente, sendo aquoso ou não aquoso.

O tratamento de óxidos metálicos sob condições hidrotérmicas constitui um aspecto importante do processamento hidrotérmico de materiais devido às suas vantagens na preparação de nanopartículas altamente monodispersas com um controle sobre o tamanho e morfologia.

O processamento de materiais sob estas condições requer um recipiente de pressão capaz de conter um solvente altamente corrosivo a altas temperaturas e pressões e instalações que devem funcionar de forma rotineira e confiável sob condições extremas. Os parâmetros que devem ser considerados na escolha de um reator apropriado são as condições de temperatura e de pressão experimentais e a sua resistência à corrosão na gama de temperaturas e pressões num determinado solvente ou fluido hidrotérmico.

Projetar um aparato hidrotermal adequado ou ideal, popularmente conhecido como autoclave, reator, vaso de pressão ou ainda bomba de alta pressão, constitui-se em tarefa de difícil definição pois cada projeto tem objetivos diferentes e tolerâncias. Nas FIGs. 3.12 e 3.13 são ilustrados modelos de autoclaves mais comuns, tais como autoclaves de uso geral, autoclaves Morey, autoclaves Bridgman modificados e autoclaves Tuttle-Roy[29]. 


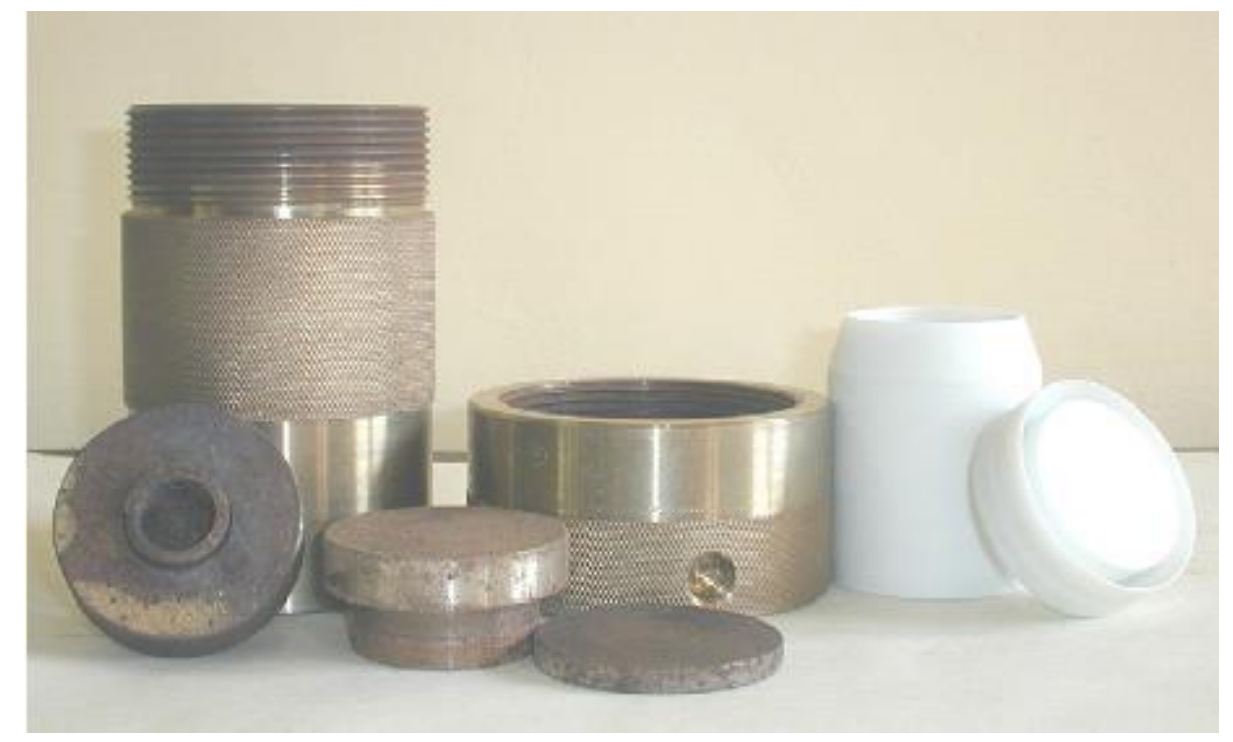

Figura 3.12 - Autoclave de uso geral, usada para tratamento e síntese hidrotermal [29].
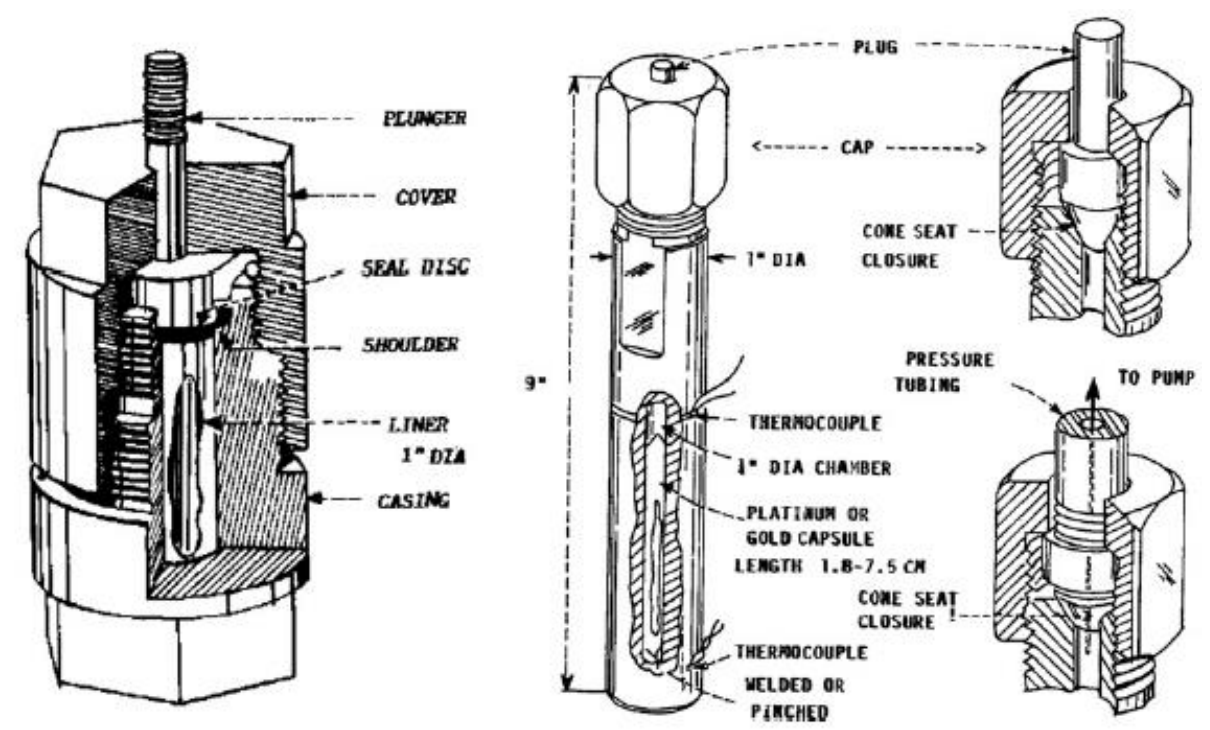

Figura 3.13 - Reatores mais utilizados no processamento hidrotérmico de materiais: (esq.) Autoclave de Morey (dir.) Autoclave de Tuttle-Roy [29].

Existem vários outros reatores popularmente utilizados para 0 processamento de materiais em condições hidrotermais com instalações especiais para micro-ondas, mecanoquímica, uso de energias eletroquímicas ou sonoquímicas, reatores de fluxo, autoclaves de balanço e assim por diante, o que ajuda muito no fornecimento de uma cinética aprimorada para reações hidrotermais. 


\subsection{Surfactantes}

Surfactante[30] ou agente tensoativo significa literalmente ativo numa superfície. Em outras palavras, um surfactante é caracterizado pela sua tendência em ser adsorvido em superfícies e interfaces. Por interface compreende-se um limite entre quaisquer duas fases imiscíveis, enquanto que superfície indica que uma das fases é um gás, geralmente ar. A força motriz para um surfactante adsorver numa interface é diminuir a energia livre desta.

A energia livre da interface por unidade de área representa a quantidade de trabalho necessário para expandir a interface. O termo tensão interfacial é frequentemente usado em vez de energia livre interfacial por unidade de área. Assim, a tensão superficial da água é equivalente à energia livre interfacial por unidade de área do limite entre a água e o ar acima dele. Quando essa fronteira é coberta por moléculas de surfactante a tensão superficial (ou a quantidade de trabalho necessária para expandir a interface) é reduzida. Quanto mais denso for o tensoativo empacotando na interface, maior será a redução da tensão superficial.

A tendência a acumular em interfaces é uma propriedade fundamental de um surfactante. Em princípio, quanto mais forte for essa tendência, melhor será o surfactante. O grau de concentração de tensoativo num limite depende da estrutura do tensoativo e também da natureza das duas fases que se encontram na interface.

Surfactantes são anfifílicos, ou seja, todas as moléculas de surfactante consistem em pelo menos duas partes, uma que é solúvel em um fluido específico (a parte liofilizada) e uma que é insolúvel (a parte liofóbica). Quando o fluido é água, refere-se geralmente a estas partes como hidrofílica e hidrofóbica, respectivamente. A parte hidrofílica é referida como cabeça e a parte hidrofóbica como a cauda.

Outra propriedade fundamental dos agentes tensoativos é que os monômeros em solução tendem a formar agregados, denominadas micelas. A formação de micelas, ou micelização, pode ser vista como um mecanismo alternativo à adsorção nas interfaces para remoção de grupos hidrofóbicos do contato com a água, reduzindo assim a energia livre do sistema. É um fenômeno importante uma vez que as moléculas de tensoativo se comportam de forma muito 
diferente na forma de micelas, quando comparadas ao comportamento no momento em que estão como monômeros livres em solução.

Somente os monômeros de surfactante contribuem para a redução da tensão superficial e interfacial e os fenômenos dinâmicos, como o molhamento e a formação de espuma, sendo governados pela concentração de monômeros livres na solução. As micelas podem ser vistas como um reservatório para monômeros de tensoativos. A taxa de troca de uma molécula de tensoativo entre a micela e a solução pode variar de muitas ordens de grandeza dependendo do tamanho e estrutura do tensoativo.

Micelas são geradas mesmo em concentrações muito baixas de surfactante em água. A concentração à qual as micelas começam a formar-se é chamada de concentração micelar crítica, ou CMC, e é uma característica importante de um surfactante.

A concentração acima da qual as micelas se formam é chamada a concentração micelar crítica (CMC). Portanto, a CMC representa uma separação de fases entre as moléculas de surfactante e agregados do surfactante, em equilíbrio dinâmico.
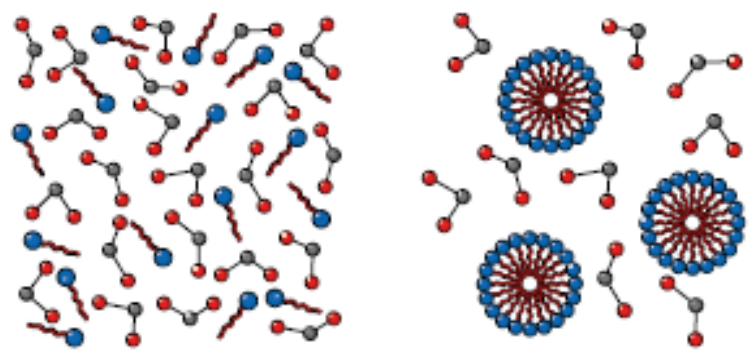

Figura 3.14 - Abaixo da CMC (Esq.) as moléculas estão dispersas; Acima da CMC (Dir.) há a formação de Micelas [31].

\subsubsection{CTAB - Diagrama de Fases}

A proporção de água ou outras moléculas de solvente pode causar alterações nas estruturas micelares. Em baixa concentração (abaixo da CMC), as moléculas estão dispersas sem ordenação. Ao aumentar a concentração em massa $(\% w)$ do surfactante, as moléculas se rearranjam, formando outras estruturas, como mostrado no diagrama de fases para o CTAB apresentado na FIG 3.15. 


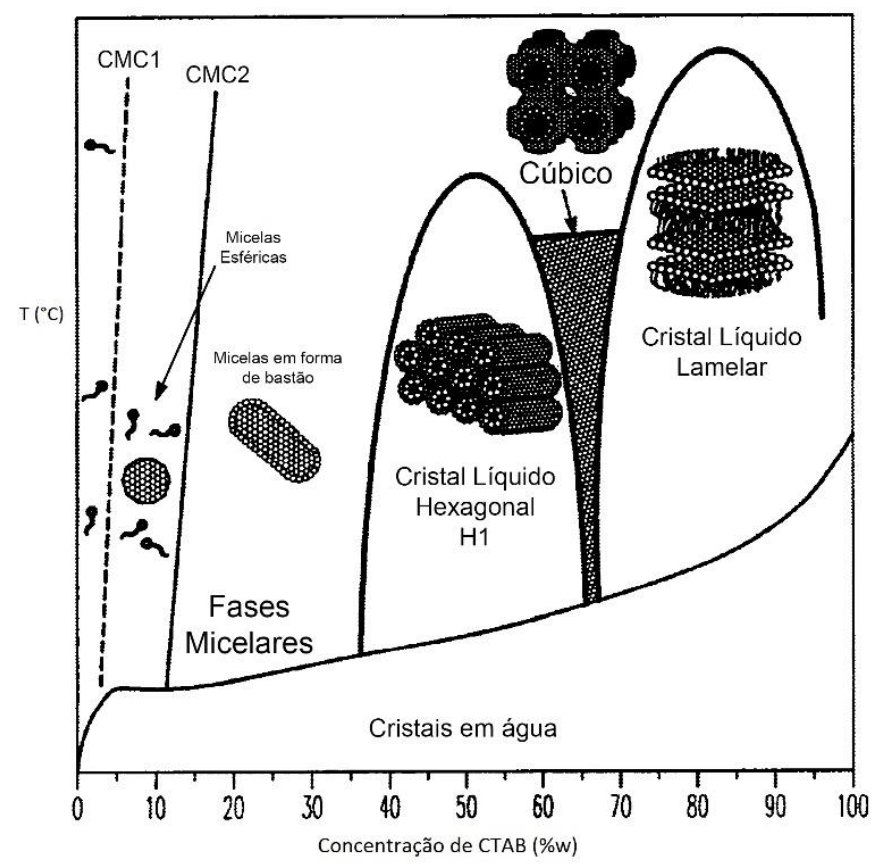

Figura 3.15 - Diagrama de Fases de formação de micelas para o surfactante CTAB. CMC1 é classificada como micela esférica e CMC2 como micela em forma de bastão [32].

O Brometo de N-cetil-N,N,N-trimetil-amônio (CTAB) (MM = 364,45 g/mol) é um surfactante de amônio quaternário, catiônico, que possui CMC entre 0,92 mM e 1,0 mM [33], em solução aquosa.<smiles>CCCCCCCCCCCCCCCC[N+](C)(C)Br</smiles>

Figura 3.16 - Representação da molécula de CTAB.

3.11 Análise por difração de raios $X$

\subsubsection{Análise de Fase}

Experimentos que envolvem a difração de raios $X$ de materiais micro e nanoestruturados são muito utilizados por fornecerem informações precisas sobre a estrutura dos materiais, sendo em alguns casos, a única opção viável para 
determinação confiável da estrutura cristalina. O padrão de difração apresenta várias contribuições devido a diferentes parâmetros estruturais da amostra.

Um difratograma de um material policristalino apresenta a intensidade difratada por uma família de planos cristalinos versus o ângulo de Bragg, que representa 0 ângulo entre a direção de incidência da radiação e os planos cristalinos do material, que formam os picos de difração. A identificação de uma ou mais fases cristalinas pode ser realizada analisando-se um conjunto de picos de difração, que possuem posições específicas[34].

\subsubsection{Tamanho médio de cristalitos e microdeformações}

A análise de perfis de difração de raios X (XLPA - X-Ray Line Profile Analysis) é um método bem estabelecido e amplamente reconhecido para a caracterização da microestrutura dos materiais cristalinos. Juntamente com os outros principais métodos de caracterização, especialmente Microscopia Eletrônica de Transmissão e Microscopia Eletrônica de Varredura (MET e MEV) e os diferentes métodos de resolução atômica, em particular Microscopia de Tunelamento com Varredura e Microscopia de Força Atômica (MTV e MFA), esta análise pode fornecer informações microestruturais adicionais como, por exemplo, tamanho médio de cristalitos e distribuição de tamanhos, densidade de discordâncias e características das discordâncias, densidade de defeitos planares ou diferentes tipos de tensões internas. Nos materiais nanocristalinos os cristalitos são extremamente pequenos e a densidade de defeitos pode ser muito alta. Por conseguinte, a microscopia eletrônica e métodos de resolução atômica encontram dificuldades experimentais ou até falham em caracterizar a microestrutura. Nesses casos, a XLPA torna-se praticamente o único método para a caracterização de microestruturas, que podem se encontrar na forma de pós ou materiais compactos, cerâmicas, metais ou cristais iônicos[35].

A forma e a largura de um perfil de difração são basicamente determinadas pelo tamanho médio de cristalitos e por microdeformações presentes na rede cristalina do material estudado, além da contribuição instrumental. O tamanho médio de cristalitos pode ser considerado como o tamanho médio de domínios do cristal coerentemente difratantes ou, ainda, a média do comprimento 
de colunas das celas unitárias normais aos planos difratantes[11]. Desta forma, ao realizar o estudo da largura dos picos, pode-se determinar o tamanho médio dos cristalitos e microdeformações presentes na amostra.

\subsection{FT-IR}

A espectroscopia no infravermelho (espectroscopia IV) é um tipo de espectroscopia de absorção, em que a energia absorvida se encontra na região do infravermelho do espectro eletromagnético. Esta está relacionada ao fato de que as ligações químicas das substâncias possuem frequências de vibração específicas, as quais correspondem a níveis de energia da molécula (chamados nesse caso de níveis vibracionais). Estas frequências dependem da forma da superfície de energia potencial da molécula, da geometria molecular, das massas dos átomos e eventualmente do acoplamento vibracional.

A espectrometria no infravermelho com transformada de Fourier (Fourier Transform Infrared (FT-IR) spectrometry) foi desenvolvida para ultrapassar as limitações encontradas com instrumentos convencionais, devido ao lento processo de escaneamento. Esta técnica permite a obtenção de dados mais rapidamente, guiando a radiação IV por meio de um interferômetro, gerando um espectro denominado interferograma. Realizando-se uma transformada de Fourier no sinal, tem-se como resultado um espectro idêntico ao da espectroscopia IV convencional.

Como as demais técnicas espectroscópicas, ela pode ser usada para identificar um composto ou investigar a composição de uma amostra.

\subsection{Estruturas}

\subsubsection{Fase $\beta-\mathrm{FeOOH}$}

Akaganéita é a nomenclatura dada para a ocorrência natural do óxihidróxido férrico $\beta-\mathrm{FeOOH}$, descoberto na mina Akagané, no Japão. Este mineral ocorre naturalmente em ambientes ricos em cloretos, como oceanos, lagos salinos, salmouras quentes, minas, solos e pode se formar a partir da oxidação da pirrotita $\left(\mathrm{Fe}_{(1-\mathrm{x})} \mathrm{S}_{\mathrm{x}}\right)[36]$. 
Os produtos de corrosão contendo cloretos são frequentemente detectados em objetos de ferro, especialmente aqueles expostos a ambientes marinhos, sendo a Akaganéita o produto de corrosão mais frequentemente encontrado[37].

Partículas finas de $\beta-\mathrm{FeOOH}$ podem ser preparadas pela hidrólise de soluções aquosas de $\mathrm{FeCl}_{3}$. Diferente de outros hidróxidos férricos, a formação de $\beta$-FeOOH é estabilizada pela presença de halógenos $\mathrm{Cl}^{-}$e $\mathrm{F}^{-}$, os quais ficam contidos em túneis da estrutura de $\beta-\mathrm{FeOOH}$, estabilizando os cristais[38].

A estrutura de $\beta-\mathrm{FeOOH}$ é similar à da holandita, a qual consiste de duplas cadeias de $\mathrm{Mn}^{4+}-\mathrm{O}$ formando um octaedro e partilhando os vértices de modo a formar uma estrutura contendo túneis, com seção transversal medindo dois octaedros em cada sítio. $\mathrm{Na}$ estrutura de $\beta-\mathrm{FeOOH}$, os sítios octaédricos são ocupados por $\mathrm{Fe}^{3+}$, sendo $\mathrm{Cl}^{-}$e talvez $\mathrm{H}_{2} \mathrm{O}$ localizados nos túneis[39], como mostrado na FIG. 3.17.

Compostos com esta estrutura possuem uma cela unitária tetragonal ou monoclínica e diferem dos demais óxidos e hidróxidos de ferro pelo fato dos ânions (quando presentes) possuírem um arranjo cúbico de corpo centrado, tornando a akaganéita menos densa que as fases $\alpha-\mathrm{FeOOH}$ e $\gamma-\mathrm{FeOOH}[40]$.

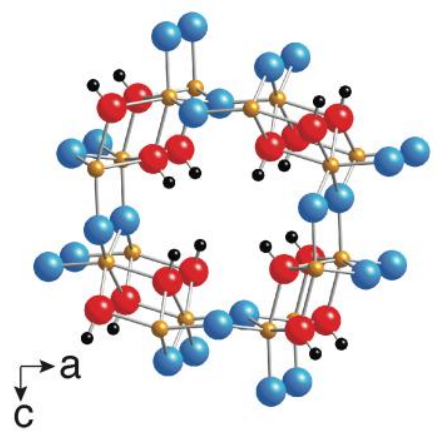

(a)

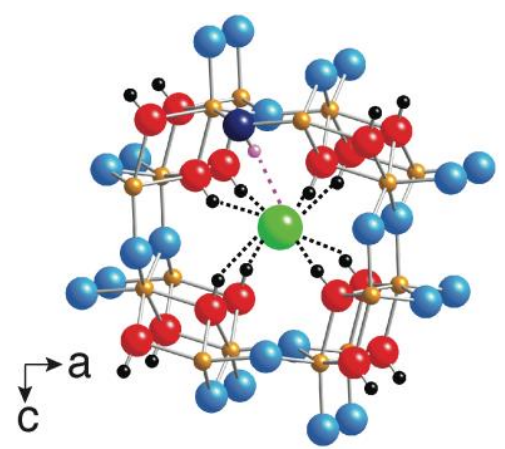

(b)

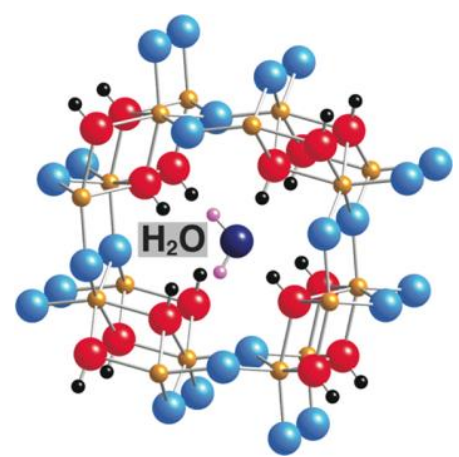

(c)

Figura 3.17-Estruturas da Akaganéita, com túnel vazio (a), túnel ocupado por uma molécula de $\mathrm{Cr}$ (b) e túnel ocupado por uma molécula de $\mathrm{H}_{2} \mathrm{O}$ (c) [36].

\subsubsection{Fase Espinélio}

A estrutura cúbica espinélio (spinel cubic) é um composto do tipo $\mathrm{AB}_{2} \mathrm{O}_{4}$ que possui dois sítios intersticiais, sendo um tetraédrico $A$, contendo um metal com 
os quatro vizinhos mais próximos sendo oxigênios; e $B$, contendo um metal com os seis vizinhos mais próximos também oxigênios. Portanto, o cátion no sítio A possui uma coordenação tetraédrica oxigênios e o cátion no sítio $B$ possui uma coordenação octaédrica de oxigênios.

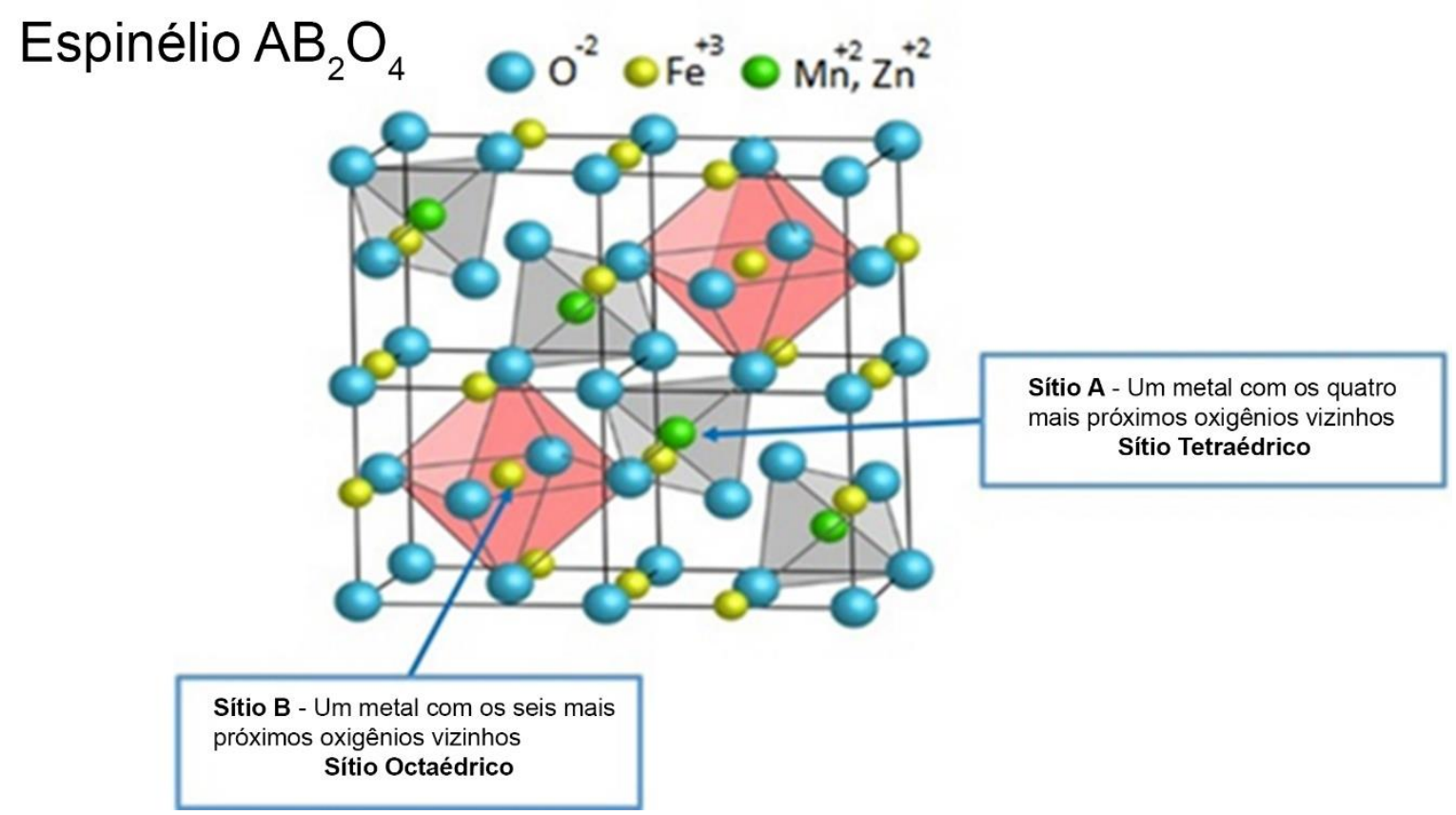

Figura 3.18 - Representação da cela unitária da ferrita $\mathrm{Zn}_{0,25} \mathrm{Mn}_{0,75} \mathrm{Fe}_{2} \mathrm{O}_{4}$ (Adaptado de [41])

$\mathrm{Na}$ ferrita sintetizada, $\mathrm{Zn}_{0,25} \mathrm{Mn}_{0,75} \mathrm{Fe}_{2} \mathrm{O}_{4}$ (também denominada Frankilinita), os sítios tetraédricos são ocupados proporcionalmente por $\mathrm{Mn}^{2+} \mathrm{e}$ $\mathrm{Zn}^{2+}$, e os sítios octaédricos por $\mathrm{Fe}^{3+}$. 


\section{MATERIAIS E MÉTODOS}

\subsection{Síntese das Amostras}

Foram realizadas 6 sínteses de ferritas pelo método da coprecipitação, com composição nominal $\mathrm{Mn}_{0,75} \mathrm{Zn}_{0,25} \mathrm{Fe}_{2} \mathrm{O}_{4}$, variando-se a concentração do surfactante para cada síntese, sem alterar as proporções de Mn e Zn, conforme tabela seguinte:

Tabela 4.1 - Relação mássica entre os elementos da ferrita.

\begin{tabular}{cccc}
\hline Elemento & $\begin{array}{c}\text { Proporção } \\
\text { estequiométrica }\end{array}$ & Massa atômica (u) & (\% em massa) \\
\hline $\mathrm{Mn}$ & 0,75 & 54,93805 & 17,66 \\
$\mathrm{Zn}$ & 0,25 & 65,40900 & 7,010 \\
$\mathrm{Fe}$ & 2,00 & 55,84570 & 47,89 \\
$\mathrm{O}$ & 4,00 & 15,99940 & 27,44 \\
\hline
\end{tabular}

A referência para a concentração do surfactante foi a sua Concentração Micelar Crítica (CMC), que representa a concentração mínima na qual se tem início a formação de micelas. A partir desta concentração ( $C M C \times 1)$ foram feitas sínteses com múltiplos: $x 2, x 3, x 4, x 5, x 10$, mostrados na TAB. 4.2 em conjunto com a porcentagem em massa $(\% \mathrm{w})$.

Por meio do diagrama de fases de formação de micelas para o CTAB, as porcentagens em massa estão na faixa em que as micelas possuem formato esférico. 
Tabela 4.2 - Valores calculados a partir da CMC do CTAB.

\begin{tabular}{lcc}
\hline & CTAB \\
\hline & C (mM) & $\% \mathrm{w}$ \\
CMC & 0,98 & 0,04 \\
2x CMC & 1,96 & 0,07 \\
3x CMC & 2,94 & 0,11 \\
4x CMC & 3,92 & 0,14 \\
5x CMC & 4,90 & 0,18 \\
10x CMC & 9,80 & 0,36 \\
\hline
\end{tabular}

Foram utilizados como reagentes os sais apresentados na TAB. 4.3, com pureza analítica, e o CTAB como surfactante:

Tabela 4.3 - Dados dos Reagentes

\begin{tabular}{cc}
\hline Reagentes & Peso Molecular (g/mol) \\
\hline $\mathrm{FeCl}_{3} \cdot 6 \mathrm{H}_{2} \mathrm{O}$ & 270,03 \\
$\mathrm{MnCl}_{2} .4 \mathrm{H}_{2} \mathrm{O}$ & 197,91 \\
$\mathrm{ZnCl}_{2}$ (anidro) & 136,30 \\
$\mathrm{NaOH}$ & 40,00 \\
\hline
\end{tabular}

\begin{tabular}{cc}
\hline Surfactante & Peso Molecular $(\mathbf{g} / \mathbf{m o l})$ \\
\hline CTAB & 364,45 \\
\hline
\end{tabular}

Foi preparada uma solução estoque em um balão onde foram dissolvidos em $360 \mathrm{ml}$ de água deionizada os sais em proporção suficiente para que cada síntese produzisse $0,3 \mathrm{~g}$ de precipitado.

Para cada síntese, foram dissolvidos $0,2 \mathrm{M}$ de $\mathrm{NaOH}$ em $300 \mathrm{ml}$ de água deionizada, para que a solução ficasse com pH entre 11 e 12, propiciando a ocorrência do processo de coprecipitação. Em seguida, alíquotas de $60 \mathrm{ml}$ da solução estoque juntamente com a proporção de CTAB para cada síntese, foram adicionadas à solução com $\mathrm{NaOH}$.

O processo de digestão da amostra foi realizado em um agitador magnético com aquecimento, mostrado na FIG. 4.1, ajustando a temperatura de modo que a solução entrasse em ebulição em agitação constante e com a presença 
de um condensador, permitindo que a mistura fosse aquecida à temperatura de ebulição do solvente sem que esta seja perdida para a atmosfera.

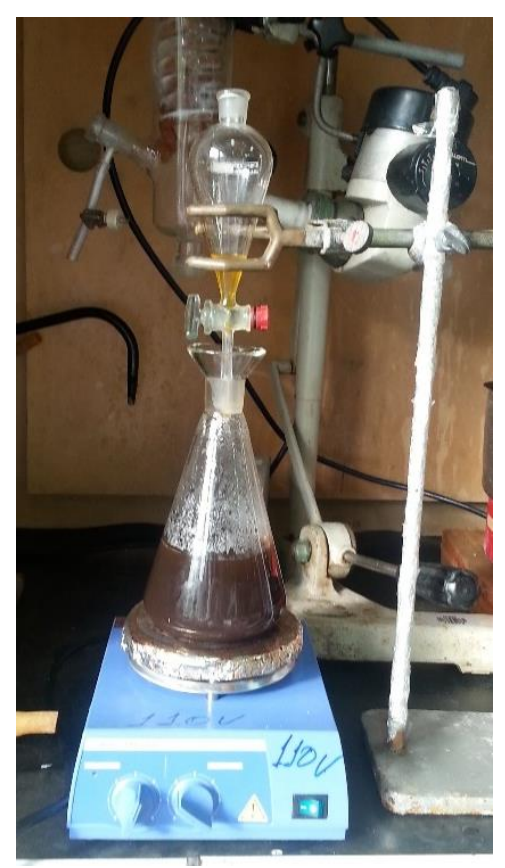

Figura 4.1 - Agitador magnético com aquecimento utilizado para a preparação das amostras de ferritas.

Após a digestão de 1h, a solução foi separada em duas partes. Uma delas, com $100 \mathrm{ml}$ da solução foi acondicionada em dois reatores hidrotérmicos (dividas em alíquotas de $50 \mathrm{ml}$, cada) e levada à mufla, pré-aquecida a $150{ }^{\circ} \mathrm{C}$, durante $8 \mathrm{~h}$.

A pressão interna no reator, a qual foi submetida a solução, foi estimada pela equação de Clausius-Clapeyron[42]:

$$
\ln \left(\frac{P_{\text {vap }, T 1}}{P_{\text {vap }, T 2}}\right)=\frac{\Delta H_{\text {vap }}}{R} \times\left(\frac{1}{T_{2}}-\frac{1}{T_{1}}\right)
$$

\begin{tabular}{|l|l|}
\hline \multicolumn{2}{|c|}{ Pressão da solução no reator } \\
\hline $\mathrm{p}_{1}=$ pressão ebulição água & $1 \mathrm{~atm}$ \\
\hline $\mathrm{T}_{1}=$ Temp. ebulição água & $100{ }^{\circ} \mathrm{C}$ \\
\hline $\mathrm{T}_{2}=$ Temp. no reator & $150^{\circ} \mathrm{C}$ \\
\hline & \\
\hline $\mathbf{p}_{\mathbf{2}}=$ Pressão no reator & $\mathbf{4 , 7} \mathrm{atm}$ \\
\hline
\end{tabular}

\begin{tabular}{|l|r|}
\hline$\Delta$ Hvap água & $40608 \mathrm{~J} / \mathrm{mol}$ \\
\hline $\mathrm{R}$ & $8,3145 \mathrm{~J} / \mathrm{mol} . \mathrm{K}$ \\
\hline
\end{tabular}


A outra parte da solução foi acondicionada em um béquer onde foi adicionada água deionizada e, alternando períodos de decantação, passou por sucessivas lavagens em água deionizada, até que o $\mathrm{pH}$ se aproximasse da neutralidade $(\mathrm{pH} \approx 7)$. Este processo foi repetido para a solução submetida ao tratamento hidrotermal em uma mufla, mostrada na FIG. 4.2.

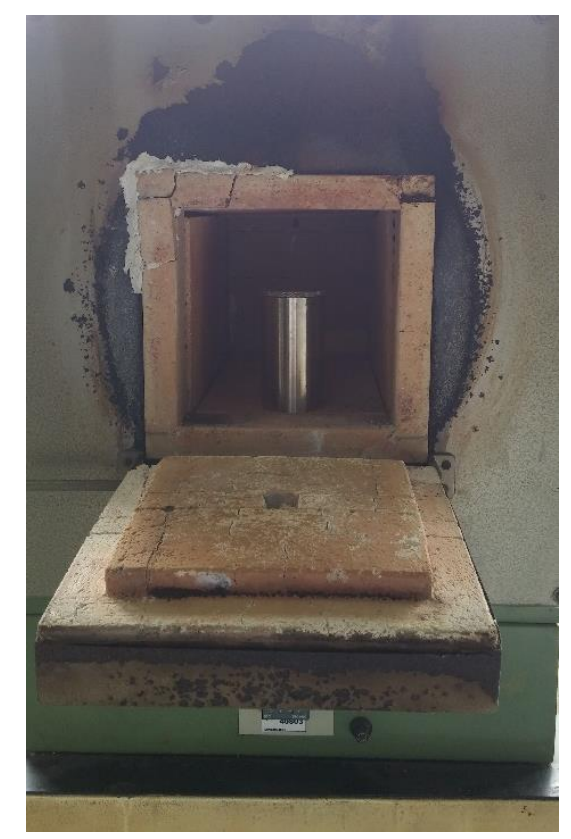

Figura 4.2 - Mufla utilizada para a preparação das amostras de ferritas com reator hidrotermal.

Após o processo de lavagem por meio de trocas de água seguida de decantação do sólido, foi retirado o excesso de água, minimizando o volume da solução contendo água e precipitado para aproximadamente $40 \mathrm{~mL}$, que permaneceram em secagem em uma mufla a $60^{\circ} \mathrm{C}$.

Ao final dos processos, foram obtidas 12 amostras, sendo 6 que passaram por tratamento hidrotermal, denominadas: HMZFC-1, HMZFC-2, HMZFC-3, HMZFC-4, HMZFC-5 e HMZFC-10 e 6 que foram diretamente para decantação, denominadas: CMZFC-1, CMZFC-2, CMZFC-3, CMZFC-4, CMZFC-5 E CMZFC-10. Os prefixos $\mathrm{H}$ e $\mathrm{C}$ dos nomes das amostras significam tratamento hidrotermal e coprecipitação, respectivamente. Os sufixos numéricos 1, 2, 3, 4, 5 e 10 indicam a proporção do surfactante CTAB, em múltiplos da concentração micelar crítica. 
A síntese das ferritas pelo método de coprecipitação ocorre em elevado valor de $\mathrm{pH}$. Para avaliar as espécies que podem estar presentes na solução, foi construído um diagrama de distribuição das espécies químicas utilizando o software Medusa-Hydra[43], que mostra o cálculo termodinâmico das concentrações presentes em função do pH. No gráfico mostrado na FIG. 4.3 está representado o metal de maior concentração, o $\mathrm{Fe}^{3+}$ e sua forma reduzida $\mathrm{Fe}^{2+}$.

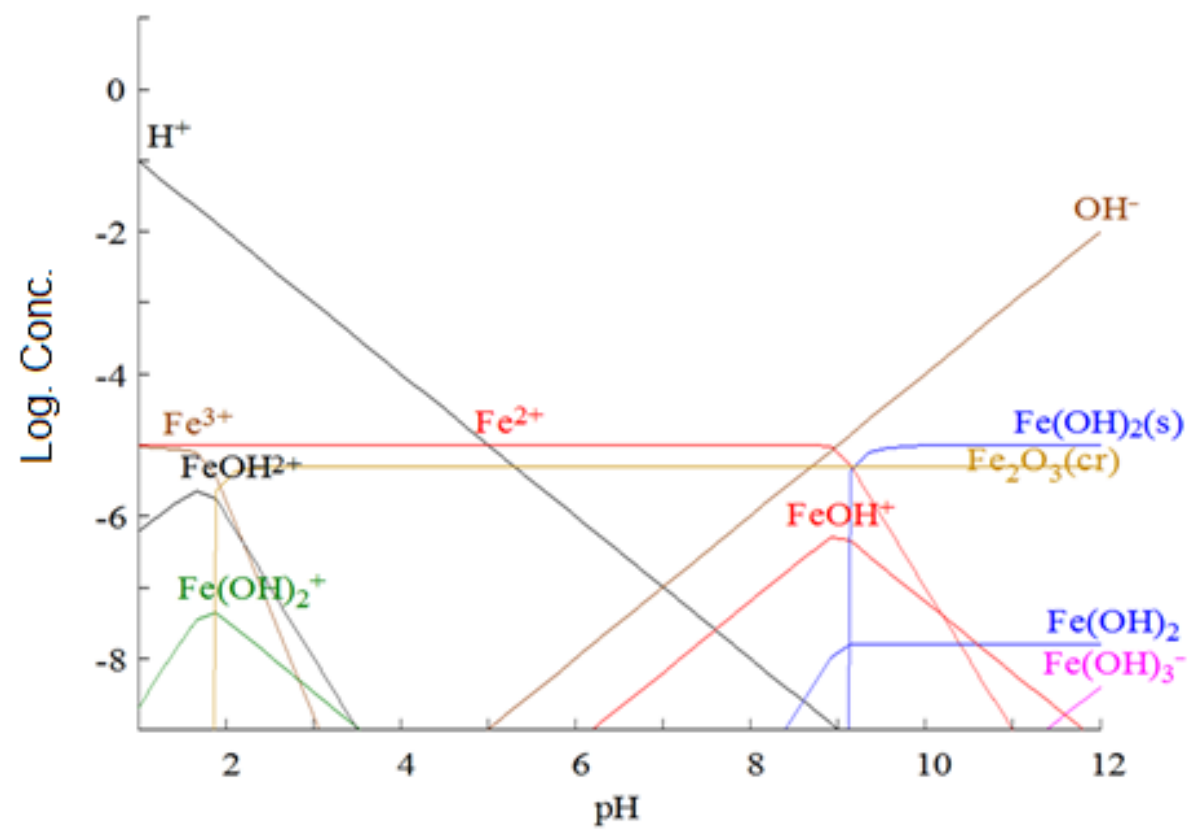

Figura 4.3- Cálculos termodinâmicos das concentrações das espécies $\mathrm{Fe}^{3+}$ e $\mathrm{Fe}^{2+}$ formadas em diferentes valores de $\mathrm{pH}$ [43].

Como um dos precursores metálicos utilizados foi $\mathrm{FeCl}_{3}$, a seguinte reação ocorre em pH elevado:

$$
\begin{gathered}
\mathrm{FeCl}_{3(s)}+3 \mathrm{OH}_{(a q)}^{-} \rightleftharpoons \mathrm{Fe}(\mathrm{OH})_{3(a q)}+3 \mathrm{Cl}_{(a q)}^{-} \\
{\left[\mathrm{Fe}\left(\mathrm{H}_{2} \mathrm{O}\right)_{6}\right]_{(a q)}^{3+} \rightleftharpoons \beta-\mathrm{FeOOH}_{(s)}+4 \mathrm{H}_{2} \mathrm{O}_{(l)}+3 \mathrm{H}_{(a q)}^{+}}
\end{gathered}
$$

Formando um óxido de ferro hidratado (III), a fase $\beta-\mathrm{FeOOH}_{(s)}$, também denominada Akaganéita. 


\subsection{Análise por FTIR}

A análise por FTIR foram realizadas em um Espectrômetro Varian FT-IR 660 , sendo as amostras acondicionadas em pastilhas de $\mathrm{KBr}$.

\subsection{Análise por difração de raios $X$}

As fases cristalinas das amostras foram examinadas por difração de raios $\mathrm{X}$, utilizando um difratômetro Bruker D8 Advance de $3 \mathrm{~kW}$, equipado com tubo de radiação de cobre e detector de cintilação, na geometria Bragg-Brentano.

\subsection{Susceptômetro AC}

As medidas magnéticas foram realizadas no Laboratório de Altas Pressões - PRESLAB (High Pressure Laboratory) do Departamento de Física da Universidade Federal do Espírito Santo, utilizando um susceptômetro AC desenvolvido localmente[44].

O susceptômetro AC, esquematizado na FIG. 4.4, atua por meio de indutâncias mútuas, em que uma bobina externa ligada a um gerador produz um campo AC induzindo tensão em duas bobinas internas.

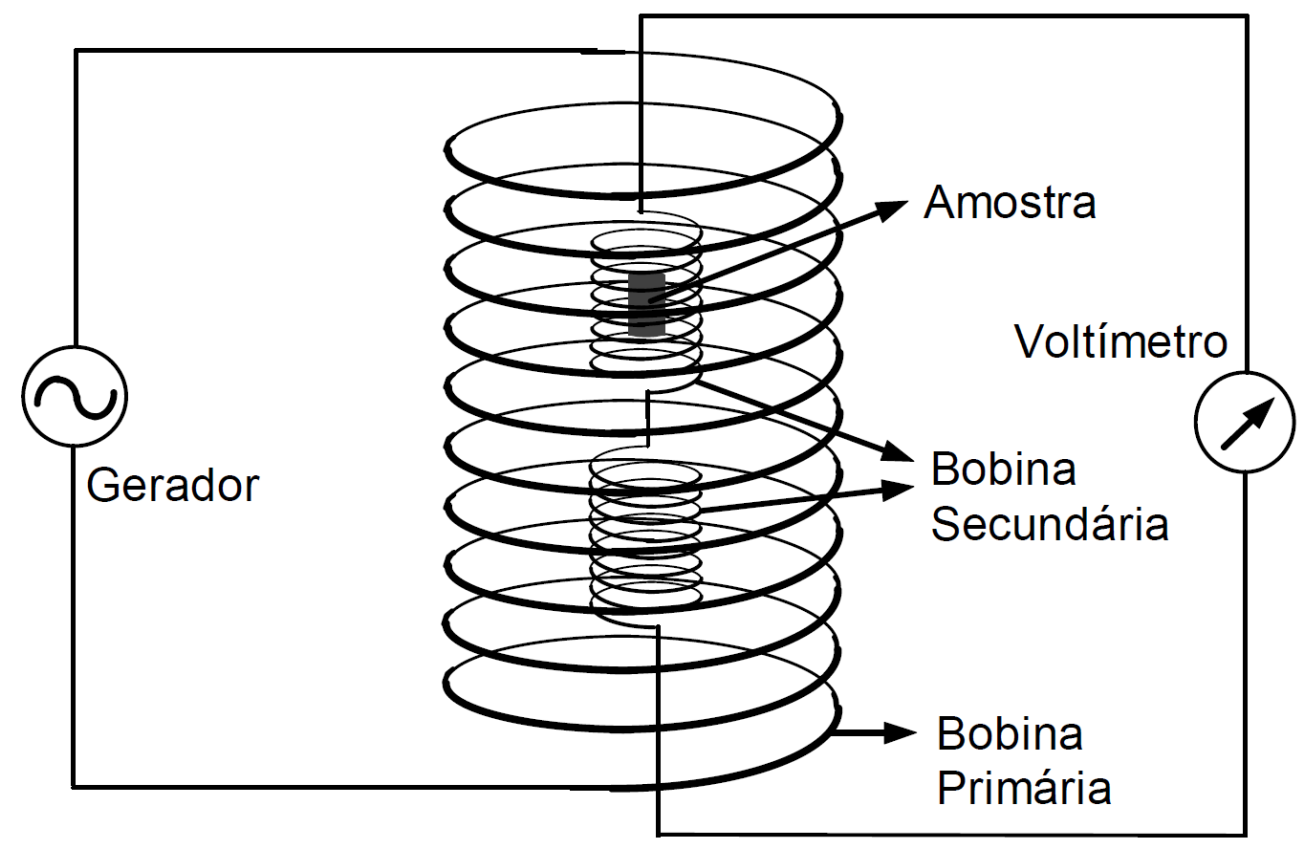

Figura 4.4 - Desenho esquemático do método de indutâncias mútuas com duas bobinas internas [45]. 
Estas estão dispostas em série e possuem as mesmas características, porém com enrolamento em sentido oposto, para que a tensão induzida esteja com uma defasagem de $180^{\circ}$, sendo ambas com a mesma amplitude. Assim, um dos solenoides possuirá tensão $\mathrm{V}$ e o outro tensão $-\mathrm{V}$. $\mathrm{O}$ valor $\Delta V$ entre os solenoides pode ser obtido com a introdução da amostra em um deles, que corresponde à susceptibilidade da amostra.

As medidas foram realizadas na região linear de excitação, com campo magnético de $6 \mu T$, frequência de $1 \mathrm{kHz}$ e com temperatura ambiente de $22^{\circ} \mathrm{C}$. Esta frequência foi escolhida por não ser um harmônico da rede elétrica 


\section{RESULTADOS E DISCUSSÕES}

\subsection{Análise por difração de raios $X$}

Os padrões de difração para as amostras sintetizadas por coprecipitação, denominadas: CMZFC-1, CMZFC-2, CMZFC-3, CMZFC-4, CMZFC-5 e CMZFC-10; e para as frações que passaram por tratamento hidrotermal, denominadas: HMZFC-1, HMZFC-2, HMZFC-3, HMZFC-4, HMZFC-5 e HMZFC-10, são apresentados na FIG. 5.1.

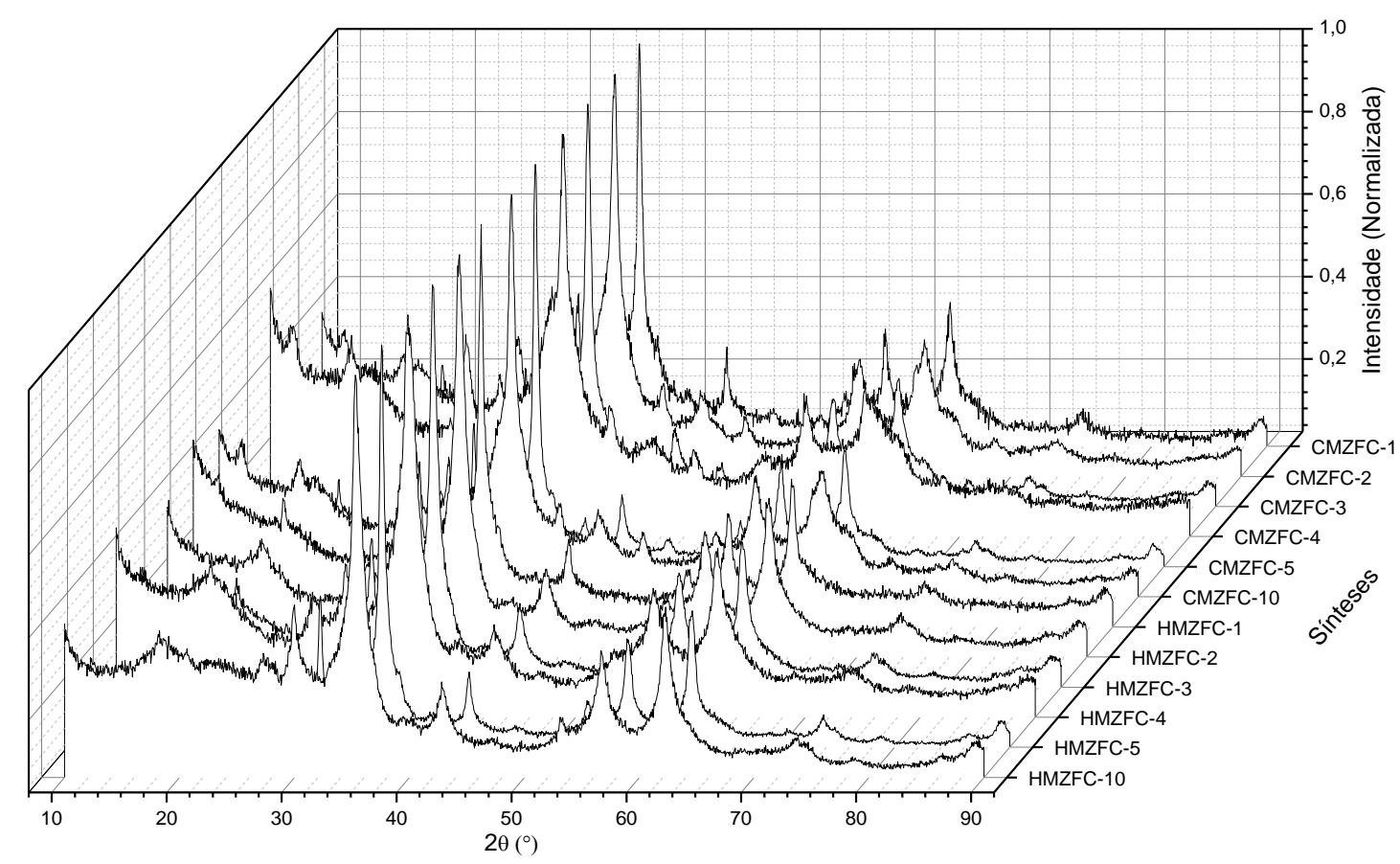

Figura 5.1 - Difratogramas das amostras sintetizadas.

Após a identificação das fases Frankilinita (ferrita de MnZn) (grupo espacial $F d 3 m$, estrutura cúbica espinélio, ICSD 280055, PDF 89-6609) e fase $\beta$ FeOOH (estrutura tetragonal, grupo espacial $I 4 / m$, ICSD 31136, PDF 75-1594), 
foram realizadas análises pelo método de Rietveld dos padrões de difração obtidos para todas as amostras, mostradas (FIG 5.2 a 5.13).

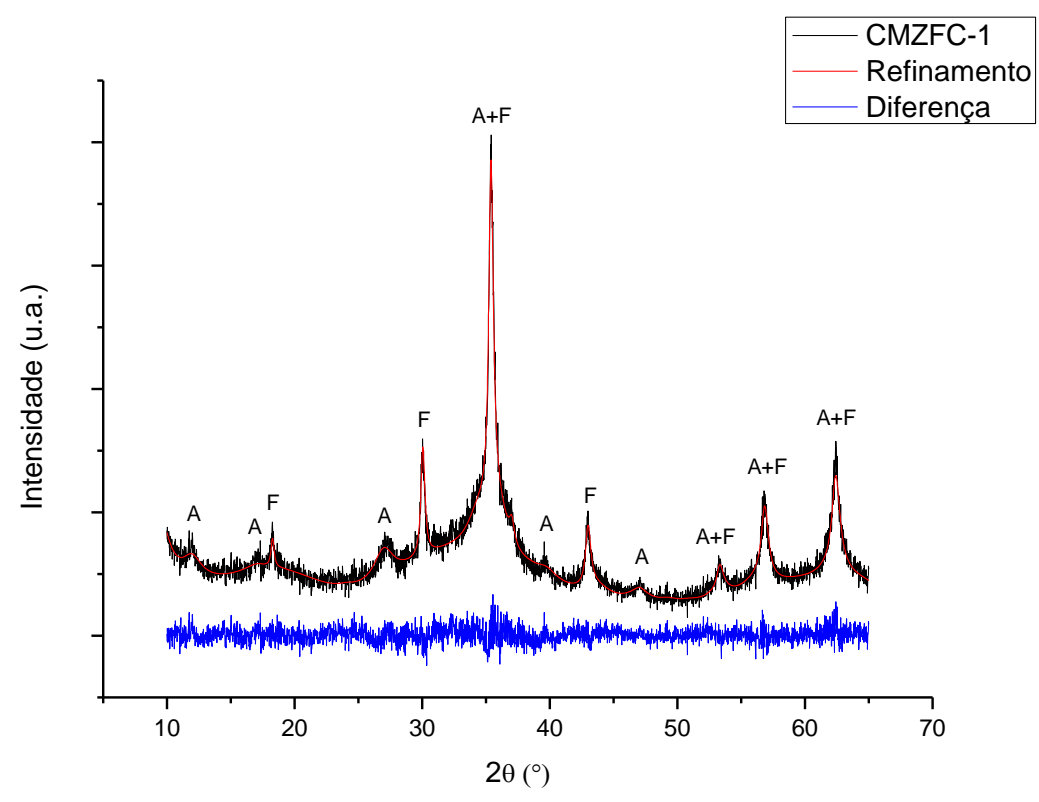

Figura 5.2 - Dados refinados da amostra CMZFC-1 para os picos característicos das fases Frankilinita ( $F-$ ferrita cúbica, estrutura espinélio) e Akaganéita ( $A$ - $\beta$-FeOOH, estrutura tetragonal).

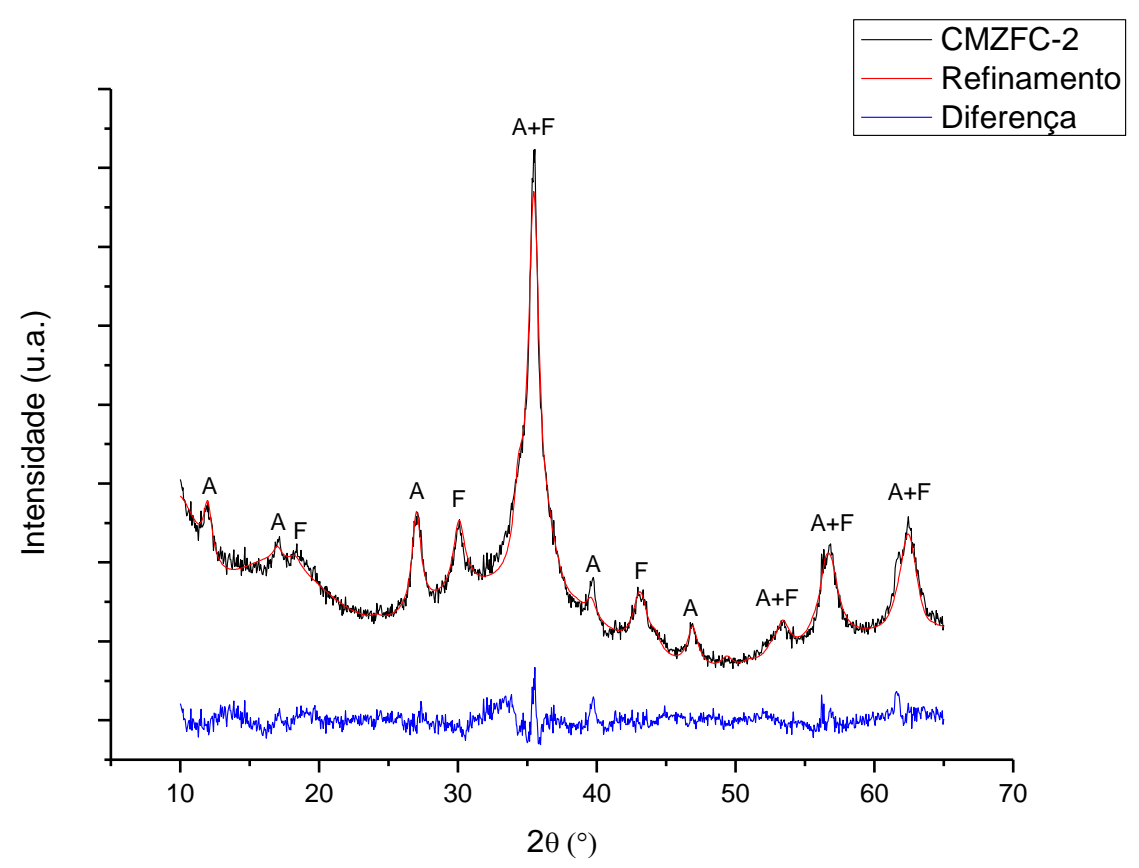

Figura 5.3 - Dados refinados da amostra CMZFC-2 para os picos característicos das fases Frankilinita ( $F$ - ferrita cúbica, estrutura espinélio) e Akaganéita ( $A$ - $\beta$-FeOOH, estrutura tetragonal). 


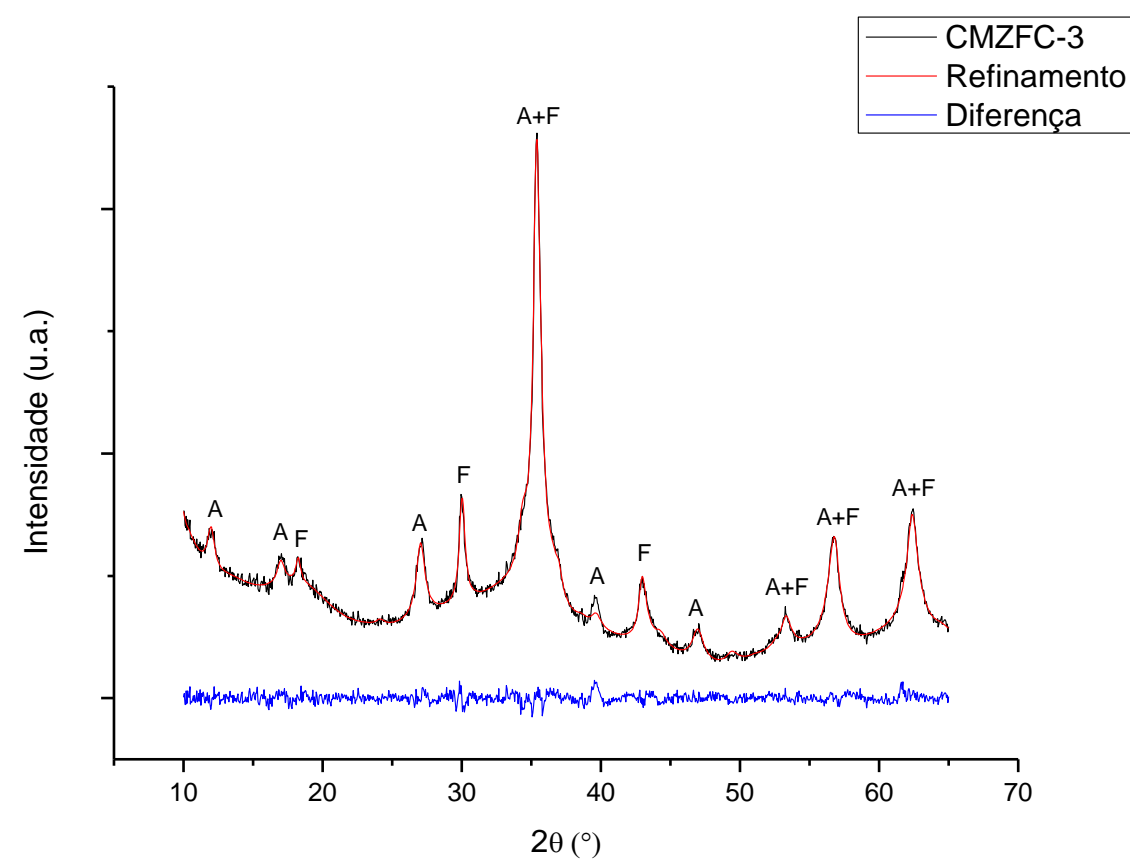

Figura 5.4 - Dados refinados da amostra CMZFC-3 para os picos característicos das fases Frankilinita ( $F$ - ferrita cúbica, estrutura espinélio) e Akaganéita $(A-\beta-F e O O H$, estrutura tetragonal).

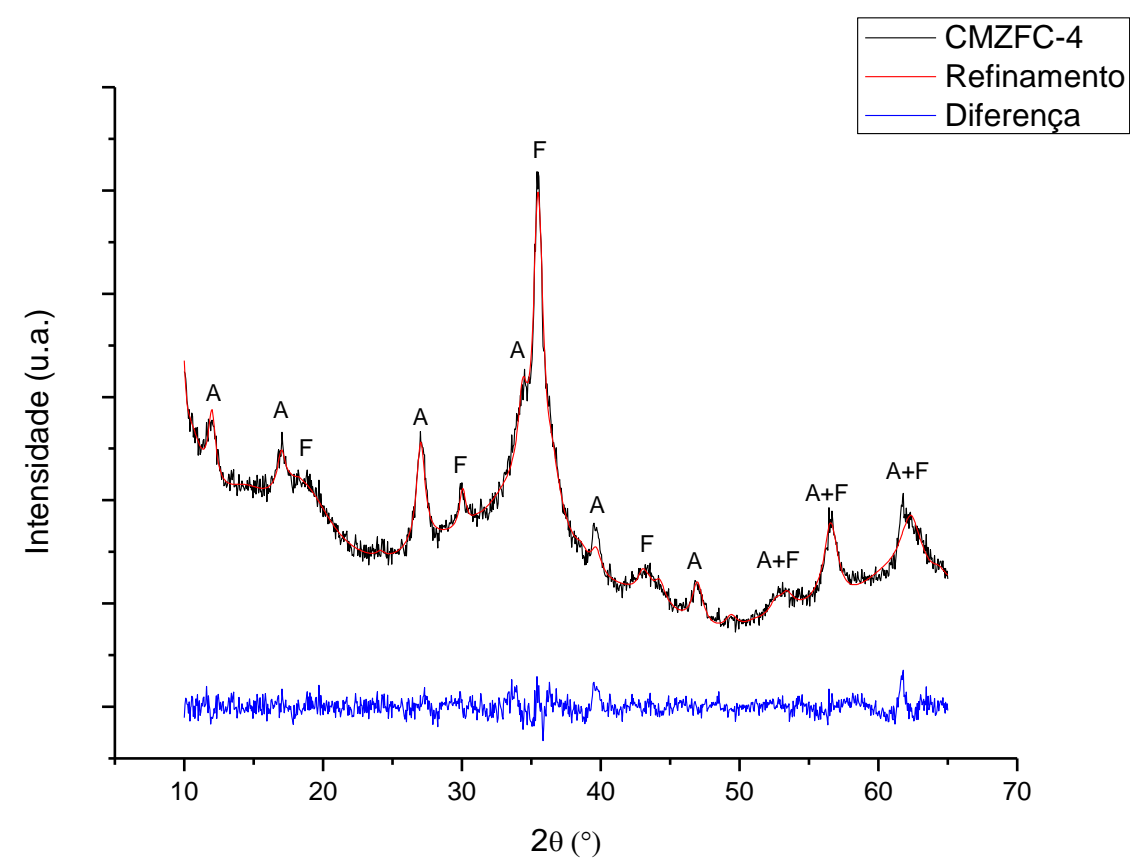

Figura 5.5 - Dados refinados da amostra CMZFC-4 para os picos característicos das fases Frankilinita ( $F-$ ferrita cúbica, estrutura espinélio) e Akaganéita $(A-\beta-F e O O H$, estrutura tetragonal). 


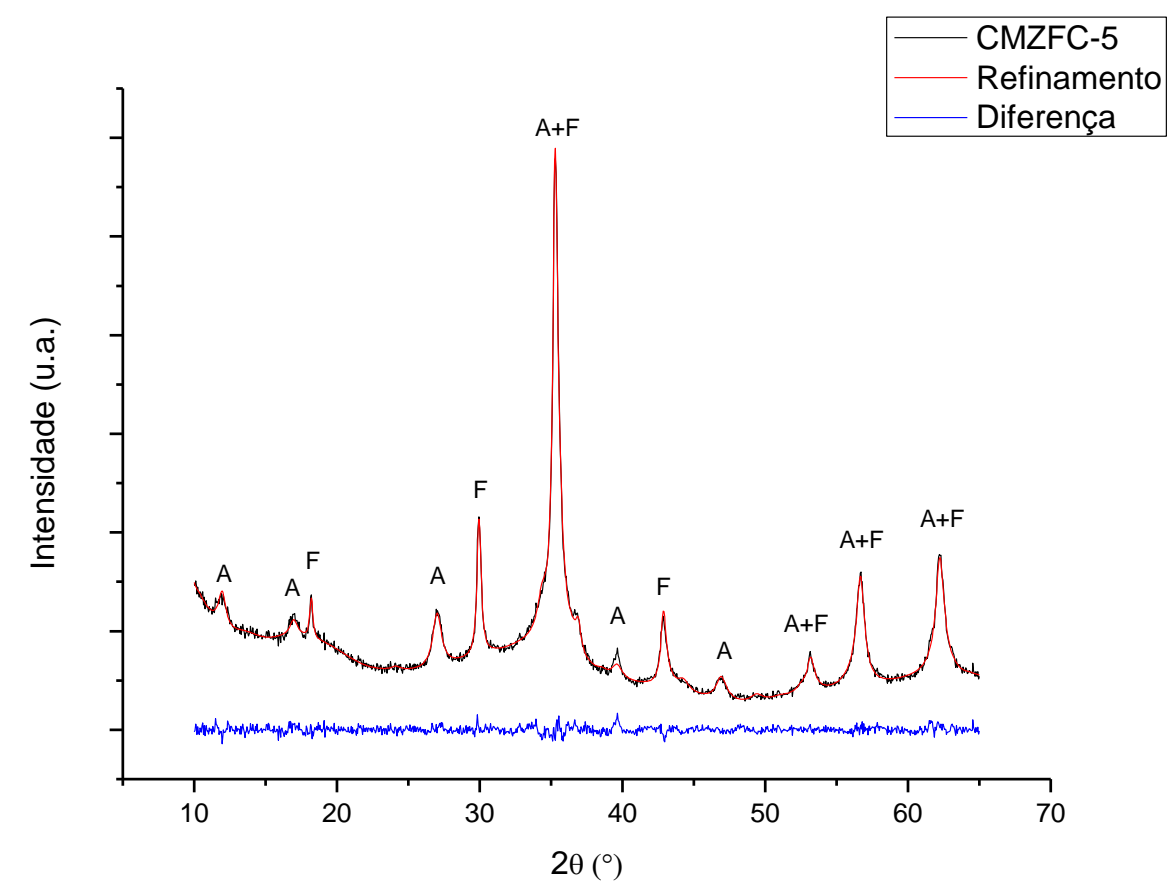

Figura 5.6 - - Dados refinados da amostra CMZFC-5 para os picos característicos das fases Frankilinita ( $F-$ ferrita cúbica, estrutura espinélio) e Akaganéita $(A-\beta-F e O O H$, estrutura tetragonal).

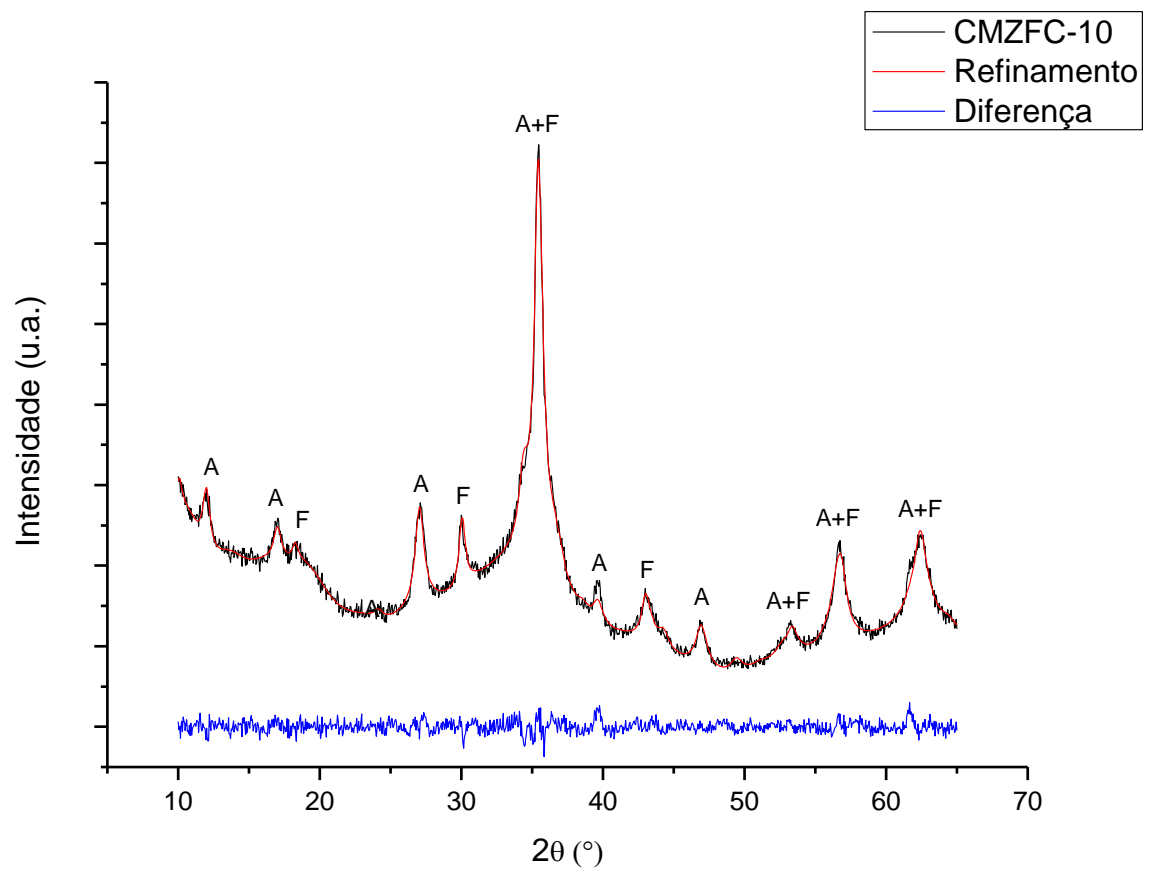

Figura 5.7 - Dados refinados da amostra CMZFC-10 para os picos característicos das fases Frankilinita ( $F-$ ferrita cúbica, estrutura espinélio) e Akaganéita ( $A-\beta-F e O O H$, estrutura tetragonal). 


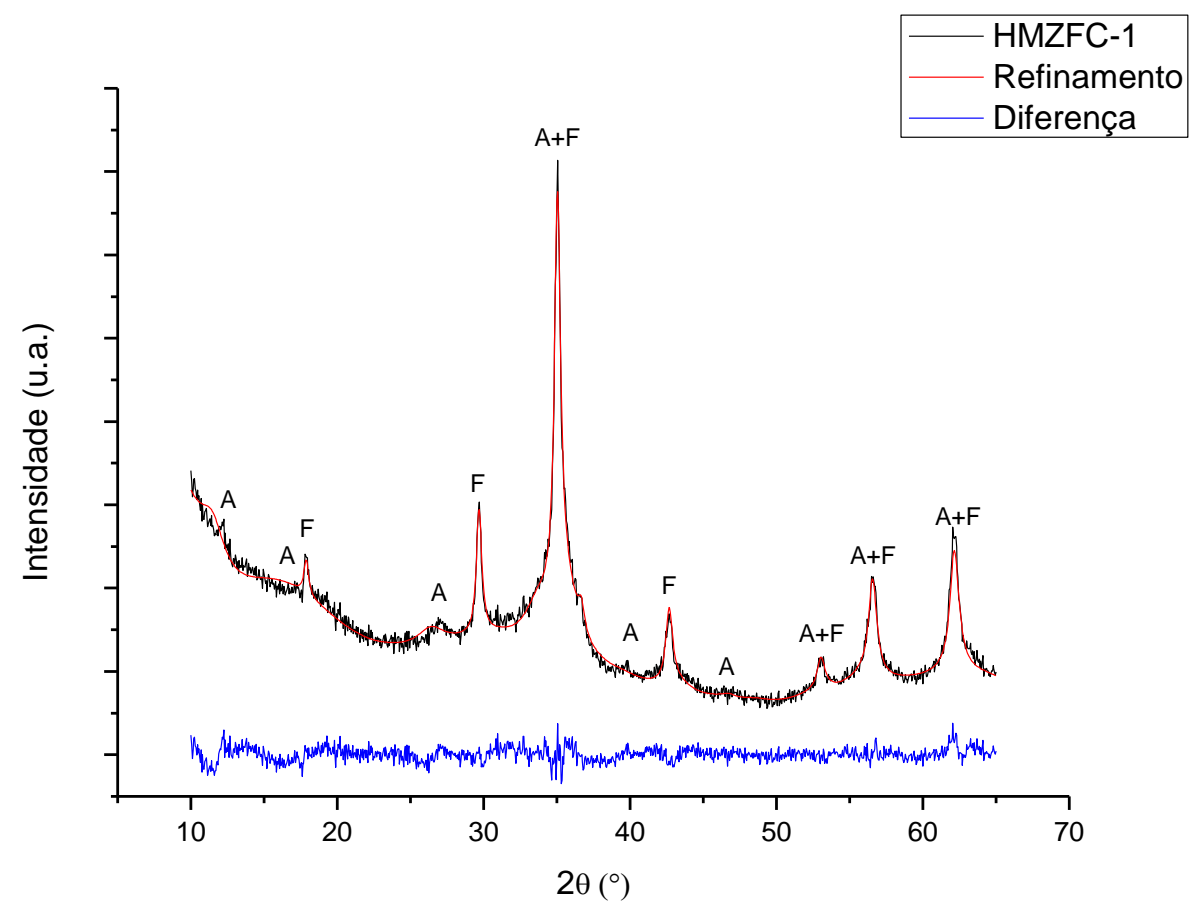

Figura 5.8 - Dados refinados da amostra HMZFC-1 para os picos característicos das fases Frankilinita ( $F-$ ferrita cúbica, estrutura espinélio) e Akaganéita ( $A-\beta-F e O O H$, estrutura tetragonal).

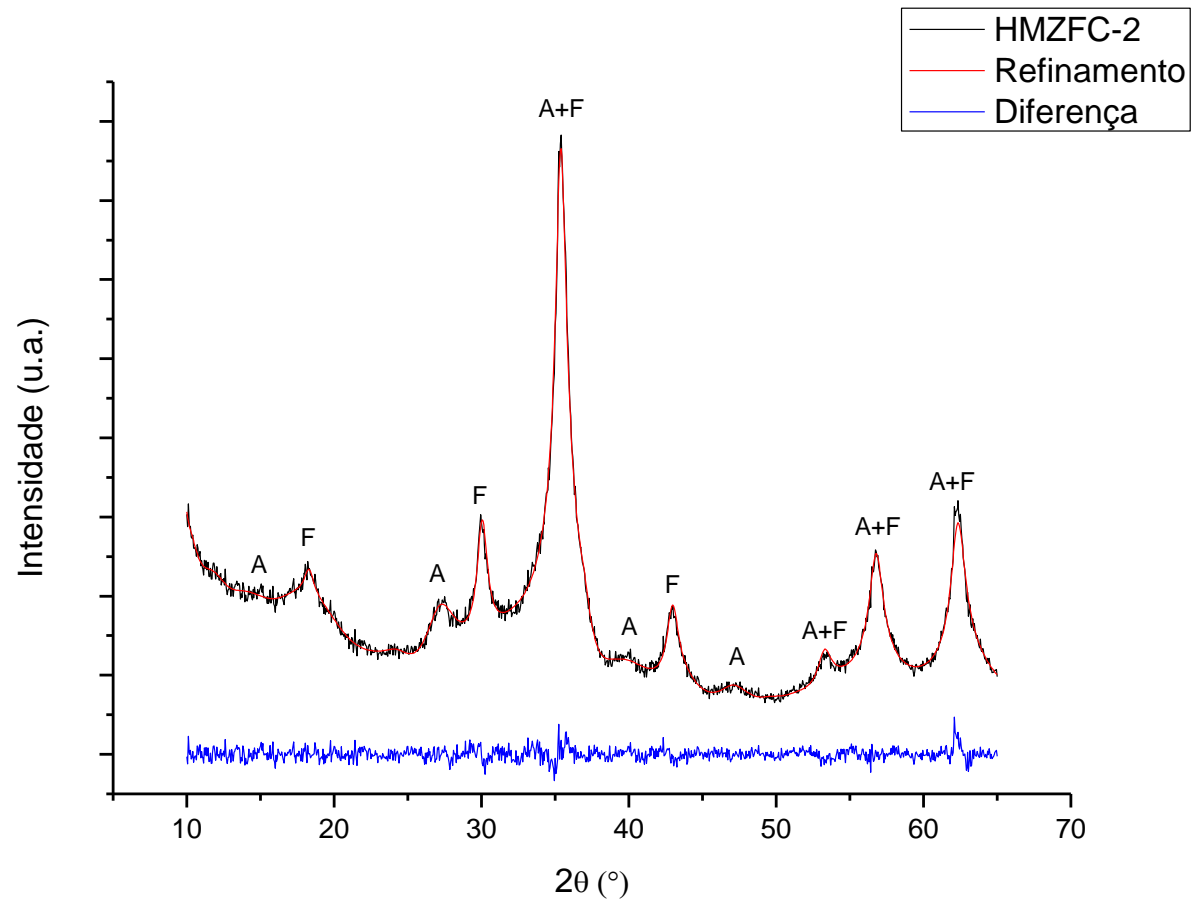

Figura 5.9 - Dados refinados da amostra HMZFC-2 para os picos característicos das fases Frankilinita ( $F-$ ferrita cúbica, estrutura espinélio) e Akaganéita ( $A-\beta-F e O O H$, estrutura tetragonal). 


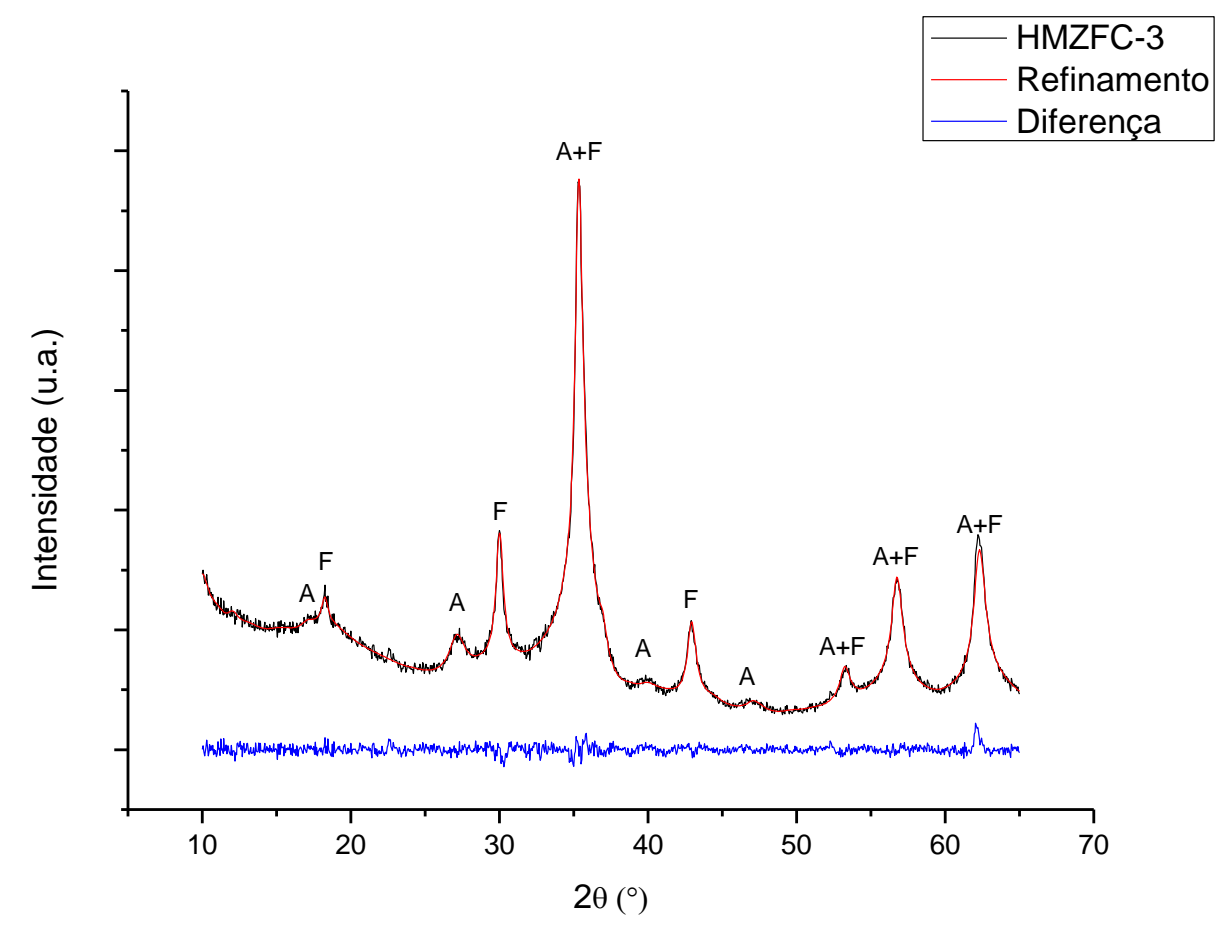

Figura 5.10 - Dados refinados da amostra HMZFC-3 para os picos característicos das fases Frankilinita ( $F-$ ferrita cúbica, estrutura espinélio) e Akaganéita $(A-\beta-F e O O H$, estrutura tetragonal).

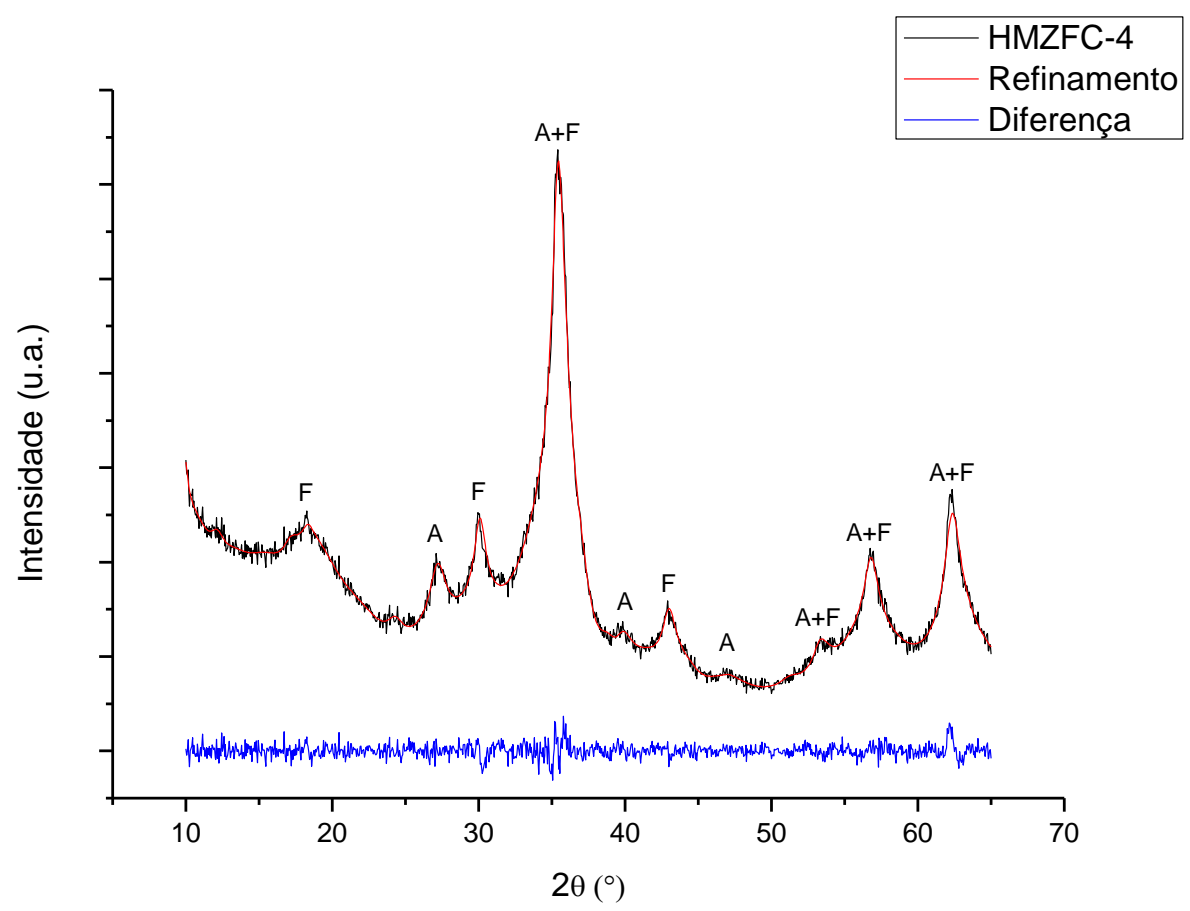

Figura 5.11 - Dados refinados da amostra HMZFC-4 para os picos característicos das fases Frankilinita ( $F-$ ferrita cúbica, estrutura espinélio) e Akaganéita $(A-\beta-F e O O H$, estrutura tetragonal). 


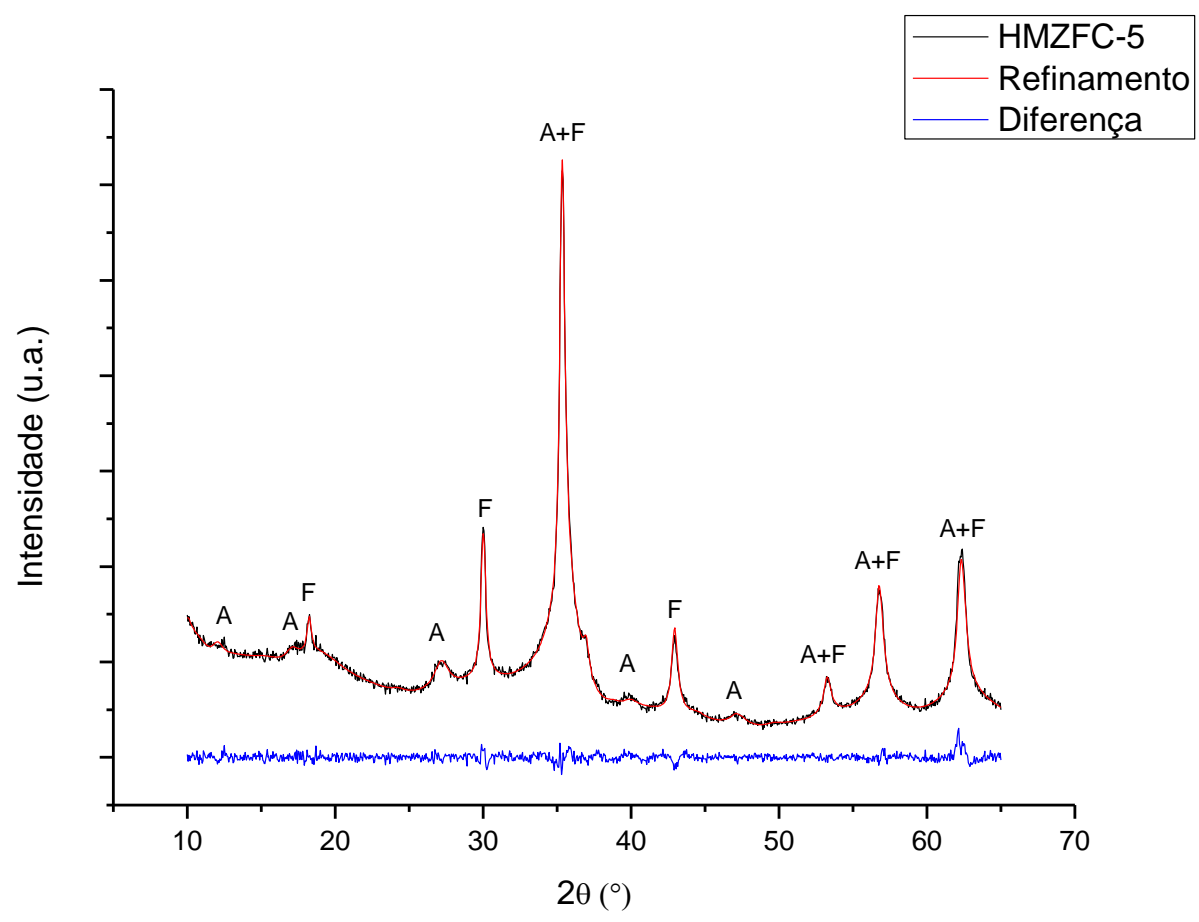

Figura 5.12 - Dados normalizados da amostra HMZFC-5 para os picos característicos das fases Frankilinita ( $F$ - ferrita cúbica, estrutura espinélio) e Akaganéita ( $A-\beta-F e O O H$, estrutura tetragonal). No detalhe, os dados refinados.

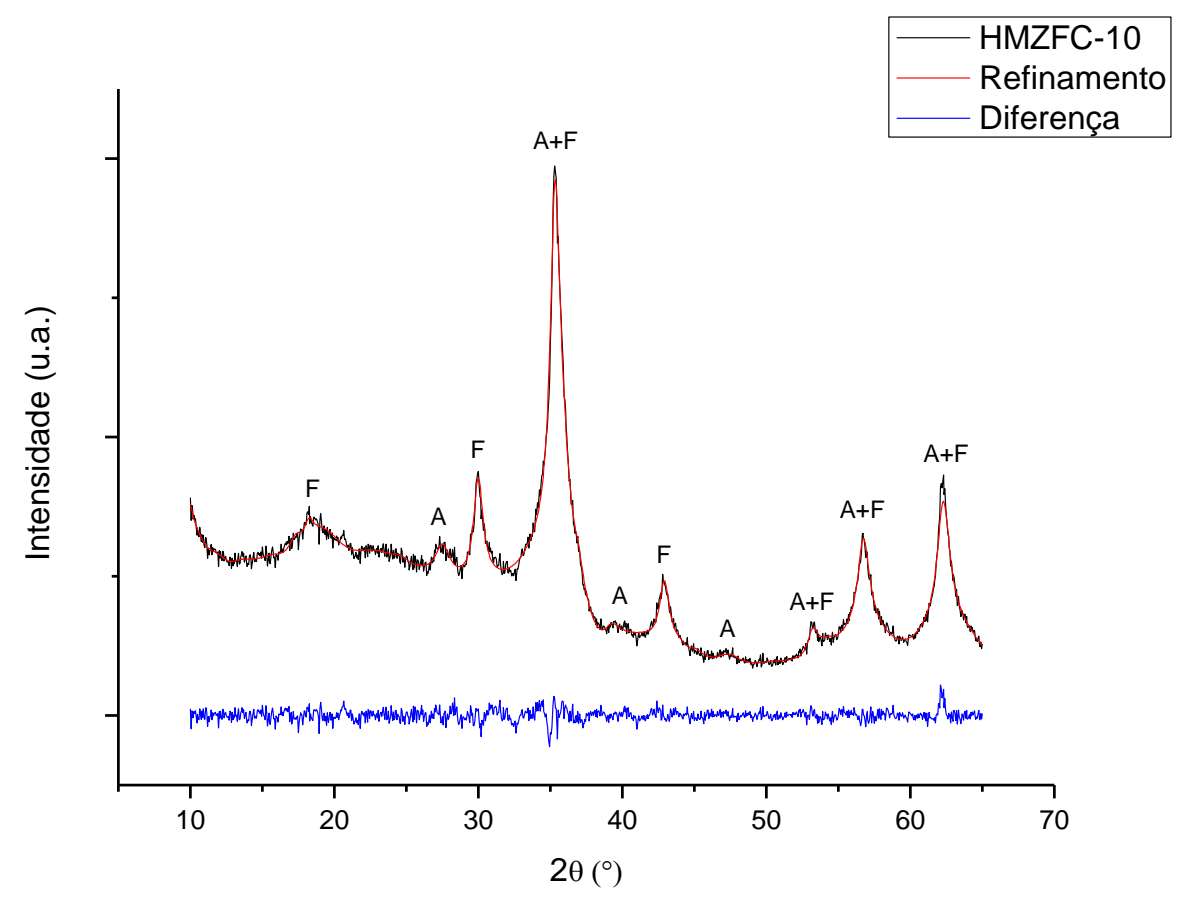

Figura 5.13 - Dados normalizados da amostra HMZFC-10 para os picos característicos das fases Frankilinita ( $F$ - ferrita cúbica, estrutura espinélio) e Akaganéita ( $A$ - $\beta$-FeOOH, estrutura tetragonal). No detalhe, os dados refinados. 


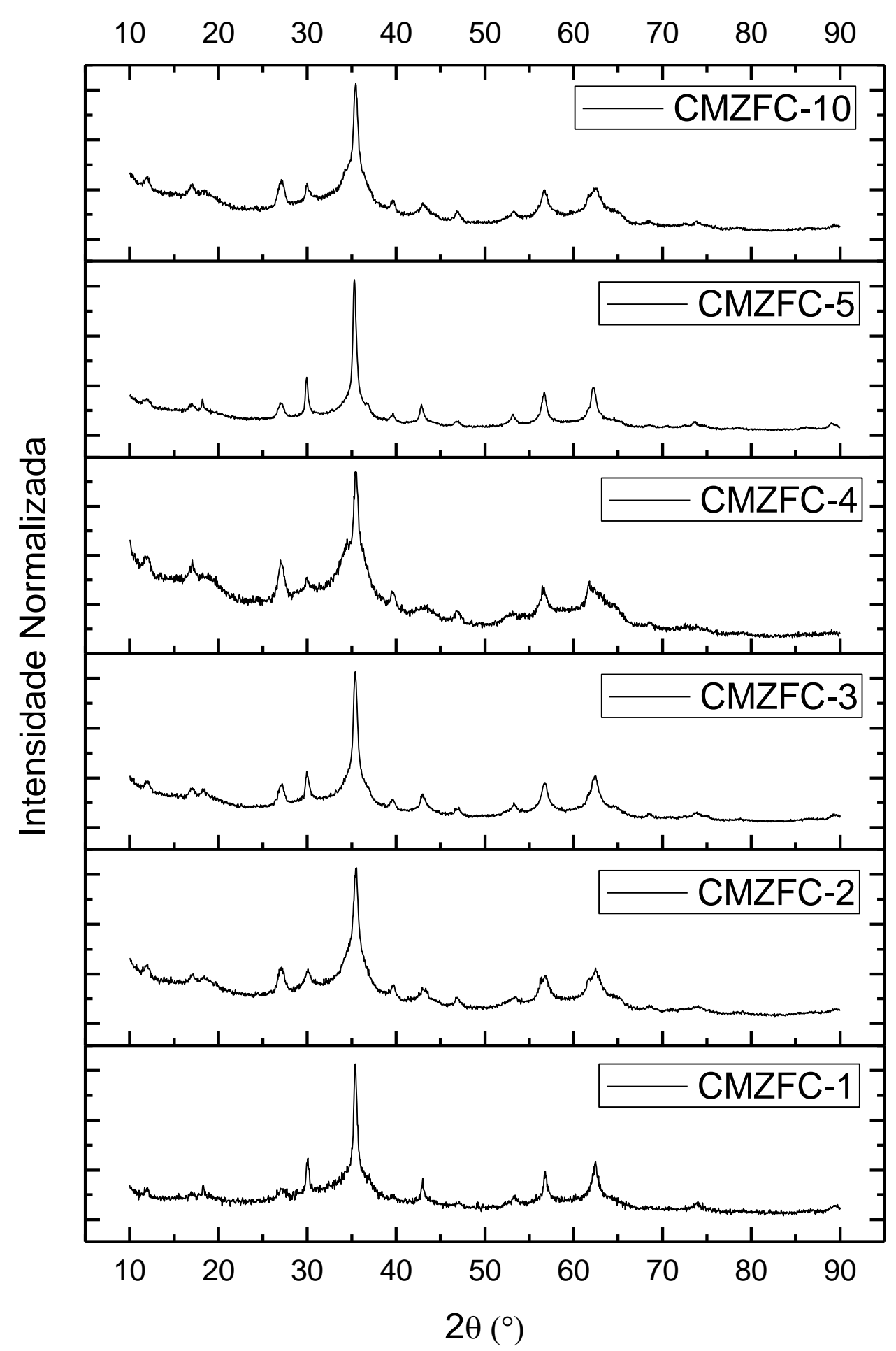

Figura 5.14 - Difratogramas normalizados e sobrepostos das amostras sintetizadas por coprecipitação. 


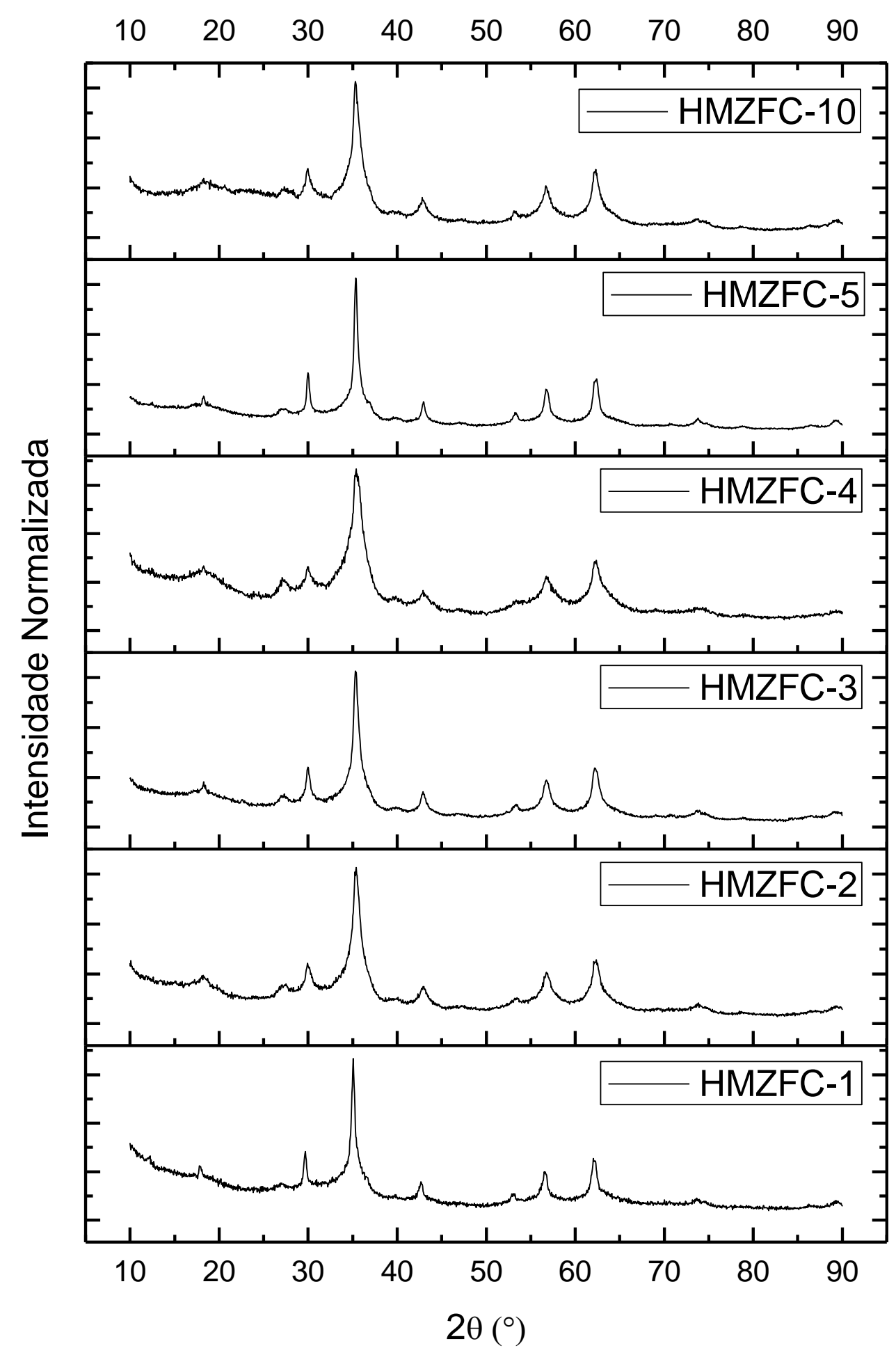

Figura 5.15 - Difratogramas normalizados e sobrepostos das amostras após tratamento hidrotermal. 
Nos difratogramas sobrepostos, apresentados nas FIG. 5.14 e FIG 5.15, observando o pico de maior intensidade pode-se verificar o alargamento deste com o aumento da concentração de CTAB. Após o processamento hidrotérmico, os picos sofrem maior alargamento, o que indica que esta etapa da síntese contribuiu para a diminuição dos tamanhos e cristalitos.

Nas TAB. 5.1 e 5.2 e nas FIG 5.16 a 5.21 são apresentados os resultados obtidos pela análise de Rietveld dos difratogramas das amostras sintetizadas

Tabela 5.1 - Dados obtidos pelo refinamento dos perfis de difração pelo método de Rietveld das amostras sintetizadas por coprecipitação, onde a e c são os parâmetros de rede e TMC os tamanhos médios de cristalitos.

\begin{tabular}{|c|c|c|c|c|c|c|}
\hline \multirow[t]{2}{*}{ Fases } & \multicolumn{6}{|c|}{ Amostras } \\
\hline & C-MZFC-1 & C-MZFC-2 & C-MZFC-3 & C-MZFC-4 & C-MZFC-5 & C-MZFC-10 \\
\hline \multicolumn{7}{|l|}{ Frankilinita } \\
\hline $\mathrm{a}(\AA \stackrel{\AA}{)}$ & $8,414(2)$ & $8,406(2)$ & $8,415(1)$ & $8,418(4)$ & $8,4325(8)$ & $8,413(2)$ \\
\hline$\%$ fase & $44(1)$ & $54(1)$ & $51(1)$ & $26(2)$ & $55(1)$ & $35(1)$ \\
\hline TMC (nm) & $23,1(3)$ & $11,3(3)$ & $16,8(3)$ & $7,3(6)$ & $21,9(3)$ & $9,7(3)$ \\
\hline Estrutura & \multicolumn{6}{|c|}{ lio Cúbico (Cubic Spinel) (Fd3m) } \\
\hline
\end{tabular}

\begin{tabular}{|c|c|c|c|c|c|c|}
\hline $\begin{array}{l}\text { Akaganéita } \\
\text { a }(\AA ̊)\end{array}$ & $10,454(9)$ & $10,443(4)$ & $10,425(3)$ & $10,444(4)$ & $10,431(3)$ & $10,431(3)$ \\
\hline$c(\AA)$ & $2,988(4)$ & $3,008(2)$ & $3,002(1)$ & $3,003(2)$ & $3,005(1)$ & $3,006(1)$ \\
\hline$\%$ fase & $56(1)$ & $46(1)$ & $49(1)$ & $74(2)$ & $45(1)$ & $65(1)$ \\
\hline TMC (nm) & $5,6(2)$ & $7(1)$ & $7,5(1)$ & $9,8(1)$ & $9,2(1)$ & $10,3(1)$ \\
\hline Estrutura & \multicolumn{6}{|c|}{ Tetragonal $(14 \mathrm{~m})$} \\
\hline Rwp (\%) & 10,9 & 6,0 & 4,8 & 4,5 & 4,6 & 4,5 \\
\hline
\end{tabular}


Tabela 5.2 - Dados obtidos pelo refinamento dos perfis de difração pelo método de Rietveld das amostras sintetizadas por tratamento hidrotermal.

\begin{tabular}{|c|c|c|c|c|c|c|}
\hline \multirow[t]{2}{*}{ Fases } & \multicolumn{6}{|c|}{ Amostras } \\
\hline & H-MZFC-1 & H-MZFC-2 & H-MZFC-3 & H-MZFC-4 & H-MZFC-5 & H-MZFC-10 \\
\hline \multicolumn{7}{|l|}{ Frankilinita } \\
\hline a $(\AA \AA)$ & $8,402(1)$ & $8,429(1)$ & $8,428(1)$ & $8,436(2)$ & $8,4243(7)$ & $8,429(1)$ \\
\hline$\%$ fase & $51(2)$ & $36(3)$ & $65(2)$ & $58(3)$ & 62(2) & $72(3)$ \\
\hline TMC (nm) & $20,3(3)$ & $8,9(1)$ & $13,9(2)$ & $8,8(2)$ & $17,6(2)$ & $11,7(2)$ \\
\hline Estrutura & \multicolumn{6}{|c|}{ pinélio Cúbico (Cubic Spinel) } \\
\hline
\end{tabular}

\begin{tabular}{|c|c|c|c|c|c|c|}
\hline $\begin{array}{l}\text { Akaganéita } \\
\text { a }(\AA \AA)\end{array}$ & $10,52(1)$ & $10,39(1)$ & $10,399(7)$ & $10,417(7)$ & $10,380(6)$ & $10,259(9)$ \\
\hline$c(\AA)$ & $2,961(6)$ & $2,989(4)$ & $2,977(3)$ & $2,992(4)$ & $2,980(3)$ & $2,986(4)$ \\
\hline$\%$ fase & 49(2) & $64(3)$ & $35(2)$ & 42(3) & $38(2)$ & $28(3)$ \\
\hline TMC (nm) & $3,9(2)$ & $5,7(2)$ & $5,8(2)$ & $4,3(2)$ & $5,5(2)$ & $4,2(2)$ \\
\hline Estrutura & \multicolumn{6}{|c|}{ Tetragonal } \\
\hline Rwp (\%) & 5,7 & 4,5 & 4,5 & 4,3 & 4,5 & 4,4 \\
\hline
\end{tabular}

$T M C=$ Tamanho médio de cristalitos

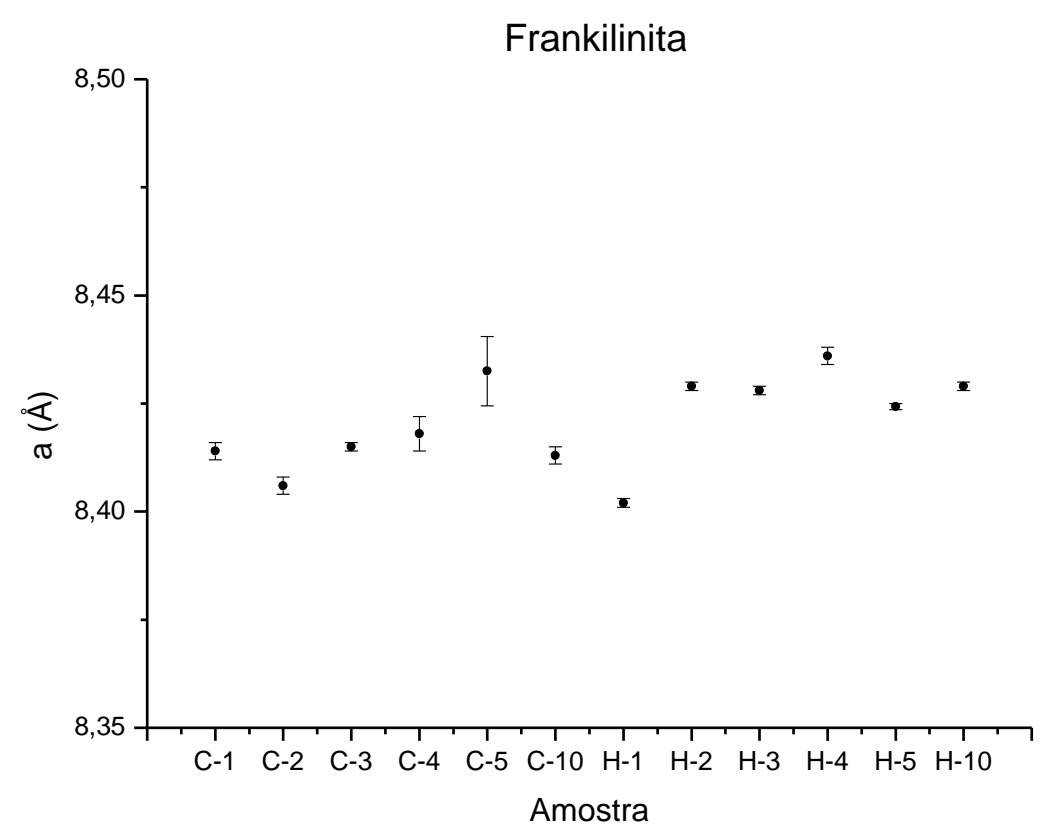

Figura 5.16 - Dados do parâmetro de rede 'a' da Frankilinita obtidos pelo refinamento dos perfis de difração pelo método de Rietveld para as amostras sintetizadas por coprecipitação $(C)$ e para as amostras que passaram por tratamento hidrotermal $(H)$. 


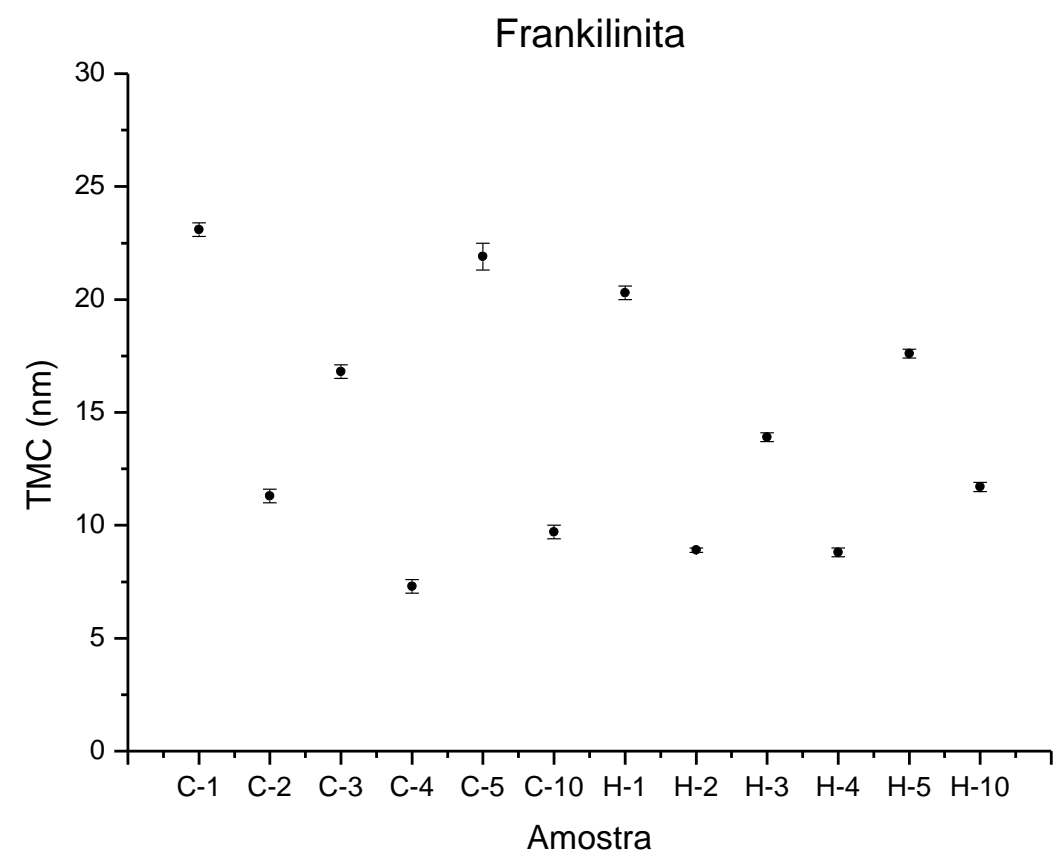

Figura 5.17 - Dados do tamanho médio de cristalito (TMC) da Frankilinita obtidos pelo refinamento dos perfis de difração pelo método de Rietveld para as amostras sintetizadas por coprecipitação $(C)$ e para as amostras que passaram por tratamento hidrotermal $(H)$.

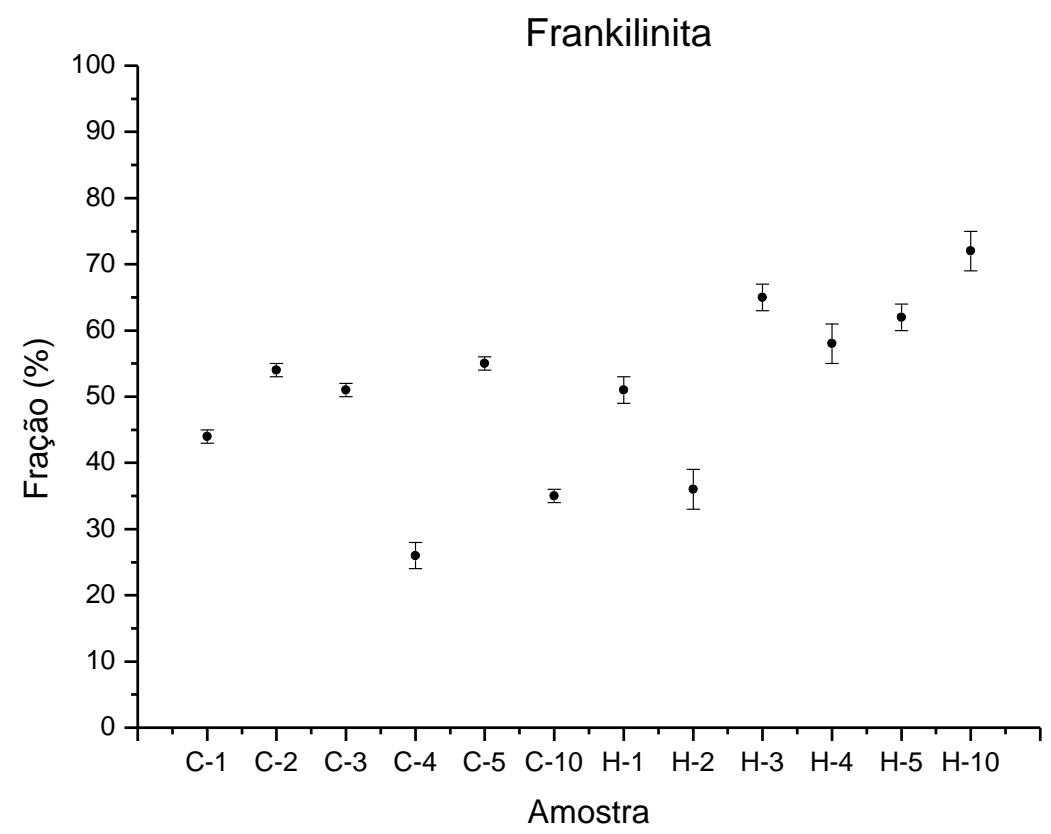

Figura 5.18 - Dados da fração da fase Frankilinita obtidos pelo refinamento dos perfis de difração pelo método de Rietveld para as amostras sintetizadas por coprecipitação (C) e para as amostras que passaram por tratamento hidrotermal $(H)$. 


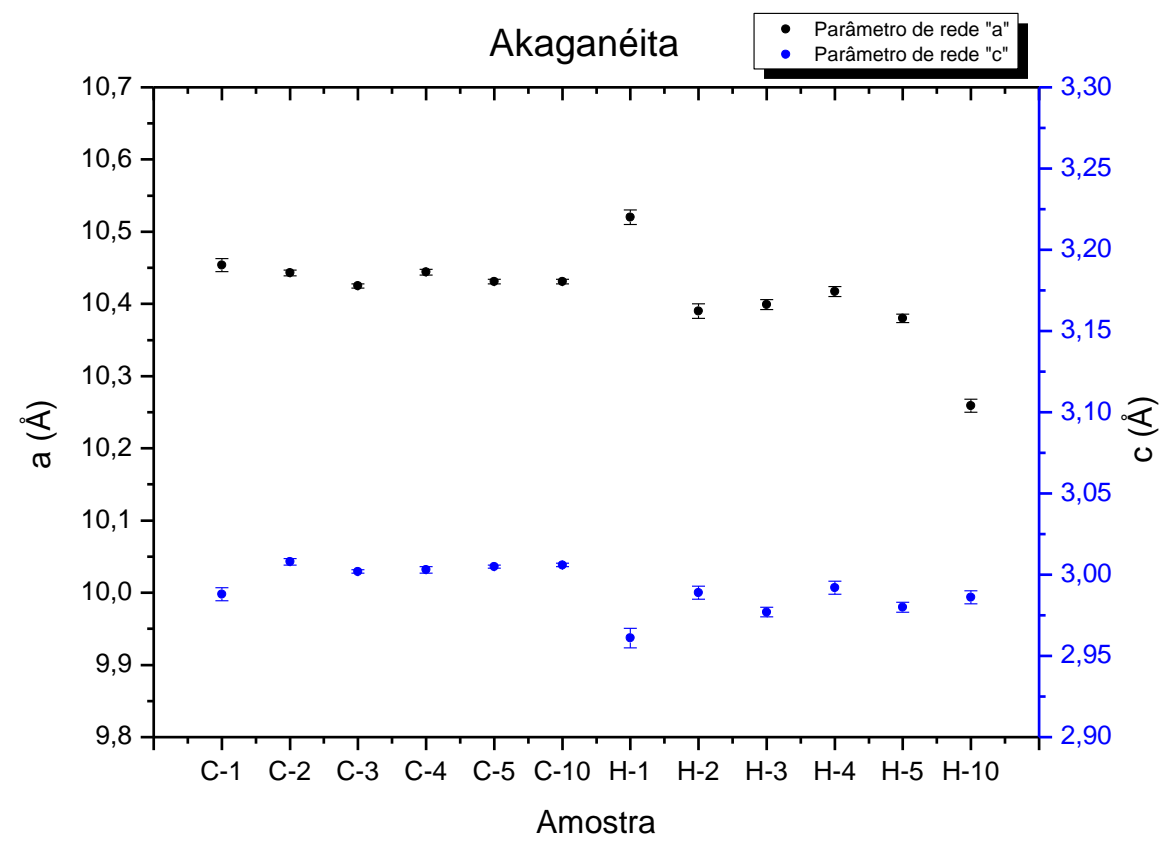

Figura 5.19 - Dados dos parâmetro de rede 'a' e 'c' da Akaganéita obtidos pelo refinamento dos perfis de difração pelo método de Rietveld para as amostras sintetizadas por coprecipitação $(C)$ e para as amostras que passaram por tratamento hidrotermal $(H)$.

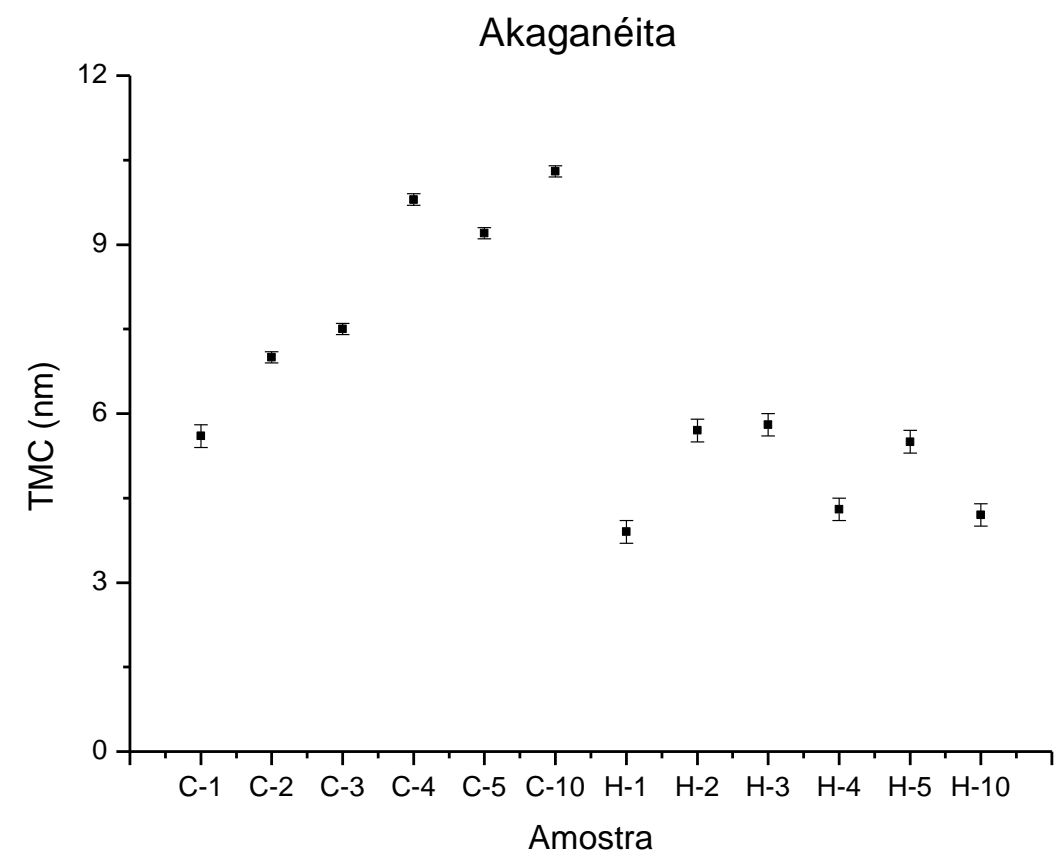

Figura 5.20 - Dados do tamanho médio de cristalito (TMC) da Akaganéita obtidos pelo refinamento dos perfis de difração pelo método de Rietveld para as amostras sintetizadas por coprecipitação $(C)$ e para as amostras que passaram por tratamento hidrotermal $(H)$. 


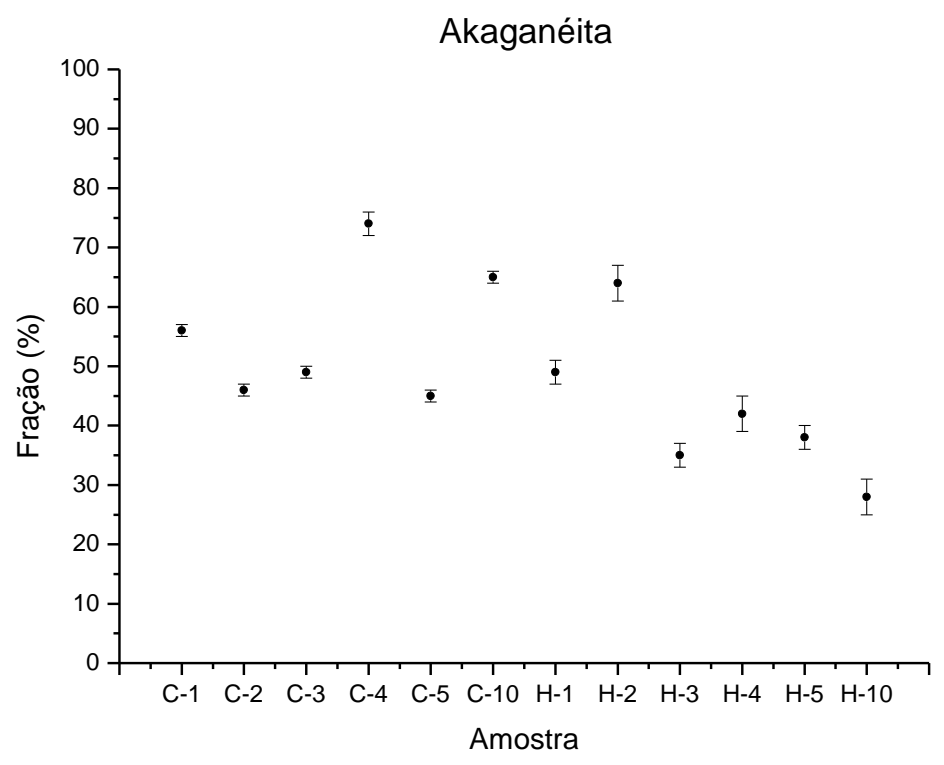

Figura 5.21 - Dados da fração da fase Akaganéita obtidos pelo refinamento dos perfis de difração pelo método de Rietveld para as amostras sintetizadas por coprecipitação (C) e para as amostras que passaram por tratamento hidrotermal $(H)$.

O tamanho médio de cristalitos (TMC) para cada síntese foi calculado por meio da equação de Scherrer utilizando o volume médio ponderado da largura integral[46].

Para estabelecer um critério de avaliação dos parâmetros estruturais com a variação da CMC do CTAB, foram construídos gráficos com a distribuição dos dados, mostrados nas FIG 5.22 à FIG 5.35, e calculado o coeficiente de correlação[47], [48] entre estes valores, que estão mostrados nas TAB. 5.3 e TAB. 5.4 . 


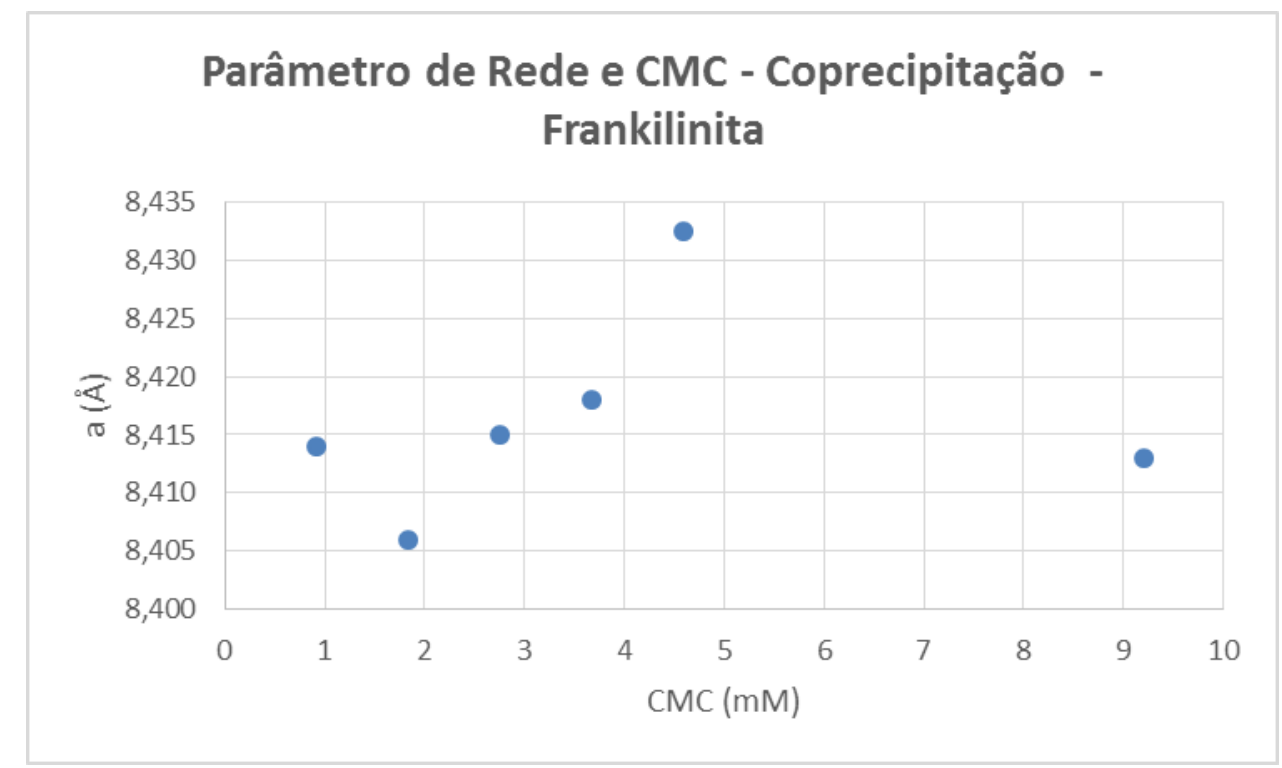

Figura 5.22 - Correlação entre o parâmetro de rede 'a' da Frankilinita e a CMC, obtida na síntese pelo método da coprecipitação.

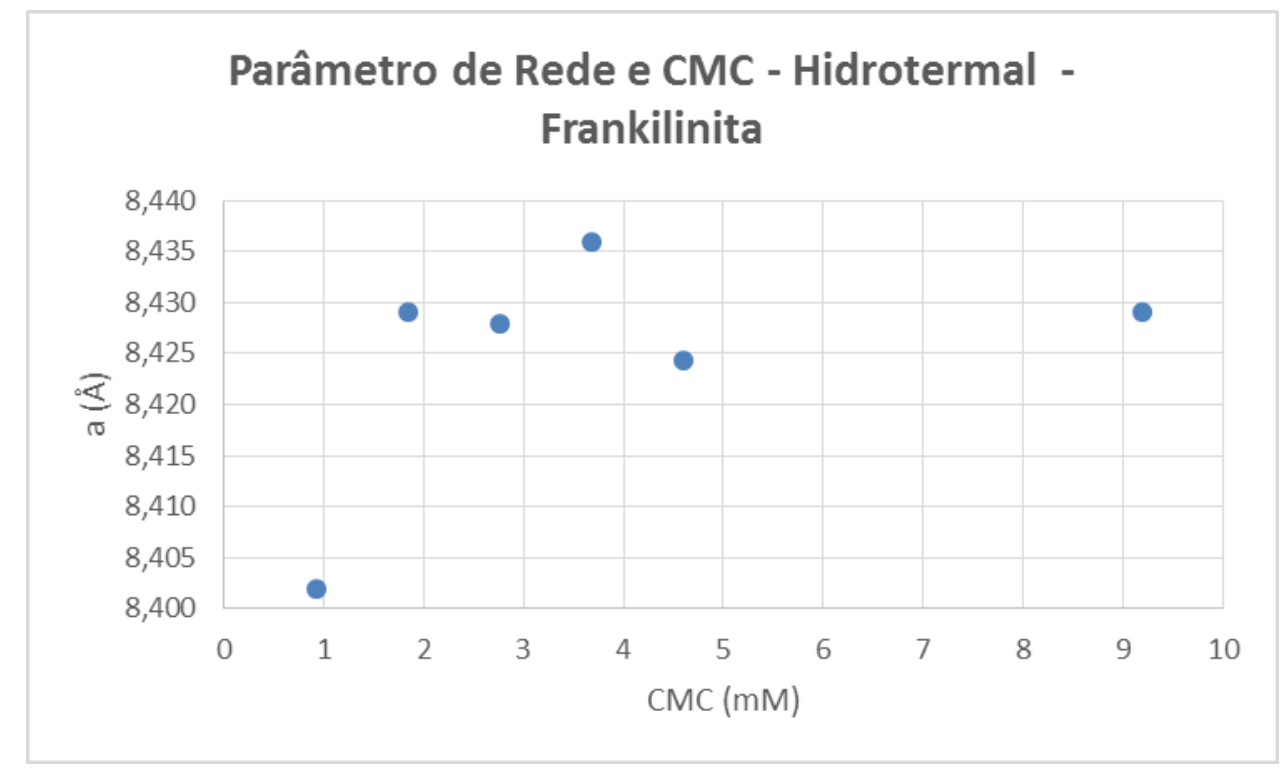

Figura 5.23 - Correlação entre o parâmetro de rede 'a' da Frankilinita e a CMC, obtida por tratamento hidrotermal. 


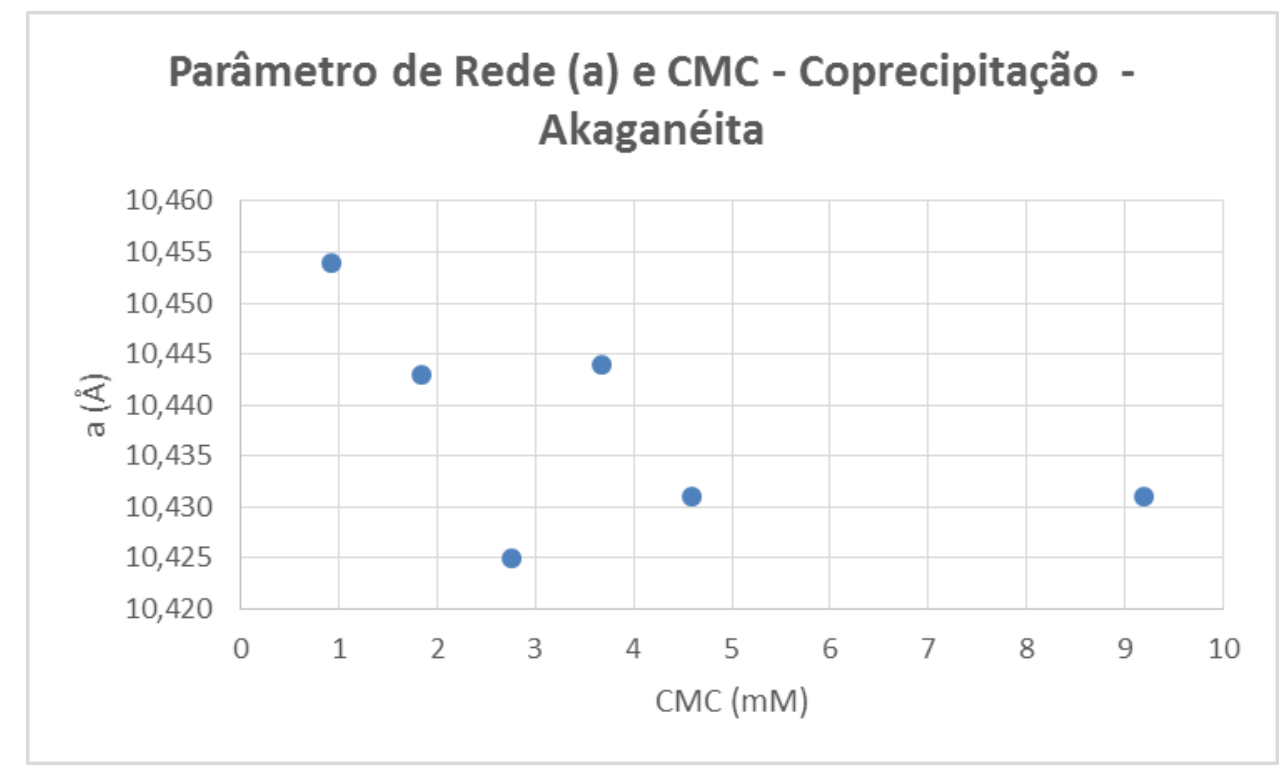

Figura 5.24 - Correlação entre o parâmetro de rede 'a' da Akaganéita e a CMC, obtida na síntese pelo método da coprecipitação.

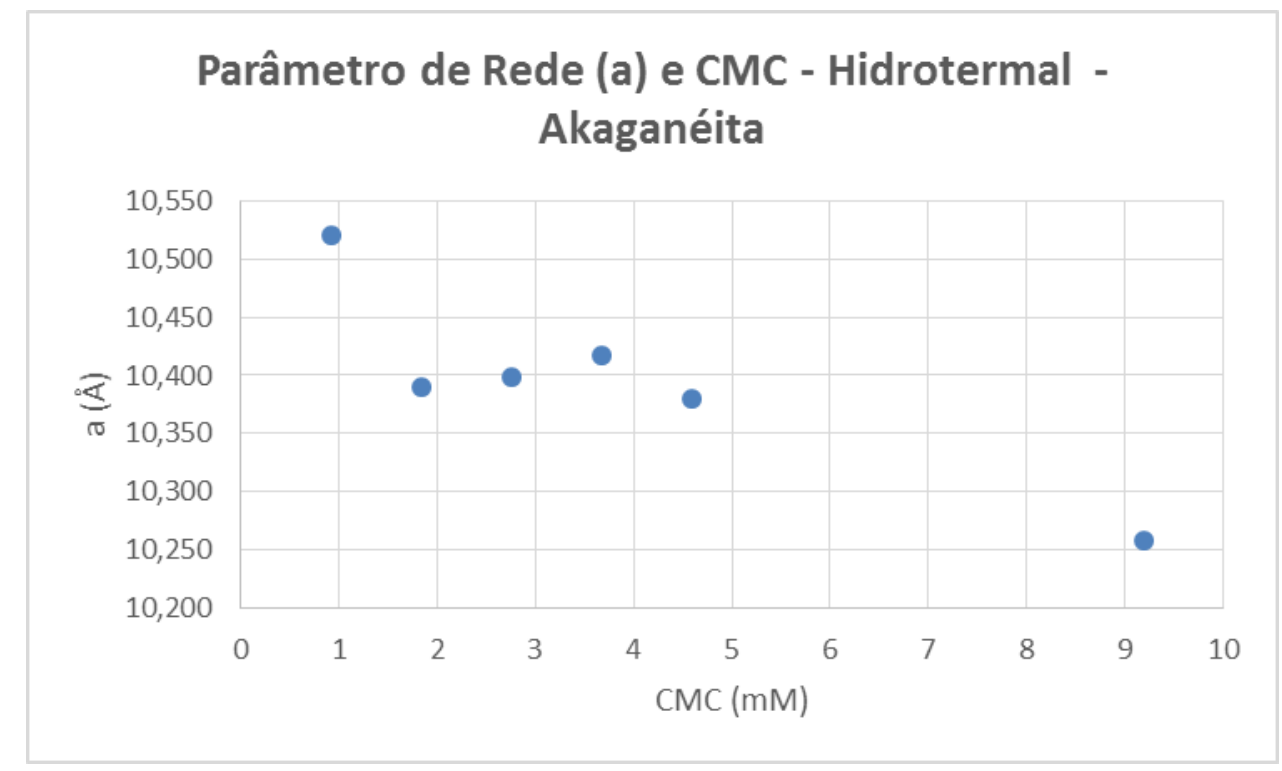

Figura 5.25 - Correlação entre o parâmetro de rede 'a' da Akaganéita e a CMC, obtida por tratamento hidrotermal. 


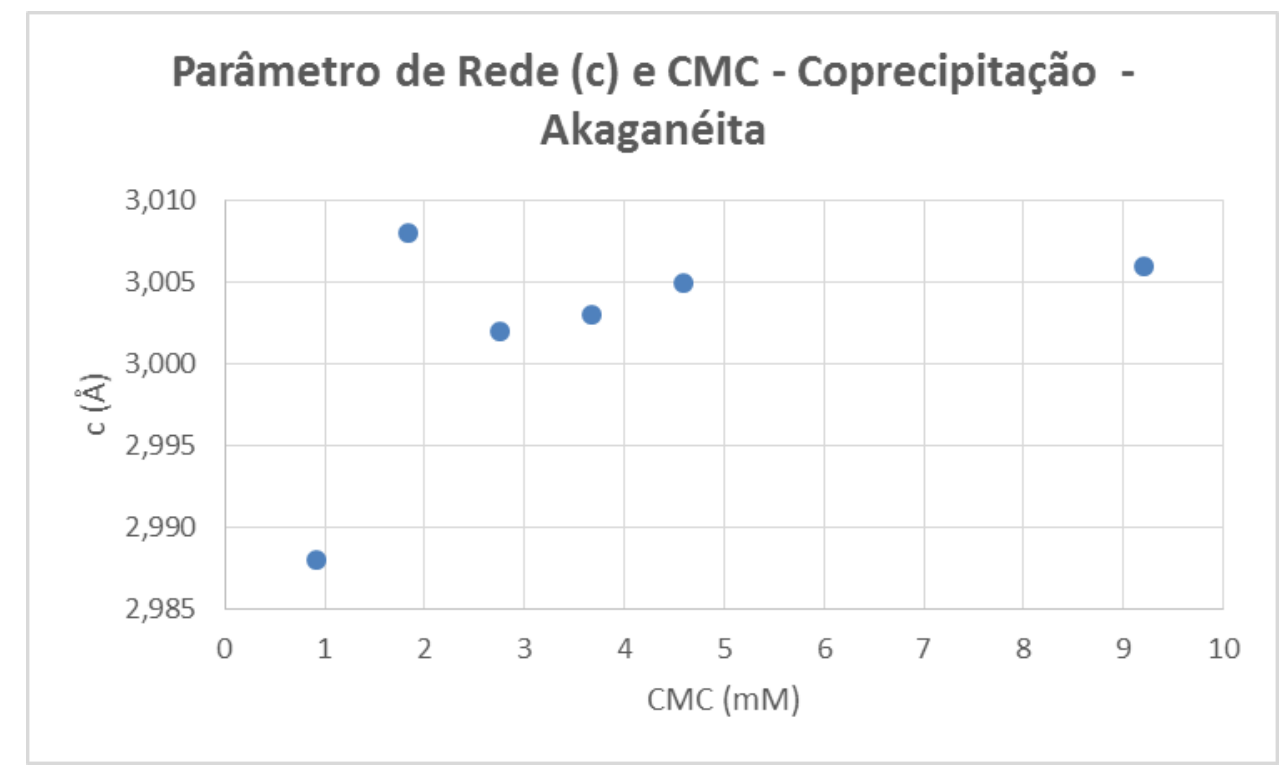

Figura 5.26 - Correlação entre o parâmetro de rede 'c' da Akaganéita e a CMC, obtida na síntese pelo método da coprecipitação.

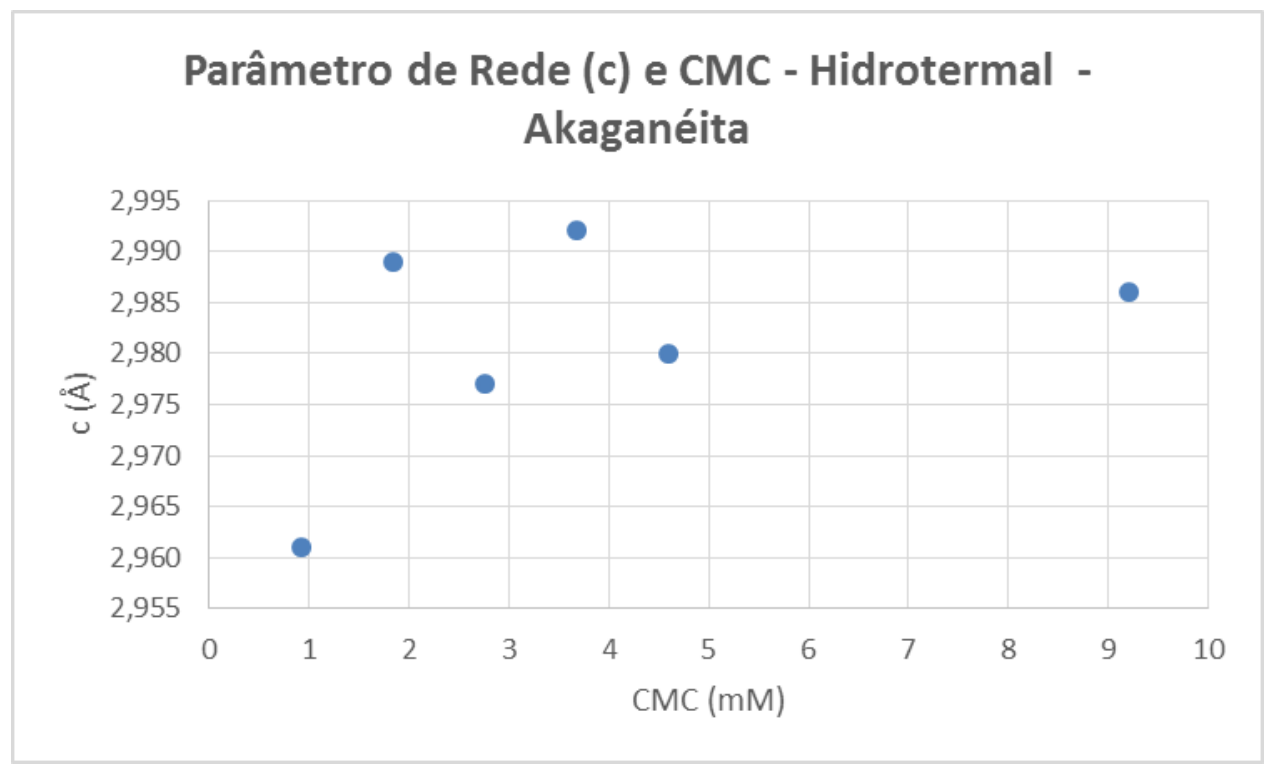

Figura 5.27 - Correlação entre o parâmetro de rede 'c' da Akaganéita e a CMC, obtida por tratamento hidrotermal. 


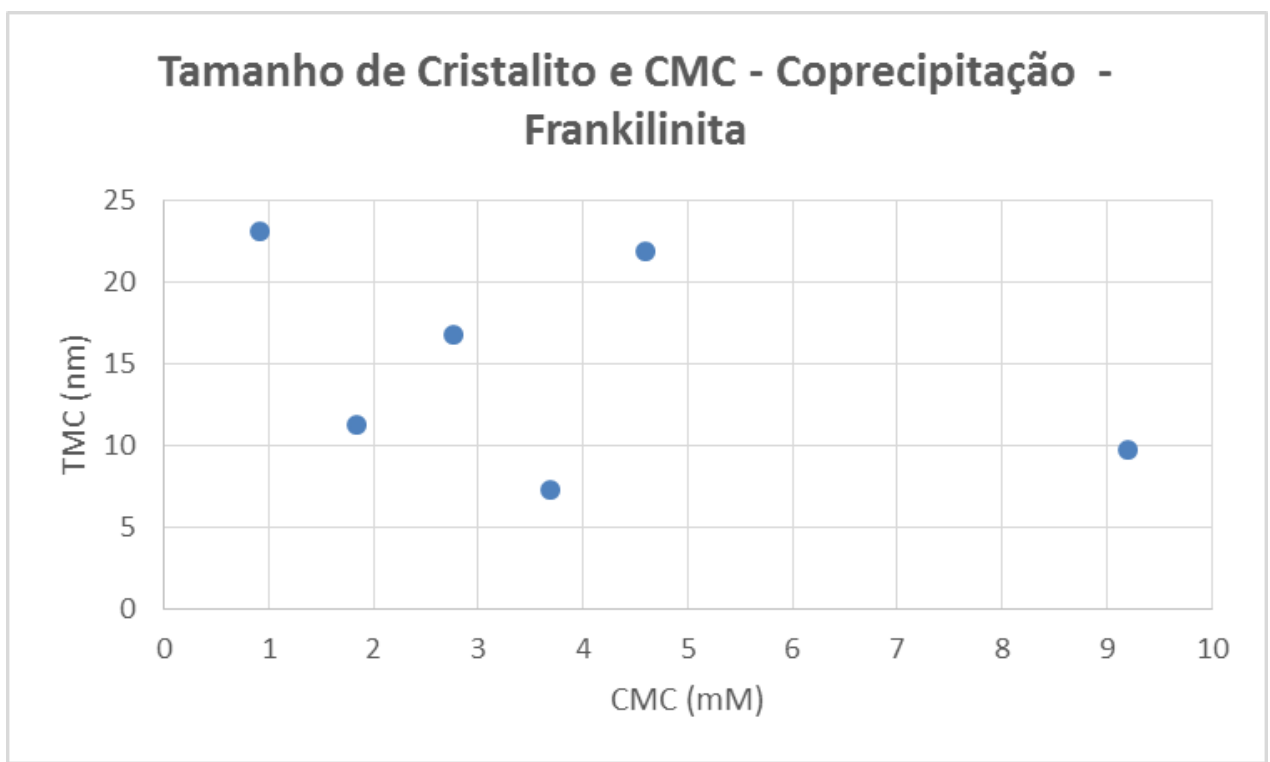

Figura 5.28 - Correlação entre o tamanho médio de cristalito (TMC) da Frankilinita e a CMC, obtida na síntese pelo método da coprecipitação.

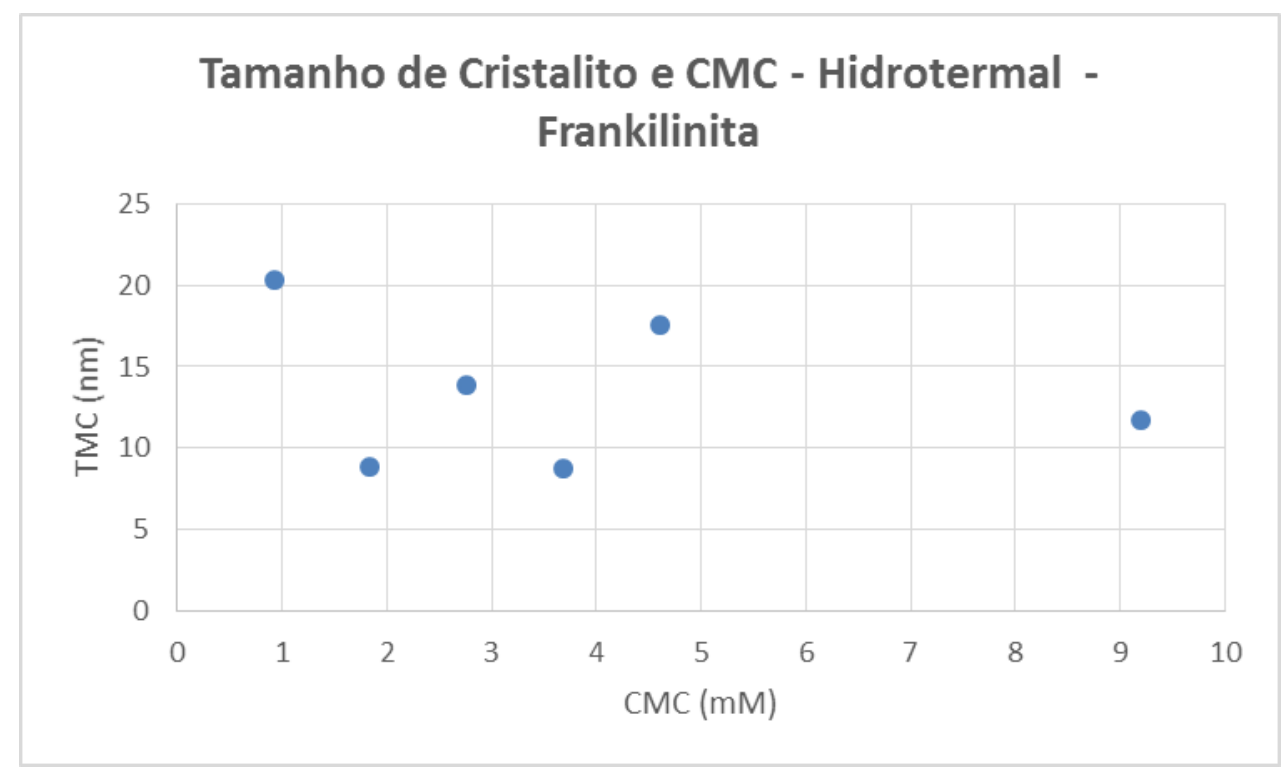

Figura 5.29 - Correlação entre o tamanho médio de cristalito (TMC) da Frankilinita e a $C M C$, obtida por tratamento hidrotermal. 


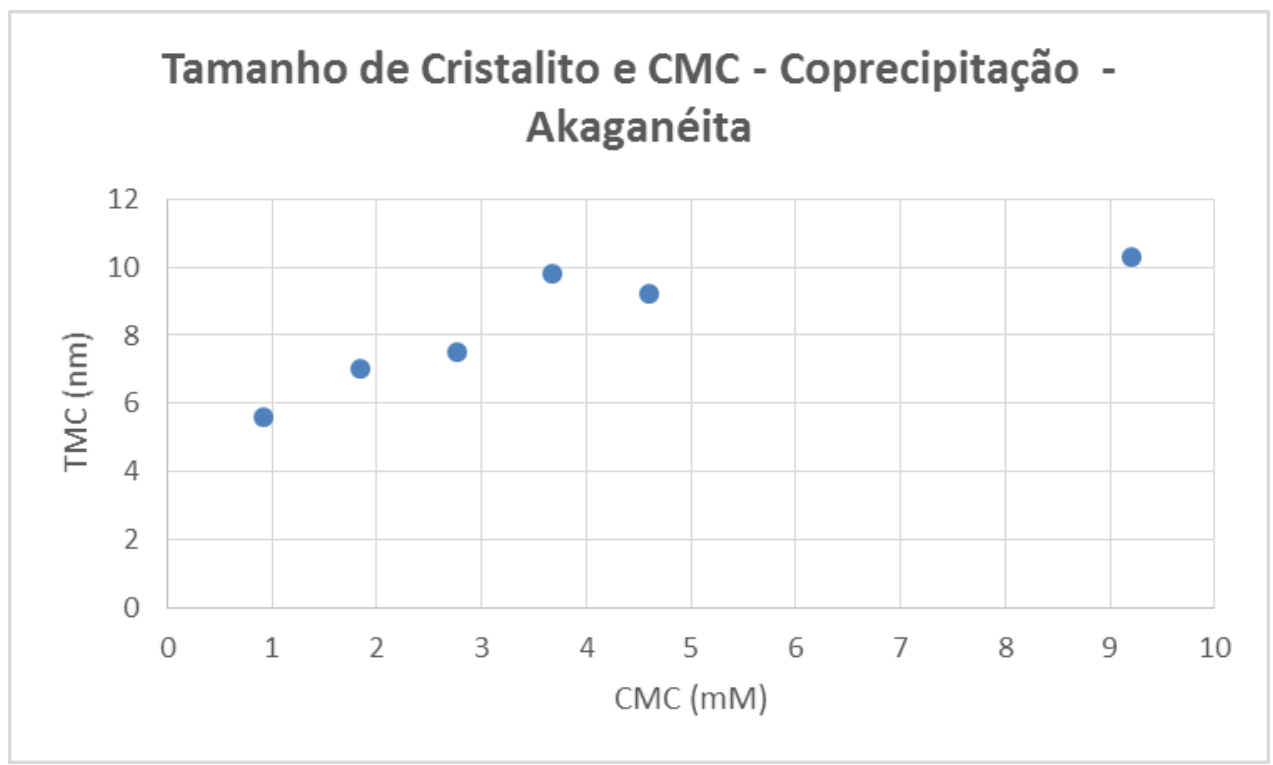

Figura 5.30 - Correlação entre o tamanho médio de cristalito (TMC) da Akaganéita e a CMC, obtida na síntese pelo método da coprecipitação.

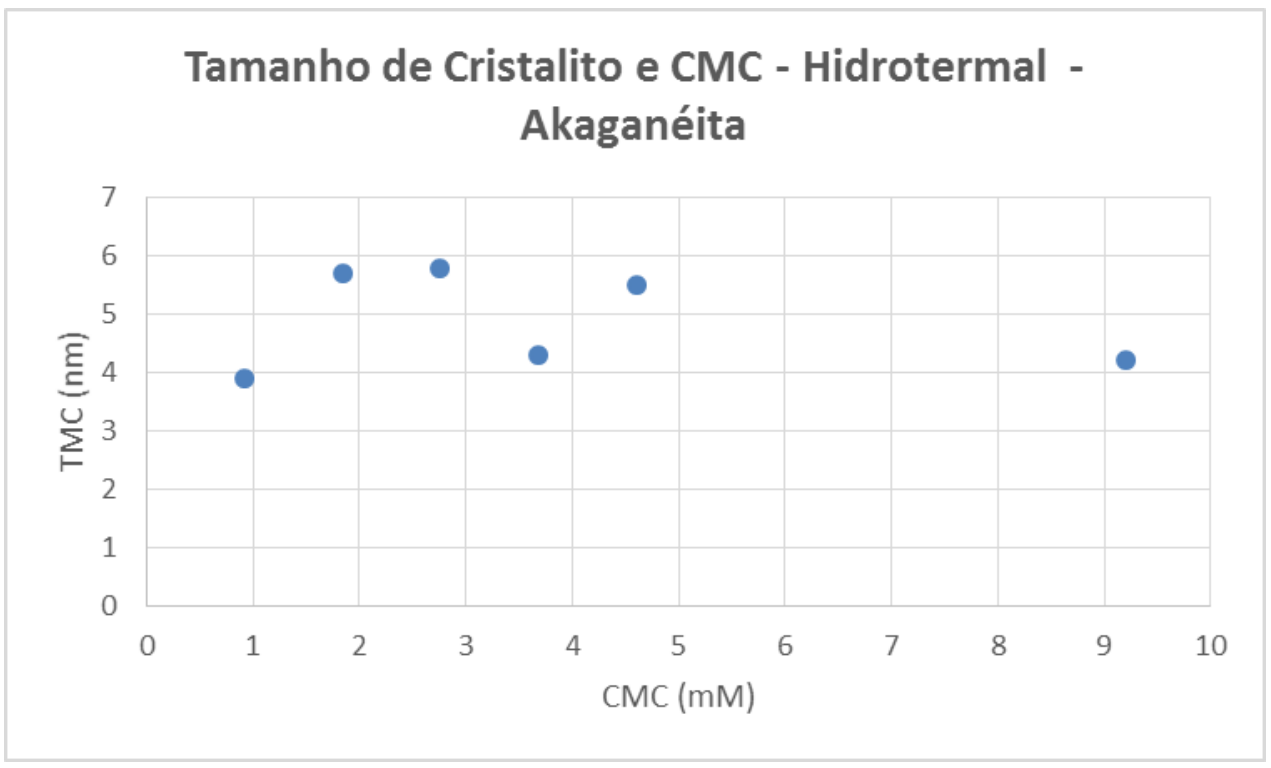

Figura 5.31 - Correlação entre o tamanho médio de cristalito (TMC) da Akaganéita e a $C M C$, obtida por tratamento hidrotermal. 


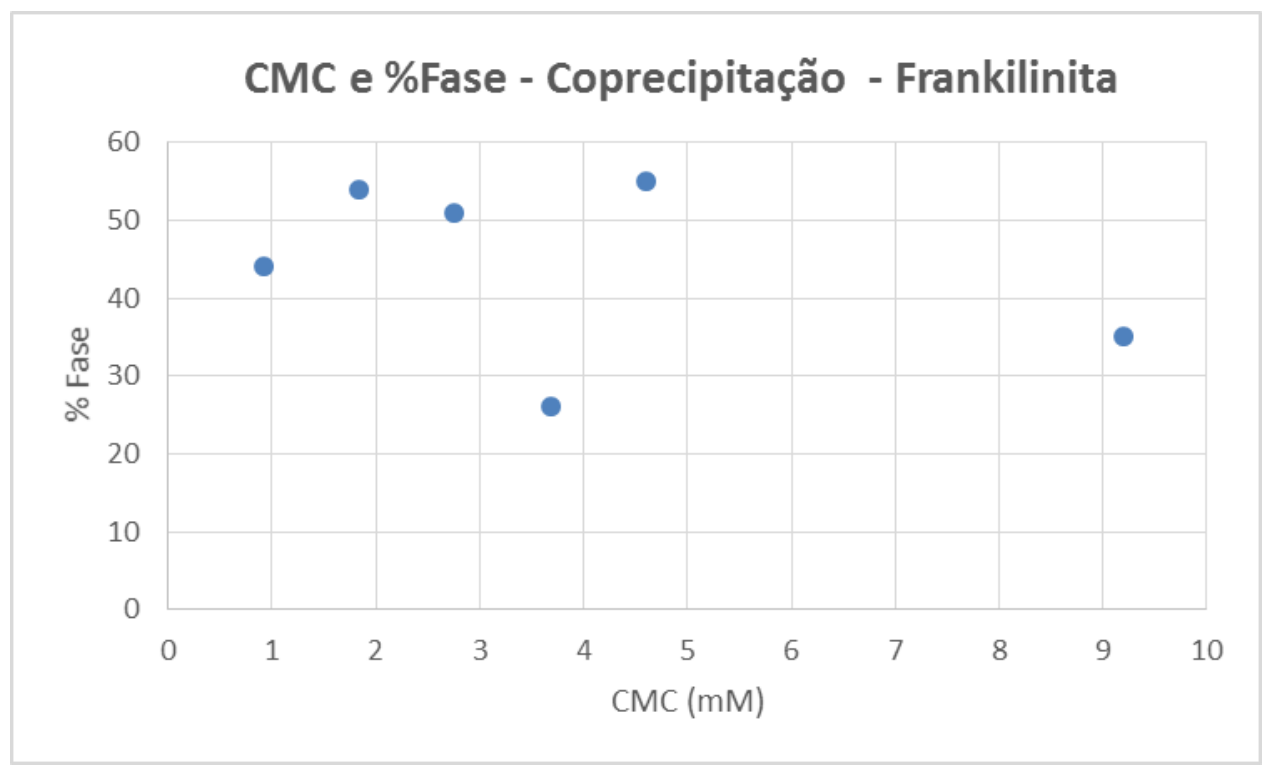

Figura 5.32 - Correlação entre a porcentagem de fase da Frankilinita e a CMC, obtida na síntese pelo método da coprecipitação.

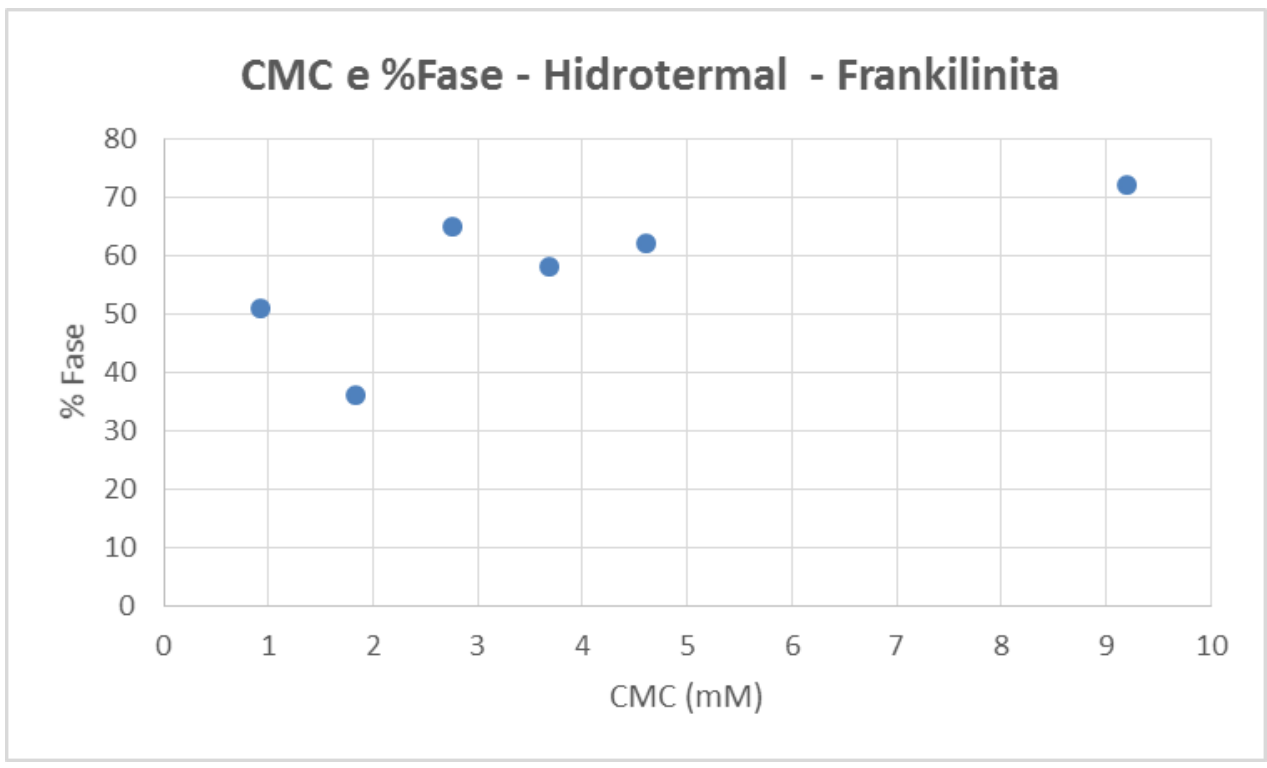

Figura 5.33 - Correlação entre a porcentagem de fase da Frankilinita e a CMC, obtida na síntese por tratamento hidrotermal. 


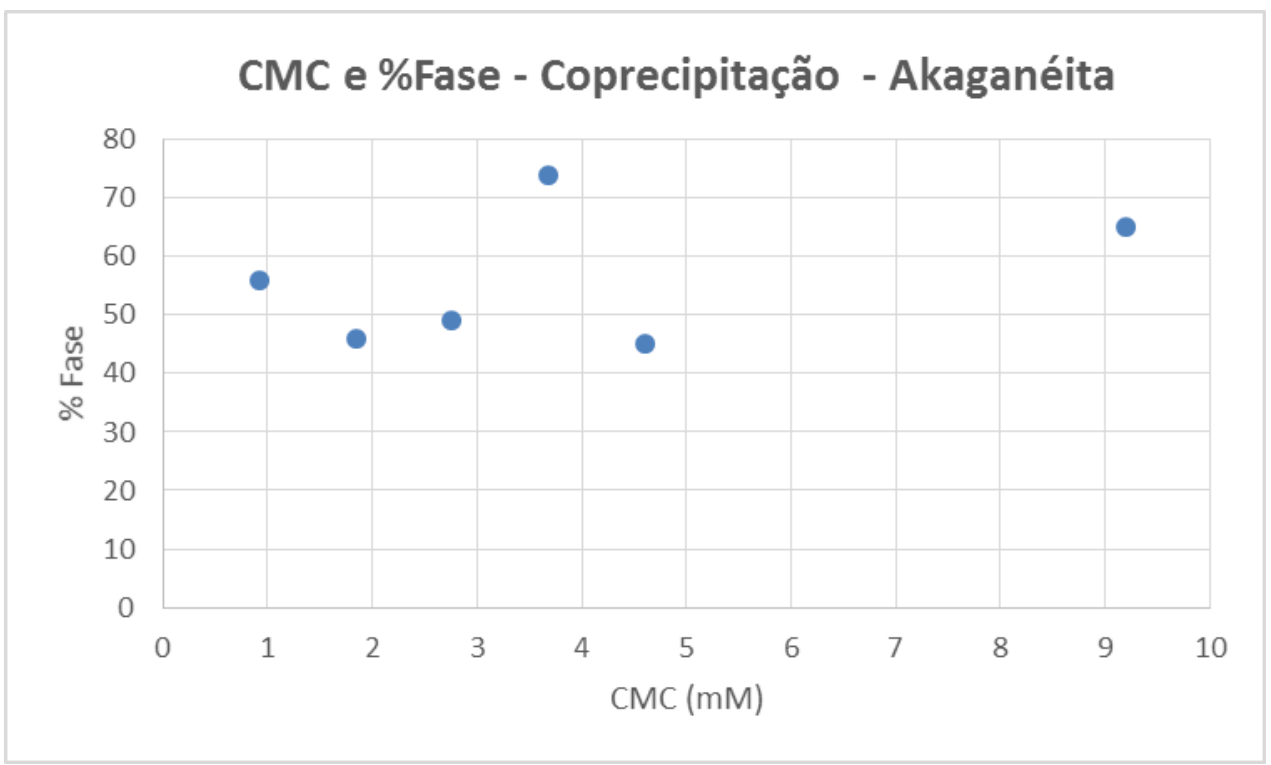

Figura 5.34 - Correlação entre a porcentagem de fase da Akaganéita e a CMC, obtida na síntese pelo método da coprecipitação.

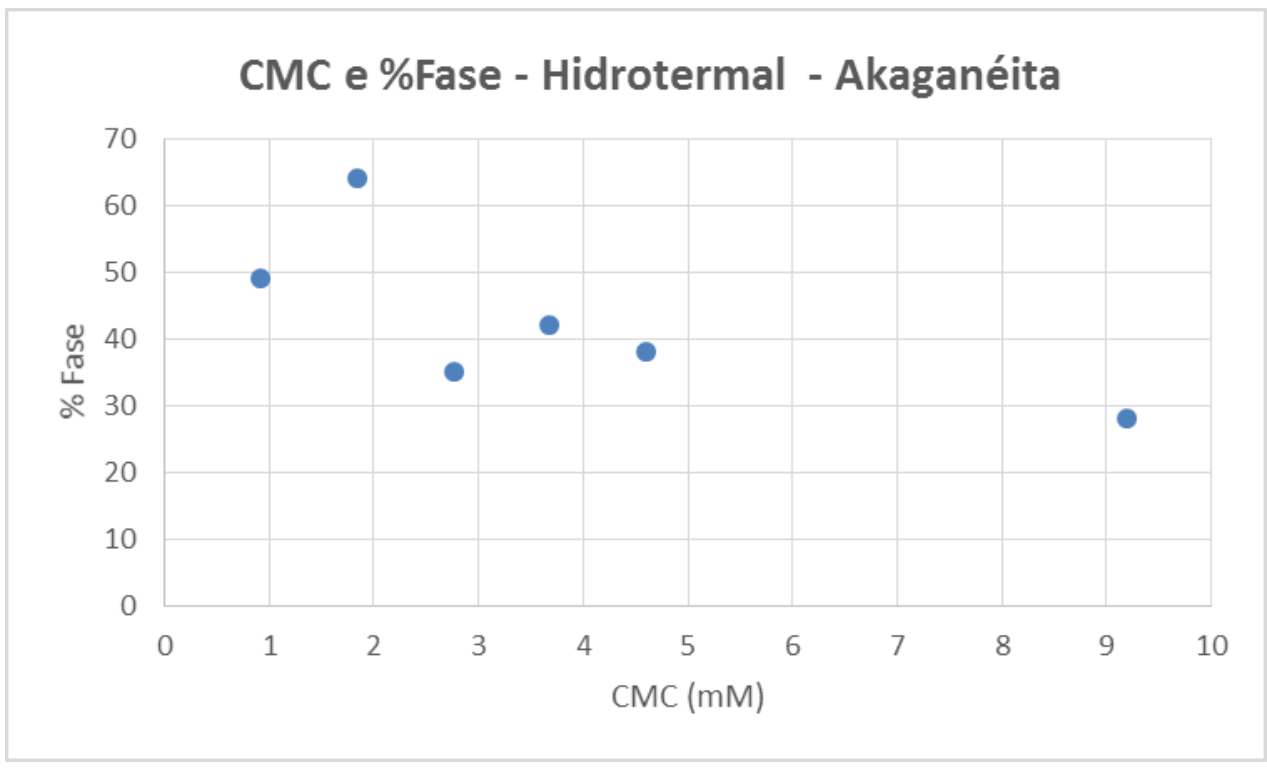

Figura 5.35 - Correlação entre a porcentagem de fase da Akaganéita e a CMC, obtida por tratamento hidrotermal. 
Tabela 5.3 - Correlação entre a variação da concentração micelar crítica (CMC) do CTAB com os parâmetros de refinamento obtidos por análise de perfil de difração de raios $X$ para as amostras sintetizadas por coprecipitação.

\begin{tabular}{cc}
\hline Coprecipitação & \\
\hline Frankilinita & CMC \\
Parâmetro de Rede & \\
$a(\AA)$ & 0,18 \\
Tamanho de Cristalito $(\mathrm{nm})$ & $-0,41$ \\
\%fase & $-0,38$ \\
\hline & \\
\hline Akaganéita & \\
\hline Parâmetro de Rede & $\mathrm{CMC}$ \\
$a(\AA)$ & $-0,55$ \\
$c(\AA)$ & 0,50 \\
\%fase & 0,84 \\
\hline \hline
\end{tabular}

Tabela 5.4 - Correlação entre a variação da concentração micelar crítica (CMC) do CTAB com os parâmetros de refinamento obtidos por análise de perfil de difração de raios $X$ para as amostras após o tratamento hidrotermal.

\begin{tabular}{|c|c|}
\hline \multicolumn{2}{|l|}{ Hidrotermal } \\
\hline \multicolumn{2}{|l|}{ Frankilinita } \\
\hline & $\mathrm{CMC}$ \\
\hline \multicolumn{2}{|l|}{ Parâmetro de Rede } \\
\hline$a(\AA)$ & 0,44 \\
\hline Tamanho de Cristalito (nm) & $-0,25$ \\
\hline \%fase & 0,73 \\
\hline \multicolumn{2}{|l|}{ Akaganéita } \\
\hline & CMC \\
\hline \multicolumn{2}{|l|}{ Parâmetro de Rede } \\
\hline$a(\AA)$ & $-0,90$ \\
\hline$c(\AA)$ & 0,43 \\
\hline Tamanho de Cristalito (nm) & $-0,23$ \\
\hline \%fase & $-0,73$ \\
\hline
\end{tabular}


Em relação à fase Akaganéita, os valores obtidos para a correlação do parâmetro de rede a apresentaram uma tendência a decrescer com o aumento da $\mathrm{CMC}$, sendo esta diminuição mais acentuada após o tratamento hidrotermal. Considerando o parâmetro de rede $c$, os valores obtidos para a correlação mostraram uma tendência ao crescimento com o aumento da CMC, sendo os valores destas correlações próximos tanto na síntese por coprecipitação quanto no tratamento hidrotermal.

As correlações calculadas para o tamanho de cristalito propuseram uma tendência à diminuição com o aumento da $\mathrm{CMC}$, sendo estes valores semelhantes, tanto na síntese por coprecipitação quanto no tratamento hidrotermal. A análise das correlações para a porcentagem de fase indicou um aumento desta com o aumento da CMC na síntese por coprecipitação e uma forte tendência de diminuição com o aumento da CMC no tratamento hidrotermal.

Considerando a fase Frankilinita, os valores obtidos para a correlação propõem uma tendência ao aumento do tamanho do parâmetro de rede a com o aumento da CMC, sendo mais pronunciado este aumento com o tratamento hidrotermal. Os valores obtidos para o tamanho de cristalito propõem uma tendência na diminuição do parâmetro de rede em função do aumento da CMC, sendo este mais destacado na síntese por coprecipitação que após tratamento hidrotermal.

Os valores para a correlação calculados para a porcentagem de fase apresentaram uma tendência ao decréscimo com o aumento da CMC na síntese por coprecipitação. Quando calculados os valores para a correlação da porcentagem de fase após o tratamento hidrotermal, apresentaram uma forte tendência ao crescimento com o aumento da CMC, indicando que o tratamento hidrotermal foi relevante para diminuição da presença da fase secundária.

Em resumo, na caracterização das estruturas pelo refinamento de Rietveld dos perfis de difração para a síntese por coprecipitação observou-se que o tamanho médio de cristalitos apresenta a tendência de aumento para a fase Akaganeita e diminuição para a fase Frankilinita, com o aumento da concentração do CTAB. Observa-se, ainda, que a porcentagem das fases varia com a concentração de CTAB, porém sem apresentar um comportamento regular. 
Nas amostras submetidas a tratamento hidrotermal observou-se que 0 tamanho médio de cristalitos apresenta a tendência à diminuição em ambas as fases, bem como o aumento da proporção da fase Frankilinita com o aumento da concentração do CTAB, indicando que o tratamento hidrotermal foi efetivo na obtenção de amostras com tamanho médio de cristalitos menores e maior proporção da fase desejada.

\subsection{Análise por FTIR}

Os interferogramas apresentados nas FIG. 5.1 e 5.2 mostram dados de transmitância ( $\mathrm{T} \%)$ por número de onda $\left(k \mathrm{em} \mathrm{cm}{ }^{-1}\right)$.

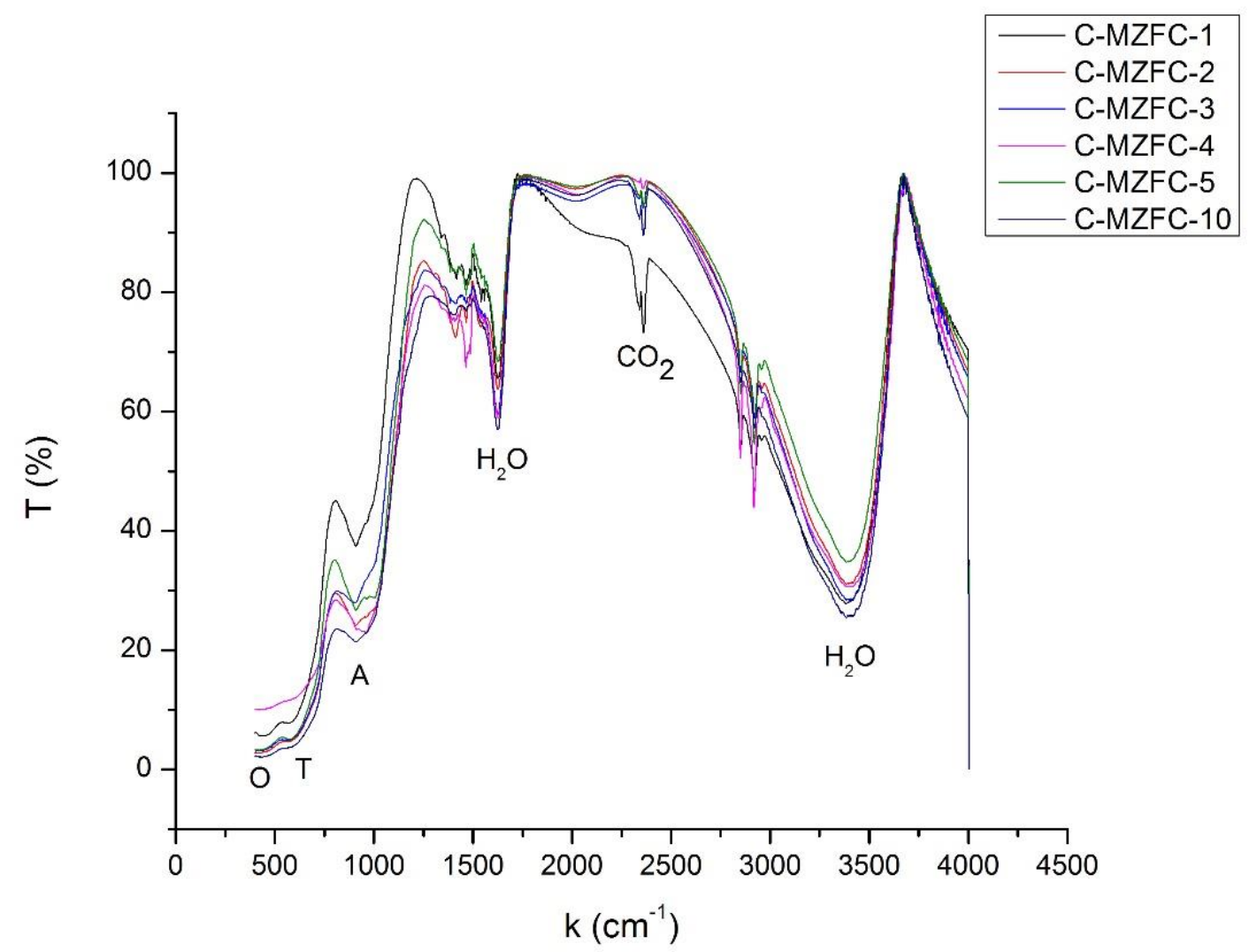

Figura 5.36 - Interferograma para as amostras sintetizadas pelo método da coprecipitação. 


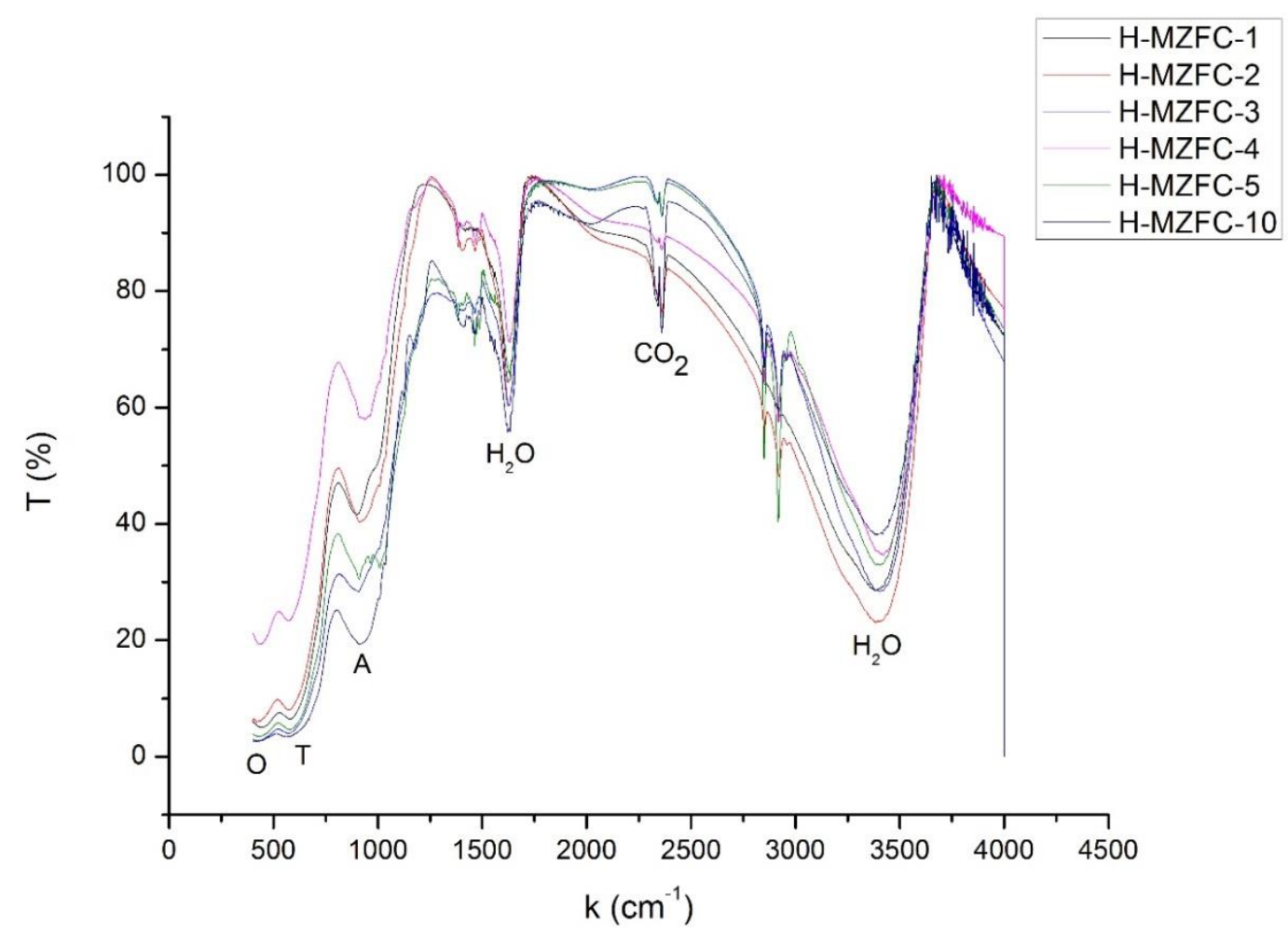

Figura 5.37 - Interferograma para as amostras sintetizadas pelo método da coprecipitação e que passaram por tratamento hidrotermal.

Nos interferogramas estão destacadas as regiões de número de onda relativos às bandas de absorção mais intensas na região inicial $\left(425-475 \mathrm{~cm}^{-1} \mathrm{e}\right.$ 550-600 $\mathrm{cm}^{-1}$ ), devidas à presença da estrutura espinélio das ferritas. Estas bandas de absorção podem ser atribuídas ao modo de vibração do complexo $\mathrm{Fe}^{3+}-\mathrm{O}^{2-}$ nos sítios tetraédricos $(T)$ e octaédricos $(O)$, respectivamente[49].

As bandas de absorção da akaganéita (A) $\left(600-900 \mathrm{~cm}^{-1}\right)$, de $\mathrm{CO}_{2}$ (2400$\left.2600 \mathrm{~cm}^{-1}\right)$ e da água $\left(\mathrm{H}_{2} \mathrm{O}\right)$, devido aos estiramentos simétrico e assimétrico (3400$\left.3600 \mathrm{~cm}^{-1}\right)$ e à deformação angular $\left(1500-1700 \mathrm{~cm}^{-1}\right)[36]$ também estão mostradas.

\subsection{Susceptometria AC}

Os valores obtidos experimentalmente para a susceptibilidade magnética e o cálculo da densidade de energia das amostras sintetizadas pelo método da coprecipitação $(C)$ e que passaram por tratamento hidrotermal $(H)$, com diferentes concentrações de CTAB $(1,2,3,4,5,10)$, estão mostrados na TAB 5.5 e, respectivamente, nas FIG. 5.38 e FIG. 5.39 . 
No cálculo da energia considerou-se apenas a resposta da fase Frankilinita ao campo magnético, sendo a massa total corrigida segundo a fração da fase obtida por meio do refinamento pelo método de Rietveld (TAB. 5.1 e TAB. 5.2)

Tabela 5.5 - Dados de massa (corrigida para a fração de Frankilinita) e susceptibilidade magnética obtidos experimentalmente e cálculo da densidade de energia para as amostras sintetizadas por coprecipitação $(C)$ e para as amostras que passaram por tratamento hidrotermal $(H)$.

\begin{tabular}{|c|c|c|c|}
\hline Amostra & $\begin{array}{l}\text { Susceptibilidade } \\
\text { Magnética }\left(\times 10^{-3}\right)\end{array}$ & $\begin{array}{c}\text { Massa } \\
\text { corrigida } \\
\text { (Frankilinita) } \\
\text { (mg) }\end{array}$ & $\begin{array}{c}\text { Densidade de } \\
\text { Energia }\left(\mathrm{kJ} / \mathrm{g} \cdot \mathrm{cm}^{3}\right)\end{array}$ \\
\hline$C-1$ & $0,52(4)$ & $2,8(1)$ & $5,2(1)$ \\
\hline$C-2$ & $0,81(6)$ & $4,5(1)$ & $3,2(1)$ \\
\hline$C-3$ & $0,60(4)$ & $1,6(1)$ & $9,2(7)$ \\
\hline$C-4$ & $0,36(3)$ & $3,7(1)$ & $3,9(1)$ \\
\hline$C-5$ & $0,54(4)$ & $1,4(1)$ & $10,0(4)$ \\
\hline$C-10$ & $0,75(5)$ & $2,1(1)$ & $6,8(3)$ \\
\hline $\mathrm{H}-1$ & $4,8(3)$ & $1,5(1)$ & $9,7(8)$ \\
\hline $\mathrm{H}-2$ & $0,16(1)$ & $4,0(1)$ & $3,6(1)$ \\
\hline $\mathrm{H}-3$ & $0,50(4)$ & $3,4(2)$ & $4,3(2)$ \\
\hline $\mathrm{H}-4$ & $0,08(1)$ & $2,5(1)$ & $5,8(2)$ \\
\hline $\mathrm{H}-5$ & $0,46(3)$ & $2,0(1)$ & $7,1(4)$ \\
\hline $\mathrm{H}-10$ & $0,13(1)$ & $2,8(1)$ & $5,2(1)$ \\
\hline
\end{tabular}




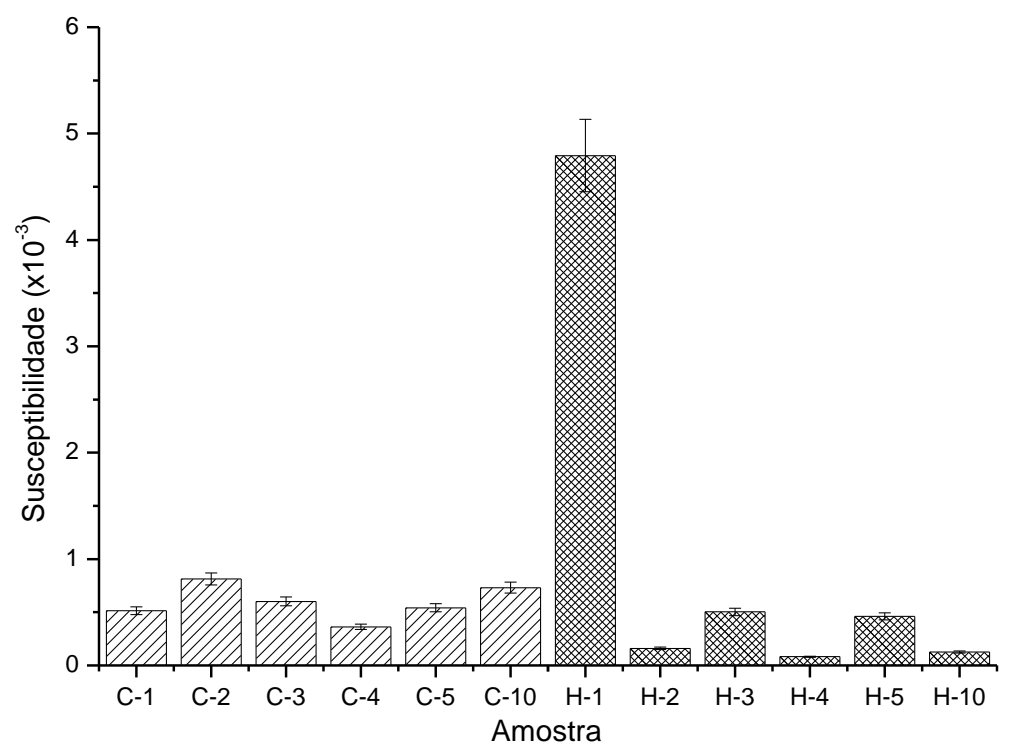

Figura 5.38 - Susceptibilidade Magnética para as amostras sintetizadas por coprecipitação $(C)$ e para as amostras que passaram por tratamento hidrotermal $(H)$.

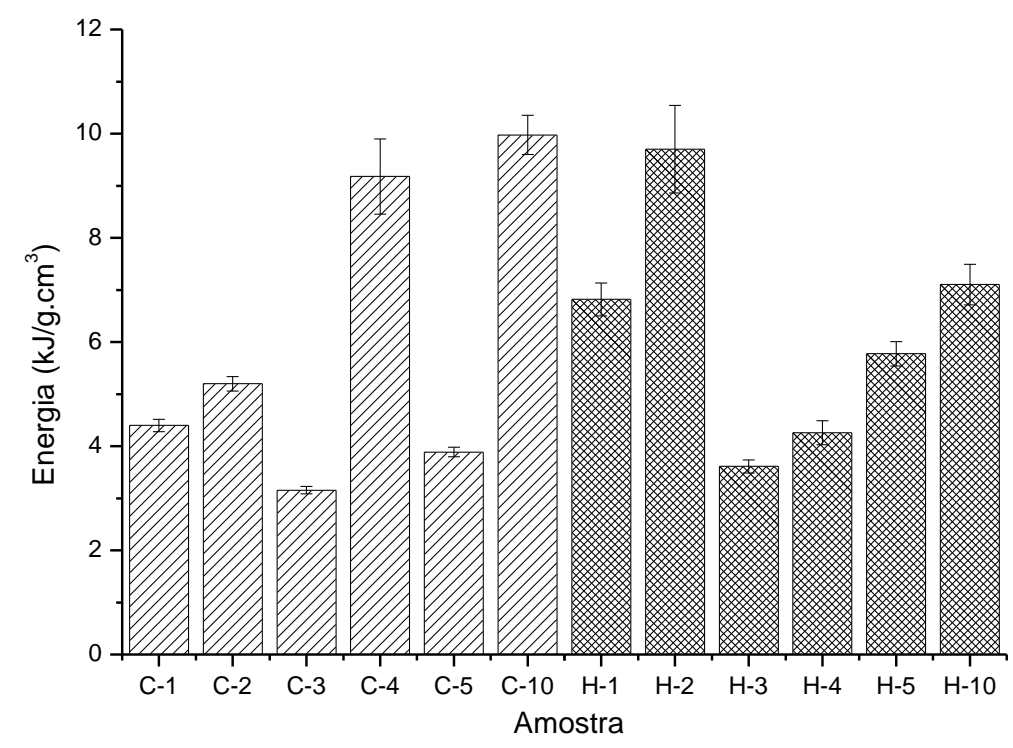

Figura 5.39 - Densidade de energia por volume e por grama para as amostras sintetizadas por coprecipitação $(C)$ e para as amostras que passaram por tratamento hidrotermal $(H)$.

Para estabelecer um critério de avaliação da susceptibilidade magnética e da densidade de energia magnética com a variação da CMC do CTAB, foi calculado o coeficiente de correlação [47], [48] entre estes valores, que estão mostrados na TAB. 5.6. 
Tabela 5.6 - Correlação entre a variação da concentração micelar crítica (CMC) do CTAB com a susceptibilidade magnética e a densidade de energia magnética para as amostras sintetizadas

\begin{tabular}{lcc}
\hline \multirow{2}{*}{ Característica } & \multicolumn{2}{c}{ Correlação } \\
\cline { 2 - 3 } & Coprecipitação & Hidrotermal \\
\hline & & CMC \\
Susceptibilidade Magnética & 0,22 & $-0,51$ \\
Densidade de Energia Magnética & 0,67 & $-0,04$ \\
\hline \hline
\end{tabular}

A susceptibilidade magnética, que indica o grau de magnetização devido a um campo magnético $\mathrm{H}$ aplicado, sofreu variação com a CMC em ambos os tratamentos, na síntese por coprecipitação e após tratamento hidrotermal. Mostrou uma tendência ao crescimento, no primeiro caso, e à diminuição no segundo.

Observa-se um pico de susceptibilidade na amostra HMZFC-1, indicando que esta deva ser a que possui melhor resposta ao campo aplicado, no conjunto das sínteses. A densidade de energia magnética variou com a CMC nas amostras que não foram submetidas ao tratamento hidrotermal, indicando uma tendência ao crescimento. Nas amostras que foram submetidas ao tratamento hidrotermal não foi observada correlação.

Em trabalhos correlatos, R. Arulmurugan et al. [6] reportaram a preparação de ferritas $M n_{1-x} Z n_{x} F e_{2} O_{4}$, com x variando de 0,1 a 0,5 , pelo método de coprecipitação, resultando em partículas de tamanho menores que $12 \mathrm{~nm}$, com modificações nas propriedades magnéticas, parâmetros de rede, tamanho de cristalito e em outras propriedades. O tamanho de cristalitos estimado mostrou uma tendência em decrescer com o aumento da proporção de $\mathrm{Zn}$. As ferritas de $\mathrm{Mn}-\mathrm{Zn}$ com baixa temperatura de Curie podem ser utilizadas para preparação de ferrofluidos sensíveis à temperatura.

A dependência do tamanho de cristalitos com a proporção de $Z n$ também foi verificada no trabalho de $Y$. Xuan et al. [50], determinando, ainda, que a magnetização das partículas aumenta com o aumento da ocupação de Zn para baixos valores de $x$, porém decresce com o posterior aumento da concentração de Zn para $x>0,6$. Em ferritas de $\mathrm{Mn}-\mathrm{Zn}$, a proporção $Z n=0,25$ reduz o cristalito a 
um tamanho mínimo, para uma concentração de $\mathrm{NaOH}$ de $0,1 \mathrm{M}$ [51], sendo esta a utilizada neste trabalho.

A fase Akaganéita resultante do processo de síntese com a adição de CTAB foi reportada por Zhifa Pu et. al. [52], sendo realizada por meio da dissolução de CTAB em água deionizada e misturada a $\mathrm{FeCl}_{3} \cdot 6 \mathrm{H}_{2} \mathrm{O}$. Ao manter a concentração de $\mathrm{FeCl}_{3}$ e a temperatura constantes e modificando a concentração de $C T A B$, observou-se que quando o CTAB não é utilizado, as partículas crescem de forma randômica, com diferentes formatos e distribuições de tamanhos. Com concentração moderada de CTAB, nanopartículas com formato romboédrico são formadas e com alta concentração de CTAB nanopartículas de tamanhos diferentes são formadas.

O surfactante CTAB, deste modo, tem significativa importância na mediação da hidrólise de $\mathrm{FeCl}_{3}$, limitando o crescimento dos produtos no regime nanométrico por meio de um ambiente formado por micelas de CTAB [52]. 


\section{CONCLUSÕES}

Foram realizadas 6 sínteses de ferritas pelo método da coprecipitação, com composição nominal $\mathrm{Mn}_{0,75} \mathrm{Zn}_{0,25} \mathrm{Fe}_{2} \mathrm{O}_{4}$ (frankilinita), variando-se a concentração do surfactante CTAB para cada síntese em múltiplos da CMC (concentração micelar crítica). Uma parte de cada amostra foi submetida a tratamento hidrotermal, resultando em 12 amostras.

Por meio da análise por FTIR verificou-se as bandas de absorção para as fases frankinilita e akaganéita em todas as amostras, o que foi confirmado por difração de raios $X$.

Pelas medidas magnéticas por susceptometria magnética $A C$ foi possível identificar a tendência ao aumento da susceptibilidade magnética com o aumento da CMC do CTAB nas amostras sem tratamento hidrotermal e a sua diminuição nas amostras submetidas ao tratamento hidrotermal.

A densidade de energia magnética variou com a $\mathrm{CMC}$ nas amostras que não foram submetidas ao tratamento hidrotermal, indicando uma tendência ao crescimento. Nas amostras que foram submetidas ao tratamento hidrotermal não foi observada correlação.

Por meio da análise dos dados de difração de raios $\mathrm{X}$ pelo método de Rietveld observou-se que na síntese por coprecipitação o tamanho médio de cristalitos apresenta a tendência de aumento para a fase Akaganéita e diminuição para a fase Frankilinita, com o aumento da concentração do CTAB. Observa-se, ainda, que a porcentagem das fases varia com a concentração de CTAB, porém sem apresentar um comportamento regular.

Nas amostras submetidas a tratamento hidrotermal observou-se que o tamanho médio de cristalitos apresenta a tendência à diminuição em ambas as fases, bem como o aumento da proporção da fase Frankilinita com o aumento da concentração do CTAB, indicando que o tratamento hidrotermal foi efetivo na 
obtenção de amostras com tamanho médio de cristalitos menores e maior proporção da fase desejada. 


\section{PERSPECTIVAS FUTURAS}

Foram elencadas as seguintes sugestões para trabalhos posteriores:

- Verificar a distribuição do tamanho de partícula para examinar a homogeneidade da síntese;

- Verificar a composição química das amostras sintetizadas;

- Fazer o mapeamento do comportamento de amostras sintetizadas utilizando-se outros valores de CTAB, de modo a verificar pontos críticos de densidade de energia, susceptibilidade magnética e parâmetros estruturais;

- Obter imagem das amostras por meio de Microscopia Eletrônica de Transmissão;

- Verificar por meio de espectroscopia Mössbauer a distribuição dos cátions nas amostras. 


\section{BIBLIOGRAFIA}

[1] W. D. Callister, Materials Science and Engineering: An Introduction., 8 th. New Jersey: John Wiley \& Sons, Inc., 2007.

[2] L. Khanna and N. K. Verma, "Size-dependent magnetic properties of calcium ferrite nanoparticles," J. Magn. Magn. Mater., vol. 336, pp. 1-7, 2013.

[3] G. Srajer et al., "Advances in nanomagnetism via X-ray techniques," J. Magn. Magn. Mater., vol. 307, no. 1, pp. 1-31, 2006.

[4] A. Iftikhar, M. U. Islam, M. S. Awan, M. Ahmad, S. Naseem, and M. Asif Iqbal, "Synthesis of super paramagnetic particles of $\mathrm{Mn}_{1-x} \mathrm{Mg}_{\mathrm{x}} \mathrm{Fe}_{2} \mathrm{O}_{4}$ ferrites for hyperthermia applications," J. Alloys Compd., vol. 601, pp. 116-119, 2014.

[5] M. L. Martins et al., "Development and characterization of a new bio-nanocomposite (bio-NCP) for diagnosis and treatment of breast cancer," J. Alloys Compd., vol. 584, pp. 514-519, 2014.

[6] R. Arulmurugan, B. Jeyadevan, G. Vaidyanathan, and S. Sendhilnathan, "Effect of zinc substitution on Co- $\mathrm{Zn}$ and $\mathrm{Mn}-\mathrm{Zn}$ ferrite nanoparticles prepared by coprecipitation," J. Magn. Magn. Mater., vol. 288, pp. 470-477, 2005.

[7] B. D. Cullity, Elements of X-Ray Diffraction, 3rd ed. London: Pearson, 2014.

[8] C. Kittel, Introduction to Solid State Physics, 8th ed. John Wiley \& Sons, Inc., 2005.

[9] V. K. Pecharsky and P. Y. Zavalij, Fundamentals of Powder Diffraction and Structural Characterization of Materials, 2nd ed. New York: Springer, 2009.

[10] R. A. Young, The Rietveld Method, 1st ed. New York: Oxford University Press, 2002.

[11] R. E. Dinnebier and S. J. L. Billinge, Powder Diffraction: Theory and Practice, 1st ed. The Royal Society of Chemistry, 2008.

[12] D. Halliday, R. Resnick, and J. Walker, Fundamentos de Física - Eletromagnetismo, 8. Rio de Janeiro: John Wiley \& Sons, Inc., 2009.

[13] B. D. Cullity and C. D. Graham, Introduction to magnetic materials, 2nd ed. New Jersey: John Wiley \& Sons, Inc., 2009.

[14] L. Néel, "Magnetic properties of ferries: ferrimagnetism and antiferromagnetism," Ann. Phys., vol. 3, pp. 98-137, 1948.

[15] R. Valenzuela, "Novel applications of ferrites," Phys. Res. Int., vol. 2012, 2012. 
[16] K. E. Sickafus, J. M. Wills, and N. W. Grimes, "Structure of spinel," J. Am. Ceram. Soc., vol. 82, no. 12, pp. 3279-3292, 1999.

[17] R. L. Carlin, Magnetochemistry, 1ª. Berlin: Springer-Verlag, 1986.

[18] N. D. Kandpal, N. Sah, R. Loshali, R. Joshi, and J. Prasad, "Co-precipitation method of synthesis and characterization of iron oxide nanoparticles," J. Sci. Ind. Res., vol. 73, no. February, pp. 87-90, 2014.

[19] M. Kurian and D. S. Nair, "Effect of preparation conditions on Nickel Zinc Ferrite nanoparticles: A comparison between sol-gel auto combustion and co-precipitation methods," J. Saudi Chem. Soc., vol. 20, pp. S517-S522, 2016.

[20] M. U. Islam, T. Abbas, S. B. Niazi, Z. Ahmad, S. Sabeen, and M. A. Chaudhry, "Electrical behaviour of fine particle, co-precipitation prepared Ni-Zn ferrites," Solid State Commun., vol. 130, no. 5, pp. 353-356, 2004.

[21] H. F. Lu, R. Y. Hong, and H. Z. Li, "Influence of surfactants on co-precipitation synthesis of strontium ferrite," J. Alloys Compd., vol. 509, no. 41, pp. 10127-10131, 2011.

[22] Y. Shi, J. Ding, X. Liu, and J. Wang, " $\mathrm{NiFe}_{2} \mathrm{O}_{4}$ ultrafine particles prepared by coprecipitation / mechanical alloying," J. Magn. Magn. Mater., vol. 205, pp. 249-254, 1999.

[23] Y. Y. Meng et al., "Structure and magnetic properties of $\mathrm{Mn}(\mathrm{Zn}) \mathrm{Fe}_{2-\mathrm{x}} \mathrm{RE}_{\mathrm{x}} \mathrm{O}_{4}$ ferrite nano-powders synthesized by co-precipitation and refluxing method," Powder Technol., vol. 229, pp. 270-275, 2012.

[24] P. Derakhshi and R. Lotfi, "Synthesis and Surfactant Effect on Structural Analysis of Nickel Doped Cobalt Ferrite Nanoparticles by C-precipitation Method," vol. 65, pp. 60-65, 2012.

[25] F. Giovannelli, C. Autret-lambert, C. Mathieu, T. Chartier, F. Delorme, and A. Seron, "Synthesis of manganese spinel nanoparticles at room temperature by coprecipitation," J. Solid State Chem., vol. 192, pp. 109-112, 2012.

[26] A. S. Teja and P. Koh, "Synthesis, properties, and applications of magnetic iron oxide nanoparticles," Prog. Cryst. Growth Charact. Mater., vol. 55, no. 1-2, pp. $22-$ 45, 2009.

[27] G. Ertl, H. Knözinger, F. Schüth, and J. Weitkamp, "Handbook of Heterogeneous Catalysis," Wiley-VCH Verlag GmbH \& Co., 2008, p. 3865.

[28] D. Harvey, Modern Analytical Chemistry. McGraw-Hill, 2000.

[29] K. Byrappa and T. Adschiri, "Hydrothermal technology for nanotechnology," Prog. Cryst. Growth Charact. Mater., vol. 53, no. 2, pp. 117-166, 2007.

[30] K. Holmberg, B. Jönsson, B. Kronberg, and B. Lindman, Surfactants and Polymers 
in Aqueous Solution, 2nd ed. John Wiley \& Sons, Inc., 2002.

[31] A. Products, "Detergents and their uses in membrane protein science.," pp. 1-17, 2007.

[32] R. Xu, W. Pang, J. Yu, Q. Huo, and J. Chen, Chemistry of Zeolites and Related Porous Materials: Synthesis and Structure. John Wiley \& Sons, Inc., 2007.

[33] S. Aldrich, "CTAB description," vol. 62, no. 2, pp. 12-13, 1999.

[34] T. Ungár and J. Gubicza, "Nanocrystalline materials studied by powder diffraction line profile analysis," Zeitschrift für Krist., vol. 222, no. 3-4, pp. 114-128, 2007.

[35] R. U. Ichikawa, "Aplicações do Método de Warren Averbach de Análise de Perfis de Difração," Universidade de São Paulo, 2013.

[36] X. Song and J. F. Boily, "Water vapor diffusion into a nanostructured iron oxyhydroxide," Inorg. Chem., vol. 52, no. 12, pp. 7107-7113, 2013.

[37] C. Rémazeilles and P. Refait, "On the formation of $\beta-\mathrm{FeOOH}$ (akaganéite) in chloride-containing environments," Corros. Sci., vol. 49, no. 2, pp. 844-857, 2007.

[38] T. Ishikawa, R. Katoh, a Yasukawa, K. Kandori, T. Nakayama, and F. Yuse, "Influences of metal ions on the formation of beta-FeOOH particles," Corros. Sci., vol. 43, pp. 1727-1738, 2001.

[39] V. F. Buchwald and E. J. Post, "Crystal structure refinement of akaganéite," Am. Mineral., vol. 76, pp. 272-277, 1991.

[40] R. M. Cornell and U. Schwertmann, The Iron Oxides: Structure, Properties, Reactions, Occurences and Uses, 2nd ed. Weinheim: WILEY-VCH, 2003.

[41] CDTi - Clean Diesel Technologies, "Spinel Structure." [Online]. Available: http://www.cdti.com/spinel/.

[42] P. Atkins and J. de Paula, Physical Chemistry, 9ª New York: W. H. Freeman and Company, 2010.

[43] I. Puigdomenech, "Chemical Equilibrium Diagrams." 2013.

[44] M. T. D. Orlando, "Caracterização Física e Estudo das Propriedades Elétricas, Magnéticas e Térmicas do Supercondutor de Alto Tc Policristalino $\mathrm{Y}_{1} \mathrm{Ba}_{2} \mathrm{Cu}_{3} \mathrm{O}_{7-x}$," Universidade de São Paulo, 1991.

[45] R. R. de Souza, "Construção de um Susceptômetro AC autobalanceado e Estudo de Polímeros Condutores Eletrônicos por Susceptibilidade Magnética e Ressonância Magnética," Universidade de São Paulo, 1998.

[46] D. Balzar, "X-Ray Diffraction Line Broadening. Modeling and Applications to High-Tc Superconductor," J. Res. Natl. Inst. Stand. Technol., vol. 98, no. 3, pp. 321-353, 1993.

[47] M. R. Spiegel, J. J. Schiller, and R. A. Srinivasan, Probability and Statistics, 4a. 
McGraw-Hill, 2013.

[48] J. I. D. Pinheiro, S. S. R. Carvajal, S. B. da Cunha, and G. C. Gomes, Probabilidade e Estatística, 1ª . Rio de Janeiro: Elsevier Editora Ltda., 2012.

[49] W. A. A. Bayoumy, "Synthesis and characterization of nano-crystalline Zn-substituted Mg-Ni-Fe-Cr ferrites via surfactant-assisted route," J. Mol. Struct., vol. 1056-1057, no. 1, pp. 285-291, 2014.

[50] Y. Xuan, Q. Li, and G. Yang, "Synthesis and magnetic properties of $\mathrm{Mn}-\mathrm{Zn}$ ferrite nanoparticles," J. Magn. Magn. Mater., vol. 312, pp. 464-469, 2007.

[51] M. L. Martins, A. O. Florentino, A. A. Cavalheiro, R. I. V Silva, D. I. Dos Santos, and M. J. Saeki, "Mechanisms of phase formation along the synthesis of Mn-Zn ferrites by the polymeric precursor method," Ceram. Int., vol. 40, no. 10, pp. 16023-16031, 2014.

[52] Z. Pu, M. Cao, J. Yang, K. Huang, and C. Hu, "Controlled synthesis and growth mechanism of hematite nanorhombohedra, nanorods and nanocubes," Nanotechnology, vol. 17, no. 3, pp. 799-804, 2006. 


\section{APÊNDICE A}

Ficha de estrutura cristalina obtida do Banco de Dados de Estruturas Cristalinas Inorganic Crystal Structure Database (ICSD) para o composto ' $\mathrm{Zn}_{0.68} \mathrm{Mn}_{0.36} \mathrm{Fe}_{1.96} \mathrm{O}_{4}$ ' (Frankilinita ICSD \# 280055) utilizada para refinamento pelo método de Rietveld da Frankilinita.

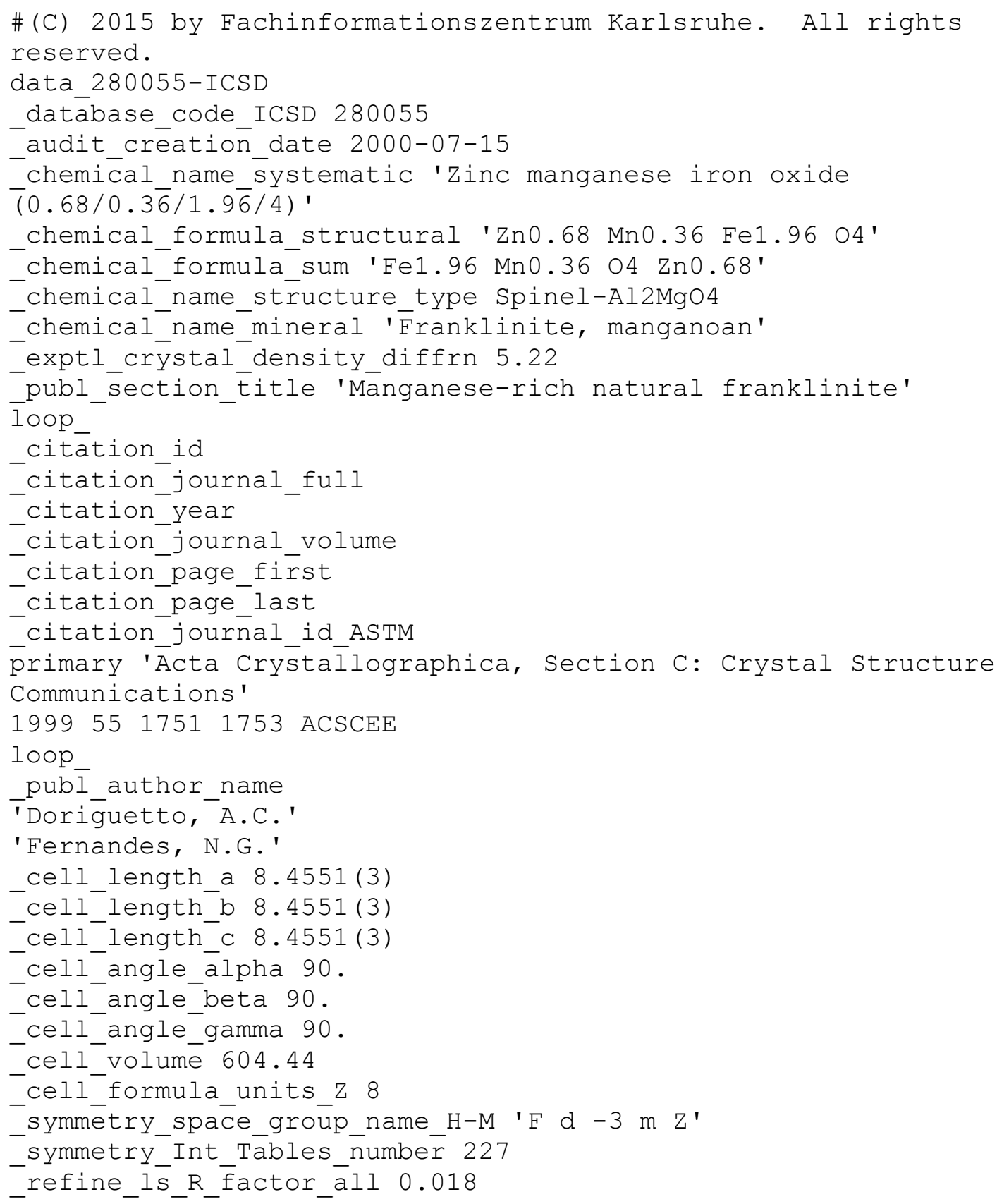




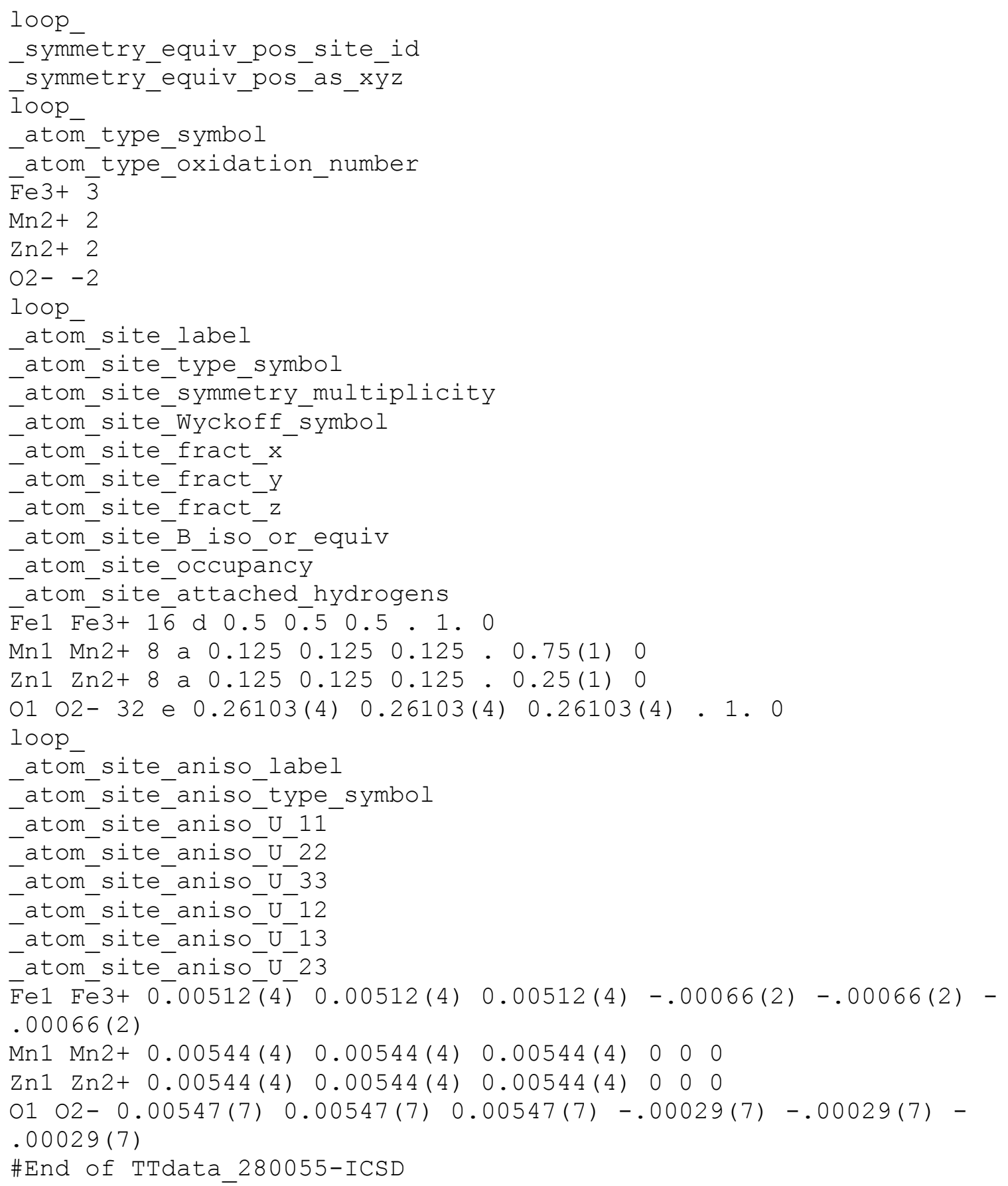


Ficha de estrutura cristalina obtida do Banco de Dados de Estruturas Cristalinas Inorganic Crystal Structure Database (ICSD) para o composto 'FeO(OH)' (Akaganéita ICSD \# 31136) utilizada para refinamento pelo método de Rietveld da Akaganéita.

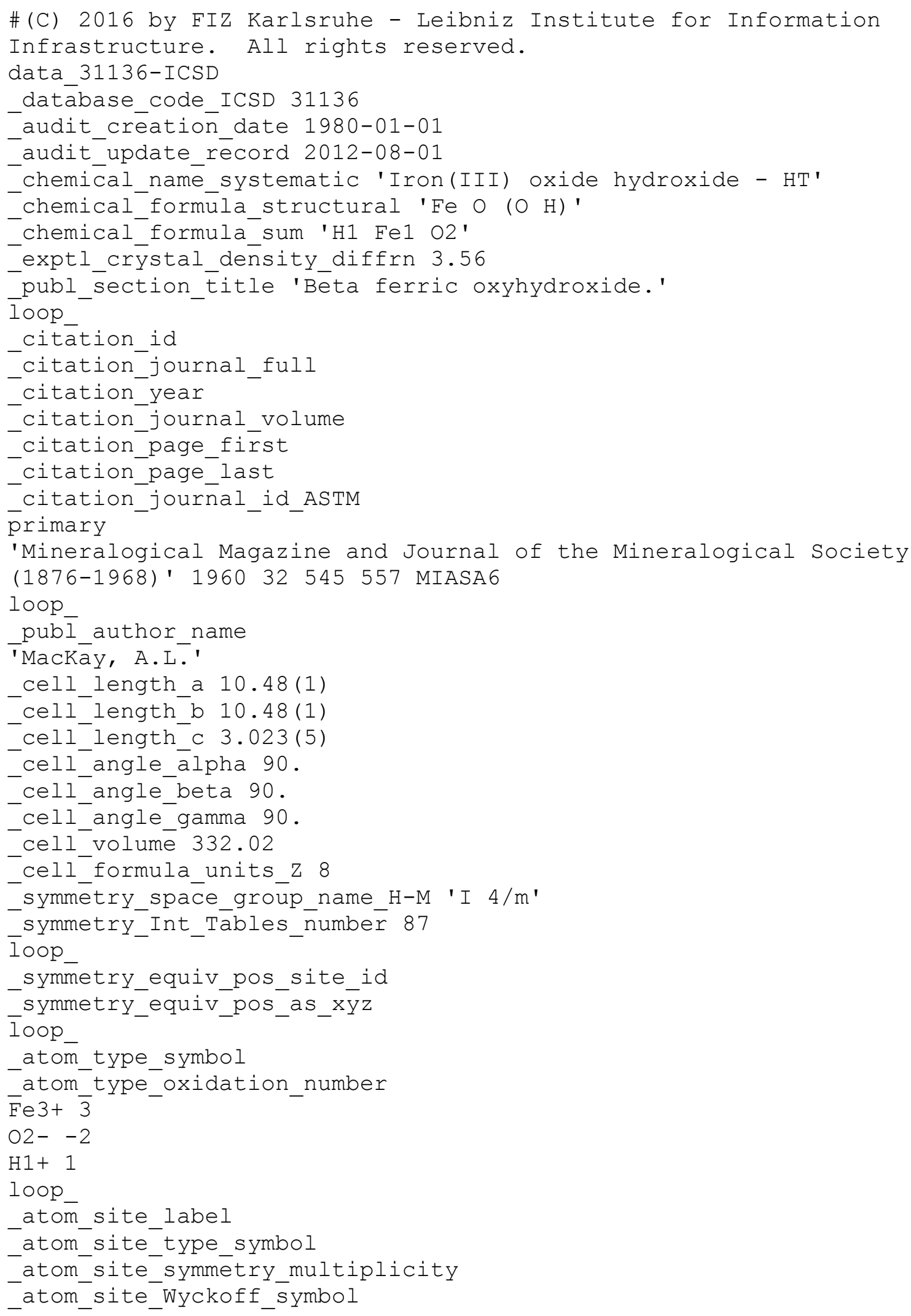


_atom_site_fract_x

-atom_site_fract_y

_atom_site_fract_z

_atom_site_B_iso_or_equiv

_atom_site_occupancy

atom_site_attached_hydrogens

$\overline{\mathrm{Fe}} 1 \mathrm{Fe} 3+8 \overline{\mathrm{h}} 0.348 \overline{0} .1670$. 1.0

$0102-8 \mathrm{~h} 0.1530 .180 .1 .0$

02 02- 8 h 0.5420 .1670 . 1. 0

\#End of TTdata_31136-ICSD 